Felipe de Lucena Moreira Lopes

\title{
Impacto dos fatores etiológicos, clínicos e cirúrgicos no prognóstico de pacientes com carcinoma hepatocelular submetidos à ressecção hepática
}

Dissertação apresentada à Faculdade de Medicina da Universidade de São Paulo para obtenção do título de Mestre em Ciências

Programa de Ciências em Gastroenterologia

Orientador: Prof. Dr. Paulo Herman

São Paulo

2015 


\section{Dados Internacionais de Catalogação na Publicação (CIP)}

Preparada pela Biblioteca da

Faculdade de Medicina da Universidade de São Paulo

Creprodução autorizada pelo autor

Lopes, Felipe de Lucena Moreira

Impacto dos fatores etiológicos, clínicos e cirúrgicos no prognóstico de pacientes com carcinoma hepatocelular submetidos à ressecção hepática / Felipe de Lucena Moreira Lopes. -- São Paulo, 2015.

Dissertação(mestrado)--Faculdade de Medicina da Universidade de São Paulo. Programa de Ciências em Gastroenterologia.

Orientador: Paulo Herman.

Descritores: 1.Neoplasias hepáticas 2.Carcinoma hepatocelular 3.Hepatectomia 4.Análise de sobrevida 5.Carcinoma hepatocelular/etiologia 6.Cirrose hepática 7.Prognóstico

USP/FM/DBD-382/15 


\section{Dedicatória}

Ao meu pai, Gaspar, por sempre acreditar em mim e ser exemplo de homem, médico e cirurgião.

À minha mãe, Kuka, por seu enorme carinho e por estar sempre ao meu lado em qualquer situação.

Às minhas irmãs Patrícia e Andrea, pela amizade e convivência, que me faz cada vez mais ser uma pessoa melhor.

À minha avó, Glorinha (in memoriam), exemplo de otimismo, o meu eterno muito obrigado.

À minha avó, Nair (in memoriam), origem da inspiração para enfrentar qualquer desafio.

Aos meu avôs, Gaspar (in memoriam) e Roberto, exemplos de honestidade e força. 


\section{Agradecimentos}

Ao Prof. Dr. Paulo Herman, mentor e orientador desse trabalho, pelo convívio e ensinamentos ao longo de toda a minha formação.

Ao Prof. Dr. Ivan Cecconello, pela oportunidade de realização desse trabalho.

Ao Prof. Dr. Luiz Augusto Carneiro D'Albuquerque, pela oportunidade de engrandecimento com a pós-graduação.

Aos amigos do Serviço de Cirurgia do Fígado e Hipertensão Portal Dr. Fabricio Coelho, Dr. Marcos Perini, Dr. Renato Lupinacci, Dr. Jaime Kruger e Dr. Gilton Marques pelo convívio e ensinamentos.

À secretaria de pós-graduação em Ciências em Gastroenterologia, Vilma Libério pela dedicação e auxílio, fundamentais para a realização desta dissertação.

A todas as secretarias da Disciplina de Cirurgia do Aparelho Digestivo, em especial a Myrtes Freire de Lima e Fabiana Soares, pelo auxílio e incentivo para a realização deste trabalho. 


\section{Epígrafe}

"Uma longa viagem começa com um único passo."

Lao-Tsé 


\section{Normalização Adotada}

Esta dissertação está de acordo com as seguintes normas, em vigor no momento desta publicação:

Referências: adaptado de International Committee of Medical Journals Editors (Vancouver).

Universidade de São Paulo. Faculdade de Medicina. Divisão de Biblioteca e Documentação. Guia de apresentação de dissertações, teses e monografias. Elaborado por Anneliese Carneiro da Cunha, Maria Julia de A. L. Freddi, Maria F. Crestana, Marinalva de Souza Aragão, Suely Campos Cardoso, Valéria Vilhena. 3a ed. São Paulo: Divisão de Biblioteca e Documentação; 2011.

Abreviaturas dos títulos dos periódicos de acordo com List of Journals Indexed in Index Medicus. 


\section{SUMÁRIO}

Lista de Figuras

Lista de Tabelas

Resumo

Abstract

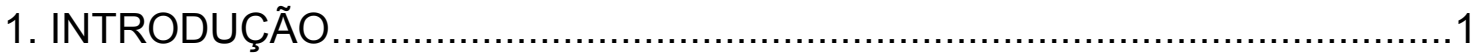

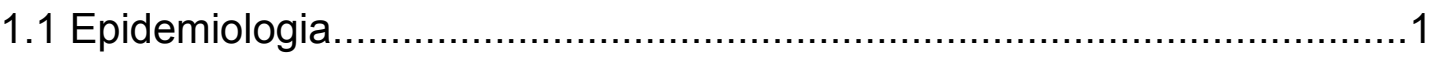

1.2 Diagnóstico e Seguimento .......................................................... 5

1.3 Estadiamento e Tratamento ................................................................

1.4 Justificativa................................................................................ 10

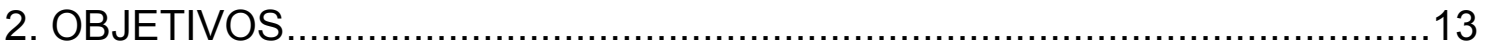

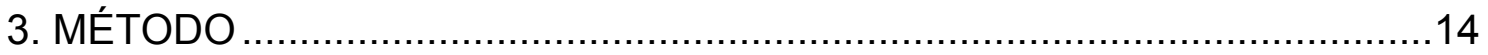

3.1 Aspectos Éticos......................................................................... 14

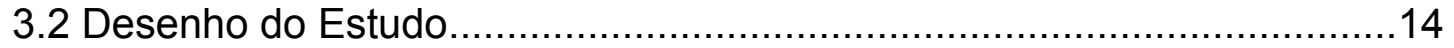

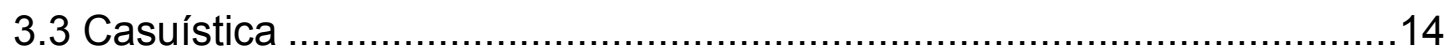

3.3.1 Critérios de Inclusão.................................................................14

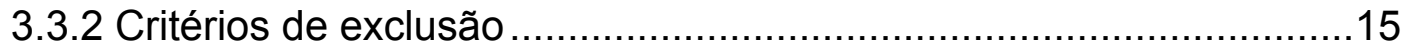

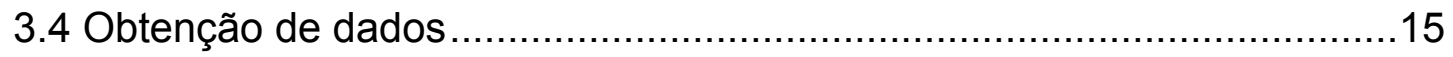

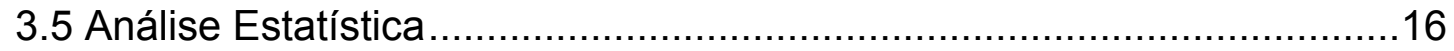

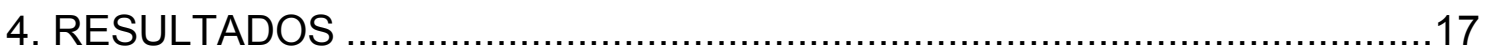

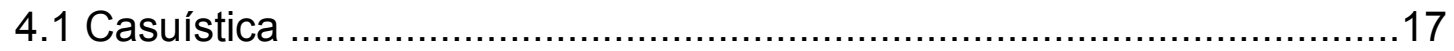

4.2 Análise Descritiva..................................................................... 17

4.3 Análise da Sobrevida Global, Intervalo Livre de Doença e Recidiva .......33

4.4 Análise da Sobrevida Global, Intervalo Livre de Doença e Recidiva com relação à etiologia do $\mathrm{CHC}$.................................................................37

4.5 Análise da Sobrevida Global, Intervalo Livre de Doença e Recidiva com relação à presença ou não de cirrose hepática .......................................41

4.6 Análise de fatores prognósticos ..................................................43

4.7 Análise Multivariada ........................................................................ 47

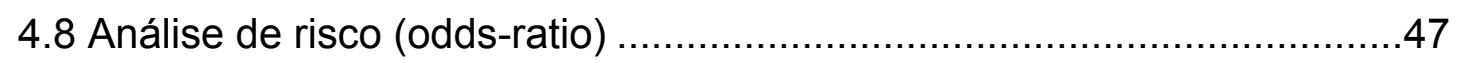

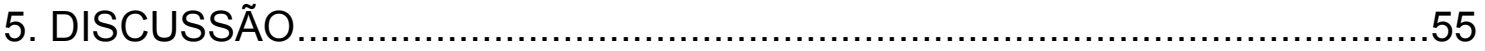

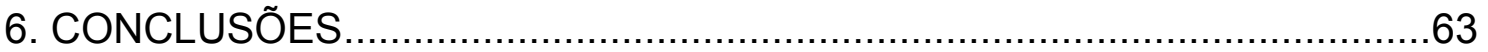

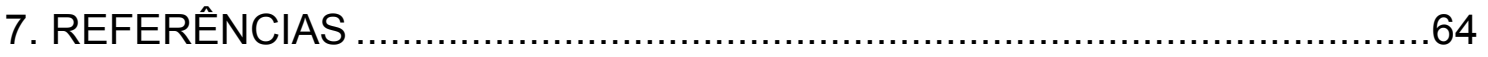

Apendice 


\section{LISTA DE FIGURAS}

Figura 1 - Distribuição do gênero dos pacientes ....

Figura 2 - Diagrama de dispersão unidimensional da idade (anos) dos

pacientes

Figura 3 - Distribuição da cor dos pacientes

Figura 4 - Diagrama de dispersão unidimensional do índice de massa corporal

$\left(\mathrm{kg} / \mathrm{m}^{2}\right)$ dos pacientes.

Figura 5 - Distribuição da presença dos principais sintomas dos pacientes com

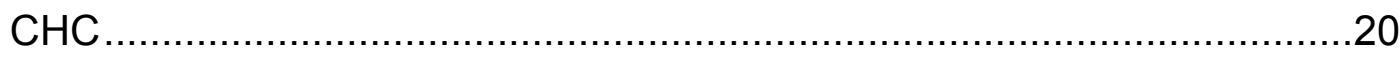

Figura 6 - Distribuição dos pacientes pela classificação ASA .........................20

Figura 7 - Distribuição dos pacientes segundo a classificação de CHILD ........21

Figura 8 - Diagrama de dispersão unidimensional do MELD dos pacientes .....21

Figura 9 - Distribuição do escore de Barcelona dos pacientes

Figura 10 - Diagrama de dispersão unidimensional do nível sérico de

alfafetoproteína $(\mathrm{ng} / \mathrm{mL})$ dos pacientes

Figura 11 - Diagrama de dispersão unidimensional do nível sérico de CA19.9

$(\mathrm{U} / \mathrm{mL})$ dos pacientes

Figura 12 - Distribuição da etiologia da doença dos pacientes com CHC........26

Figura 13 - Distribuição da presença de cirrose entre os pacientes..................26

Figura 14 - Diagrama de dispersão unidimensional do tamanho do nódulo $(\mathrm{cm})$

dos pacientes .27

Figura 15 - Distribuição do grau de Edmondson Steiner para o CHC.

Figura 16 - Distribuição da presença de cápsula e sua invasão entre os pacientes com $\mathrm{CHC}$

Figura 17 - Distribuição da presença de nódulos satélites, invasão vascular e margem livre entre os pacientes com $\mathrm{CHC}$

Figura 18 - Distribuição da presença de critérios de Milão entre os pacientes com $\mathrm{CHC}$

Figura 19 - Distribuição do tipo de cirurgia realizada pelos pacientes

Figura 20 - Distribuição do tipo de ressecção e necessidade de transfusão de sangue dos pacientes 
Figura 21 - Distribuição das complicaçõe segundo a classificação de Clavien

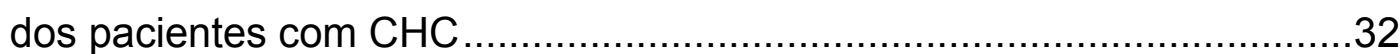

Figura 22 - Ocorrência de óbito e recidiva entre os pacientes com CHC..........34

Figura 23 - Distribuição do local da recidiva entre os pacientes ......................35

Figura 24 - Curva de sobrevida global dos pacientes ...................................36

Figura 25 - Curva de sobrevida livre de doença dos pacientes.........................37

Figura 26 - Curva de sobrevida global dos pacientes submetidos à ressecção

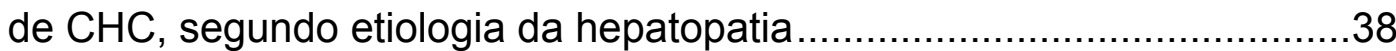

Figura 27 - Curva de sobrevida livre de doença dos pacientes submetidos à ressecção de $\mathrm{CHC}$, segundo a etiologia da hepatopatia

Figura 28 - Curva de sobrevida global dos pacientes submetidos à ressecção de $\mathrm{CHC}$, segundo etiologia(viral/não viral) da hepatopatia .40

Figura 29 - Curva de sobrevida livre de doença dos pacientes submetidos à ressecção de $\mathrm{CHC}$, segundo a etiologia (viral/não viral) da hepatopatia...41

Figura 30 - Curva de sobrevida global dos pacientes submetidos à ressecção de $\mathrm{CHC}$, segundo a presença de cirrose

Figura 31 - Sobrevida livre de doença dos pacientes submetidos à ressecção de $\mathrm{CHC}$, segundo a presença de cirrose 


\section{LISTA DE TABELAS}

Tabela 1 - Distribuição das características gerais, sintomas e ASA dos pacientes com $\mathrm{CHC}$

Tabela 2 - Distribuição da classificação de CHILD, MELD, BARCELONA e dos níveis séricos de alfafetoproteína $(\mathrm{ng} / \mathrm{mL})$ e CA $19.9(\mathrm{U} / \mathrm{mL})$ dos pacientes

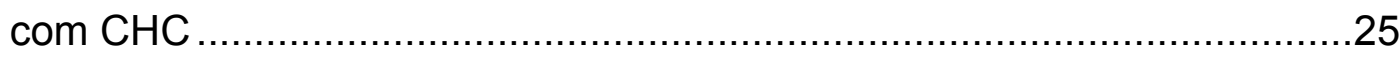

Tabela 3 - Distribuição das características da doença nos pacientes................30

Tabela 4- Distribuição das complicações pós-operatórias dos pacientes submetidos à ressecção de $\mathrm{CHC}$.

Tabela 5- Distribuição das reoperações e óbitos hospitalares dos pacientes submetidos à ressecção de $\mathrm{CHC}$

Tabela 6 - Distribuição das características cirúrgicas dos pacientes

Tabela 7 - Distribuição da sobrevida, , presença e local da recidiva entre os pacientes submetidos à ressecção de $\mathrm{CHC}$.

Tabela 8 - Distribuição das características gerais dos pacientes (em meses), segundo óbito

Tabela 9 - Distribuição das características gerais dos pacientes (em meses), segundo óbito

Tabela 10 - Distribuição das características gerais dos pacientes, segundo óbito.

Tabela 11 - Distribuição das características gerais dos pacientes, segundo óbito

Tabela 12- Distribuição da etiologia (viral/não viral) dos pacientes, segundo óbito

Tabela 13 - Distribuição das características gerais dos pacientes, segundo óbito.

Tabela 14 - Distribuição das características gerais dos pacientes, segundo recidiva

Tabela 15 - Distribuição das características gerais dos pacientes, segundo recidiva 
Tabela 16 - Distribuição das características gerais dos pacientes, segundo recidiva

Tabela A - Medidas-resumo do tempo de sobrevida global (em meses) dos pacientes submetidos à ressecção de $\mathrm{CHC}$.

Tabela B - Medidas-resumo do intervalo livre de doença (em meses) dos pacientes submetidos à ressecção de $\mathrm{CHC}$.

Tabela C - Medidas-resumo do tempo de sobrevida global (em meses) dos pacientes submetidos à ressecção de $\mathrm{CHC}$, segundo a presença de cirrose

Tabela D - Medidas-resumo do tempo livre de doença (em meses) dos pacientes submetidos à ressecção de $\mathrm{CHC}$, segundo a presença de cirrose

Tabela E - Medidas-resumo do tempo de sobrevida global (em meses) dos pacientes submetidos à ressecção de $\mathrm{CHC}$, segundo a etiologia da hepatopatia

Tabela F - Medidas-resumo do tempo livre de doença (em meses) dos pacientes submetidos à ressecção de $\mathrm{CHC}$, segundo a etiologia da hepatopatia

Tabela G - Medidas-resumo do tempo de sobrevida global (em meses) dos pacientes submetidos à ressecção de $\mathrm{CHC}$, segundo a etiologia (viral/não viral) da hepatopatia

Tabela H - Medidas-resumo do tempo livre de doença (em meses) dos pacientes submetidos à ressecção de $\mathrm{CHC}$, segundo a etiologia (viral/não viral) da hepatopatia 


\section{Resumo}

Lopes FLM. Impacto dos fatores etiológicos, clínicos e cirúrgicos no prognóstico de pacientes com carcinoma hepatocelular submetidos à ressecção hepática [dissertação]. São Paulo: Faculdade de Medicina, Universidade de São Paulo; 2015.

INTRODUÇÃO: O carcinoma hepatocelular $(\mathrm{CHC})$ é o mais frequente tipo de câncer primário do fígado e a sua incidência vem aumentando nas últimas décadas, , tornando-o hoje a terceira causa de morte por câncer no mundo. Em cerca de 70 a $80 \%$ dos pacientes, o $\mathrm{CHC}$ é precedido pelo desenvolvimento de cirrose hepática. Existe um consenso de que a ressecção cirúrgica do tumor é a única terapêutica efetivamente comprovada. Esta ressecção pode ser realizada tanto através de uma hepatectomia como pelo transplante hepático. Atualmente, apenas 30 a $40 \%$ dos pacientes se beneficiam dos tratamentos ditos curativos e, mesmo entre esses pacientes, a sobrevida em cinco anos continua baixa, em torno de 60 a $70 \%$, com taxa de recorrência do tumor em torno de $50 \%$ em três anos. Alguns estudos mostraram um pior prognóstico para os pacientes com $\mathrm{CHC}$ cuja etiologia é a infecção por vírus B ou C. Isso nos leva à questão sobre a existência de uma diferença entre as diversas etiologias do $\mathrm{CHC}$ e o seu prognóstico. OBJETIVOS: Comparar o prognóstico (sobrevida global e livre de doença em cinco anos) de pacientes submetidos à hepatectomia para o tratamento do $\mathrm{CHC}$ com relação às diversas etiologias da hepatopatia e estudar fatores prognósticos nesse grupo de pacientes. MÉTODO: Foi realizado um levantamento de prontuários dos pacientes submetidos à hepatectomia entre 2000 e 2014 para tratamento de CHC, seguido de análise estatística desse banco de dados, visando a avaliação de parâmetros clínicos, laboratoriais e cirúrgicos. Os pacientes foram divididos em grupos de acordo com a etiologia da hepatopatia, sendo feita uma análise de sobrevida para comparação. RESULTADOS: Não houve diferença estatisticamente significante de prognóstico entre os grupos de pacientes divididos conforme a etiologia do $\mathrm{CHC}$. A sobrevida global e livre de doença em cinco anos dos pacientes dessa amostra foi de 49,9\% e 40,7\%, respectivamente. As variáveis prognósticas estatisticamente significantes para sobrevida global foram nível sérico de alfafetoproteína $(p=0,043)$, nível sérico de CA19.9 $(p=0,028)$, invasão da cápsula tumoral $(p=0,030)$, margem livre $(p=0,004)$ e presença de complicações pós-operatórias $(p<0,001)$. CONCLUSÕES: Pelos dados dessa amostra, pudemos constatar que não houve diferença em relação ao prognóstico entre os grupos de pacientes das diversas etiologias de $\mathrm{CHC}$. As variáveis nível sérico de alfafetoproteína e de CA 19.9, invasão da cápsula tumoral, margem livre e complicações pósoperatórias podem ser consideradas preditoras de pior prognóstico.

Descritores: 1. Neoplasias Hepáticas 2. Carcinoma Hepatocelular

3. Hepatectomia 4. Análise de sobrevida 5. Carcinoma Hepatocelular/etiologia 6. Cirrose Hepática 7. Prognóstico 


\section{Abstract}

Lopes FLM. Impact of etiological, clinical and surgical factors in the prognosis of patients with hepatocellular carcinoma undergoing hepatic resection [dissertation]. São Paulo: Faculdade de Medicina, Universidade de São Paulo; 2015.

INTRODUCTION: Hepatocellular carcinoma (HCC) is the most frequent type of primary liver cancer and its incidence is increasing around the world in the last decades, making HCC the third cause of death by cancer in the world. In about 70 to $80 \%$ of patients, HCC is preceded by cirrhosis of the liver. It is believed that hepatic resection is the single proven curative treatment. This resection can be done in the form of a hepatectomy or liver transplantation. Nowadays, only 30 to $40 \%$ of HCC patients can benefit from these curative treatments and, among them, survival in five years is still around 60 to $70 \%$, with tumor recurrence rate around $50 \%$ in three years. Some studies have shown a worse prognosis for HCC patients whose etiology is viral. That brings us to the question about the existence of a difference between the various etiologies of HCC and its prognosis. OBJECTIVES: To compare the prognosis (overall and disease-free survival at five years) of patients undergoing hepatectomy for the treatment of $\mathrm{HCC}$ with respect to various etiologies of liver disease and to study prognostic factors in this group of patients. METHOD: We performed a review of medical records of patients undergoing hepatectomy between 2000 and 2014 for the treatment of HCC, followed by statistical analysis of this database for evaluation of clinical, laboratory and surgical parameters. Patients were divided into groups according to the etiology of liver disease followed by overall and disease-free survival analysis for comparison. RESULTS: There was no statistically significant difference in the outcomes of the groups of patients divided according to the etiology of HCC. Overall and disease-free survival at five years of patients in this sample was $49.9 \%$ and $40.7 \%$, respectively. Statistically significant prognostic variables for overall survival were serum alpha-fetoprotein $(p=0.043)$, serum CA19.9 $(p=0.028)$, invasion of the tumor capsule $(p=0.030)$, resection margins $(p=0.004)$ and presence of postoperative complications ( $p<0.001)$. CONCLUSIONS: From the data of this sample, we could verify that there was no prognostic differences between the groups of HCC patients of the various etiologies. The variables serum alphafetoprotein and CA 19.9, invasion of the tumor capsule, resection margins and presence of postoperative complications can be considered predictive of worse prognosis.

Descriptors: 1. Liver Neoplasms 2. Carcinoma, Hepatocellular 3. Hepatectomy 4. Survival analysis 5. Carcinoma, Hepatocellular/etiology 6. Liver Cirrhosis 7.Prognosis 



\section{INTRODUÇÃO}

O carcinoma hepatocelular $(\mathrm{CHC})$ é o mais frequente tipo de câncer primário do fígado (1) e a sua incidência vem aumentando em todo o mundo nas últimas décadas, sendo atualmente o quinto tipo mais comum de neoplasia maligna em homens e o nono em mulheres, com uma taxa homem/mulher de 2,4 .

A cada ano ocorrem aproximadamente 700.000 a 1.000 .000 de novos casos, dos quais cerca de 600.000 a 800.000 morrem em decorrência da doença, tornando o $\mathrm{CHC}$ a segunda causa de morte por câncer no mundo (2).

Na maior parte dos pacientes (cerca de 70 a $80 \%$ ), o $\mathrm{CHC}$ é precedido de cirrose hepática (3-5), sendo que, após o estabelecimento desta, há um risco anual de 1 a $4 \%$ de aparecimento de CHC (1). Dessa forma, torna-se evidente que fatores de risco para cirrose são também fatores de risco para $\mathrm{CHC}(1)$.

\subsection{Epidemiologia}

A epidemiologia do $\mathrm{CHC}$ está diretamente ligada à dos fatores de risco para cirrose e $\mathrm{CHC}$, de forma que a sua distribuição geográfica é bem diversa por todo o mundo $(1,4)$.

Historicamente, a grande incidência de $\mathrm{CHC}$ sempre foi observada em países orientais e africanos, devido à alta prevalência do vírus da Hepatite $B$ (VHB) nesses locais, mas nas últimas décadas notamos um aumento importante da doença também nos países ocidentais $(1,2)$.

Isso se explica principalmente pelo aumento da incidência do vírus da Hepatite $\mathrm{C}(\mathrm{VHC})$ nesses países. Acredita-se que esse aumento tenha iniciado na década de 50 com campanhas de vacinação dos governos desses países sem o uso de seringas e agulhas descartáveis e continuado com a epidemia do uso de drogas injetáveis no início dos anos 60. As pessoas infectadas pelo 
VHC nesse período apresentam mais de 30 anos da doença, tempo suficiente para o desenvolvimento da cirrose hepática e do $\mathrm{CHC}$ (4). Acrescenta-se a isso a infecção de outras pessoas por sangue contaminado usado para transfusão antes de 1990 (4).

Estima-se que o VHB e o VHC sejam responsáveis por cerca de $70 \%$ dos casos de CHC (4). O VHB é mais prevalente na Ásia oriental e na África subsaariana, locais esses que correspondem também às maiores incidências de CHC. Sherman mostrou que mais de $80 \%$ dos casos de $\mathrm{CHC}$ se concentram nesses locais, sendo aproximadamente $76 \%$ na Ásia, especialmente na China e cerca de $10 \%$ na África (4).

$\mathrm{O}$ VHB é o principal fator de risco para $\mathrm{CHC}$ em todo o mundo, sendo responsável por mais de $50 \%$ dos casos. As campanhas de vacinação contra o VHB vêm reduzindo drasticamente a taxa de VHB crônico na população, por exemplo, de $16 \%$ a $1.4 \%$ na China, $9,8 \%$ a $1,3 \%$ em Taiwan e $9,3 \%$ a $0,9 \%$ na Espanha (6). Mas existem cerca de 400 milhões de pessoas infectadas no mundo, o que ainda mantém o VHB como um grave problema de saúde pública (6). Estima-se que o risco de desenvolver $\mathrm{CHC}$ seja de 5 a 15 vezes maior nos portadores crônicos do que na população geral (7). Sabemos que cerca de 70 a $90 \%$ dos casos de $\mathrm{CHC}$ se desenvolvem em fígados cirróticos, mas o $\mathrm{CHC}$ também pode surgir em fígados não cirróticos de forma que o portador crônico do VHB também deve ser acompanhado de perto (6).

O VHC vem em segundo lugar com cerca de $20 \%$ dos casos. Como já mencionado, o VHC vem aumentando a sua prevalência nas últimas décadas e já predomina, junto com o abuso de álcool, nos países em que o VHB não é endêmico. $\mathrm{O}$ VHC aumenta em aproximadamente 15 a 20 vezes o risco de CHC em portadores crônicos em relação à população geral, mas diferentemente do VHB, raramente se desenvolve em fígados não cirróticos (6). Infelizmente, acredita-se que o pico de incidência do VHC ainda está por vir, por volta do ano 2020, de modo que a incidência de $\mathrm{CHC}$ ainda deve continuar aumentando nos próximos anos (3).

Um ponto importante é o efeito sinérgico entre o VHB e o VHC. Enquanto individualmente eles aumentam em aproximadamente 10 a 20 vezes 
o risco de $\mathrm{CHC}$, juntos em um mesmo indivíduo aumentam para até 165 vezes em relação ao risco encontrado na população geral (6).

Outros fatores de risco para cirrose e CHC são: o acima mencionado abuso de álcool, obesidade, diabetes, hemocromatose, doença de Wilson, deficiência de alfa 1 antitripsina, ingestão de aflatoxinas, cirrose biliar, colangite esclerosante, hepatite auto-imune e muitos outros (6).

Com relação ao abuso de álcool, podemos dizer que há evidência já bem estabelecida de aumento de risco de cirrose e $\mathrm{CHC}$ em pacientes com ingesta de álcool de mais de 50-70g/dia por longos períodos. O álcool também apresenta efeito sinérgico, quando em associação com VHC ou VHB, aumentando muito o risco de $\mathrm{CHC}(6)$.

No que tange à obesidade e diabetes, o seu impacto no risco de desenvolver um $\mathrm{CHC}$ sofre um viés, pois há uma tendência de análise conjunta, principalmente devido à dificuldade de separação desses fatores nas populações estudadas (6). Dessa forma, esses fatores são considerados como parte da síndrome metabólica, cuja manifestação hepática é a doença hepática gordurosa não alcoólica (NAFLD, na sigla em inglês).

A NAFLD e o seu componente mais avançado NASH (esteato-hepatite não alcoólica, na sigla em inglês) já estão bem estabelecidos como fatores de risco para cirrose e $\mathrm{CHC}$ (6). Na maioria dos casos, os $\mathrm{CHC}$ atribuídos a NAFLD/NASH se desenvolvem em fígados cirróticos (mais de $70 \%$ dos casos), o que acaba dificultando ainda mais a avaliação da etiologia NASH (6).

Quando se tenta analisar de forma independente a obesidade e o diabetes, também é possível estabelecer uma relação de causalidade com cirrose e $\mathrm{CHC}$, mas de forma mais modesta (6). Acredita-se que um índice de massa corpórea (IMC) acima de $32 \mathrm{~kg} / \mathrm{m}^{2}$ acarrete um aumento no risco de $\mathrm{CHC}(6)$.

Com relação à diabetes, apesar de estudos recentes mostrarem a diabetes como fator de risco independente para $\mathrm{CHC}$, é preciso analisar com cuidado, já que a própria doença hepática pode acarretar a intolerância à glicose e diabetes tipo 2 , tornando difícil a interpretação de causalidade $(6,8)$.

Independente disso, a crescente epidemia de síndrome metabólica nos países desenvolvidos é considerada mais um fator que colabora com o 
aumento do número de casos de $\mathrm{CHC}$ e com as previsões de crescimento ainda maior nos próximos anos (3).

O último fator de risco importante a ser considerado neste trabalho é a ingestão de aflatoxinas, especialmente em países do leste asiático e África subsaariana (3). As aflatoxinas são produzidas pelo fungo Aspergillus e costumam contaminar alimentos como milho, amendoim, grãos e legumes. Elas causam uma mutação no gene supressor tumoral p53 que leva ao desenvolvimento do $\mathrm{CHC}$ (6). Apenas a exposição a aflatoxinas aumenta em 4 vezes o risco de $\mathrm{CHC}$, mas, acredita-se que elas atuem como cofatores do VHB, aumentando o risco de CHC em cerca de 60 vezes (3).

Junto com a campanha de vacinação contra o VHB iniciada nos anos 80, alguns países do leste asiático como a China lançaram programas para tentar mudar a dieta básica da população de milho para arroz, justamente para limitar a exposição às aflatoxinas e impedir o efeito sinérgico com o VHB, numa tentativa de diminuição do número de casos de $\mathrm{CHC}$ (7).

O Brasil, apesar de ser considerado um país de baixa incidência de CHC (7), não possui muitos estudos avaliando a real situação desta neoplasia. Um estudo realizado na década de 90, com dados de diversos centros do país, revelou que cerca de $70 \%$ dos casos ocorrem em fígados cirróticos, sendo $40 \%$ dos $\mathrm{CHC}$ relacionados ao $\mathrm{VHB}, 26 \%$ relacionados ao $\mathrm{VHC}$ e $37 \%$ relacionados ao abuso de álcool. Os autores demonstraram uma grande diferença nessas proporções, com predomínio da infecção por VHC nos estados do sul e sudeste e predomínio do VHB em estados do norte/nordeste (9).

Outro estudo, também multicêntrico, analisou 1308 pacientes com $\mathrm{CHC}$ e constatou que $98 \%$ deles apresentavam cirrose, sendo que o VHC foi a principal causa com $54 \%$, seguido pelo VHB com $16 \%$ e do álcool com $14 \%$. Esse estudo também mostrou um aumento da incidência do VHB nas regiões do norte/nordeste, mas ainda com predomínio do VHC (10).

Outro estudo mais recente, publicado em 2014 (11), mostrou o VHC como principal fator etiológico do $\mathrm{CHC}(65 \%)$, bem como o predomínio do aparecimento do $\mathrm{CHC}$ em fígados cirróticos (56\%). Outro dado interessante desse estudo foi a avaliação da incidência global cumulativa do $\mathrm{CHC}$ indo de 
$1,7 \%$ no primeiro ano até $14,3 \%$ no quinto ano de seguimento. Quando individualizamos por etiologia, notamos o VHC como responsável pela maior incidência $(16,9 \%)$, seguido pelo VHB $(15,3 \%)$. As menores taxas foram encontradas na NASH (4\%) e no abuso de álcool (5,7\% em 5 anos).

\subsection{Diagnóstico e Seguimento}

Com o desenvolvimento das técnicas de imagem, o diagnóstico do $\mathrm{CHC}$ passou a ser realizado quase que exclusivamente de forma não invasiva, com tomografia computadorizada ou ressonância magnética com contraste endovenoso. O padrão típico de vascularização de fluxo rápido, caracterizado por enchimento do nódulo na fase arterial, seguido de rápido esvaziamento (washout) nas fases venosa/tardia, foi demonstrado como sendo de grande acurácia no diagnóstico do $\mathrm{CHC}$ (12).

Dessa forma, a biópsia tem espaço principalmente nos casos de dúvida diagnóstica e em pacientes não cirróticos, em que o padrão típico acima descrito não é claramente identificado (12). Com o desenvolvimento progressivo dos métodos de imagem e da análise radiológica, a tendência é de se utilizar cada vez menos o método anatomopatológico para o diagnóstico do CHC (13). Um exemplo disso é o critério de LI-RADS (Liver Imaging-Reporting and Data System) que tenta uniformizar a análise radiológica do $\mathrm{CHC}$ nos métodos de imagem disponíveis atualmente. Esse critério classifica os nódulos de LR1 (definitivamente benigno) a LR5 (definitivamente CHC), através de critérios objetivos, deixando menos espaço para a dúvida diagnóstica e orientando as condutas quanto ao seguimento dos pacientes. Obviamente, esse critério ainda necessita de validação, mas já é um avanço em relação ao padrão típico comentado acima (13).

Outro ponto fundamental é o seguimento dos pacientes com alto risco de desenvolvimento de $\mathrm{CHC}$. Como já mencionado, cerca de 70 a $80 \%$ dos casos de $\mathrm{CHC}$ surgem em fígados cirróticos (3-5). Além disso, os principais fatores de risco para cirrose e $\mathrm{CHC}$ são bem conhecidos (6).

Com isso, temos o grupo de risco que deve ser submetido a rastreamento a cada seis meses com ultrassonografia de abdome e dosagem 
de alfafetoproteína, com a finalidade de identificar possíveis tumores em estádios precoces e com maior chance de cura (14).

Zhang et al. demonstraram uma redução de $37 \%$ da mortalidade em cinco anos por $\mathrm{CHC}$ nos pacientes que fizeram seguimento a cada seis meses com ultrassonografia de abdome e dosagem sérica de alfafetoproteína. Um resultado que pode ser considerado expressivo em um grupo de pacientes em que apenas $58 \%$ participaram efetivamente do rastreamento (15).

\subsection{Estadiamento e Tratamento}

Após o diagnóstico, o passo seguinte é realizar o estadiamento clínico do paciente. Sabemos que cada tumor tem características únicas (16), mas à luz dos conhecimentos atuais é fundamental classificá-lo na categoria mais adequada, visando oferecer o melhor tratamento possível e disponível para cada paciente, bem como determinar o prognóstico individualizado (17).

Existem diversas classificações e métodos de estadiamento do $\mathrm{CHC}$ desenvolvidos em diversos centros por todo o mundo. Todos eles têm vantagens e desvantagens e se aplicam melhor a um determinado tipo de paciente (17). A mais difundida no mundo atualmente é a classificação de BCLC (Barcelona Clinic Liver Cancer Group), que utiliza parâmetros do tumor, do paciente e da função hepática para estabelecer uma classificação, para assim, recomendar um tratamento (18). No entanto, a aplicação irrestrita do BCLC, por exemplo, limita muito a ressecção hepática e pode não ser a melhor opção, especialmente em alguns pacientes do estádio B (19).

A avaliação da função hepática e da presença de hipertensão portal são fundamentais, não só no estadiamento, mas também na definição do melhor tratamento possível para cada paciente (20-25).

Especialmente nos países orientais é utilizada a avaliação da depuração do verde indocianina, um corante sintético não tóxico e não alergênico, que é injetado na corrente sanguínea e processado quase que exclusivamente pelos hepatócitos, possibilitando dessa forma uma análise funcional hepática (20).

Pela baixa praticidade e dificuldade de aplicação, a grande maioria dos países ocidentais utiliza outros métodos $(26,27)$ para avaliar a função 
hepática, dentre eles a classificação de Child-Turcotte-Pugh (CHILD) e a pontuação MELD (Model of End-stage Liver Disease).

A classificação de CHILD é baseada tanto em parâmetros laboratoriais (albumina sérica, bilirrubina total sérica e INR), quanto em parâmetros clínicos de função hepática e de hipertensão portal (ascite e encefalopatia). Os pacientes são classificados em $\mathrm{A}, \mathrm{B}$ ou $\mathrm{C}$, baseado no número de pontos obtidos (26).

Essa classificação se mostrou uma excelente forma de avaliar a gravidade da doença hepática e o risco cirúrgico de pacientes hepatopatas. Pacientes CHILD A submetidos à cirurgia abdominal tem mortalidade estimada em $10 \%$, ao passo que pacientes $\mathrm{B}$ e $\mathrm{C}$ têm $30 \%$ e $70 \%$, respectivamente (22).

Já a pontuação MELD é calculada através de uma fórmula complexa com as variáveis creatinina sérica, bilirrubina total sérica e INR. Ela estratifica tão bem a gravidade da doença hepática que em 2002 começou a ser utilizada nos EUA para a definição da alocação de órgãos para transplante de fígado (27), o que foi, posteriormente, adotada em praticamente todo o mundo.

A pontuação MELD já está validada como marcador de morbimortalidade em pacientes hepatopatas (22). Enquanto a taxa de insuficiência hepática pós-operatória irreversível em pacientes com MELD <9 foi de $0,4 \%$, em um estudo de Cescon et al., em pacientes com MELD entre $9 \mathrm{e}$ 10 , esse índice variou entre 5 e $11 \%$ e atingiu $15 \%$ em pacientes com MELD>10, mostrando a forte relação entre o MELD, a função hepática e o prognóstico desses pacientes (24).

Outro aspecto importante é a avaliação da presença ou não de hipertensão portal, que também será utilizada para a definição do tratamento. A Classificação de BCLC, mencionada antes, define a hipertensão portal como a presença de um gradiente de pressão entre a veia porta e a veia hepática $\geq 5-6$ mmHg e usa esta variável como contraindicação para uma ressecção hepática, na medida em que esta aumentaria o risco de descompensação pósoperatória, com baixa sobrevida em cinco anos (18).

Apesar disso, a medida direta desse gradiente de pressão é invasiva, sendo aplicada em poucos centros (28). A maioria dos centros opta por métodos indiretos para a avaliação de hipertensão portal, tais como a presença 
de ascite, de varizes de esôfago na avaliação por endoscopia digestiva alta e de esplenomegalia com plaquetopenia (22).

Recentemente, um novo método, chamado elastografia transitória hepática, vem surgindo como uma nova opção não invasiva na avaliação da hipertensão portal através da elasticidade do parênquima hepático analisada pelo FIBROSCAN, embora ainda sem validação adequada (29).

Após a avaliação da função hepática pelos métodos acima e da extensão local do tumor por exames de imagem abdominal, deve-se completar - estadiamento à distância para a definição da presença ou não de metástases, fato este que influenciará na decisão do melhor tratamento (30).

Sabe-se que $\mathrm{O} \mathrm{CHC}$ pode originar metástases para outros órgãos; dentre eles, os mais comuns são: pulmões $(55 \%)$, linfonodos $(53 \%)$, ossos $(28 \%)$, adrenal $(11 \%)$ e peritônio $(11 \%)$. Dessa forma, deve-se realizar também uma tomografia de tórax e cintilografia óssea para complementar a avaliação do paciente (30).

Com relação ao tratamento, existe um consenso de que a ressecção cirúrgica do tumor é a única terapêutica realmente comprovada. Esta ressecção pode ser realizada tanto através de uma hepatectomia, como pelo transplante hepático (12, 31-34).

Tem sido observado que a grande maioria dos casos de $\mathrm{CHC}$ apresenta a cirrose como lesão pré-neoplásica $(3,4)$. Dessa forma, a grande vantagem do transplante de fígado em relação à ressecção simples é o fato de que, além de retirar o tumor, substitui o órgão por um novo, eliminando a lesão préneoplásica. No entanto, o transplante de fígado apresenta vários problemas, sendo o principal a dificuldade para conseguir órgãos, culminando em um grande período de espera em lista, o que pode provocar progressão da doença e morte (35). Outro problema é o alto fator restritivo de seus critérios, sendo o mais adotado mundialmente o de Milão, que permite a realização do transplante apenas em pacientes com um nódulo de até $5 \mathrm{~cm}$ ou até três nódulos de $3 \mathrm{~cm}$ cada e sem evidência de invasão vascular $(33,36,37)$.

Nesse cenário, a ressecção hepática surge como a melhor opção (33, 36-38), especialmente em pacientes com a função hepática preservada, tumores solitários ou fora de critério para transplante (grandes tumores). 
A ressecção hepática tem algumas vantagens, como a possibilidade de aplicação imediata, sem lista de espera, sem limite de tamanho para ressecção, menor morbidade pós-operatória, ausência de necessidade de imunossupressão e ainda a possibilidade de transplante de resgate em caso de recidiva $(12,33,38)$.

Como desvantagens óbvias, são citados o não tratamento da doença de base, mantendo um fígado doente com potencial de desenvolver novas lesões neoplásicas (em caso de fígado cirrótico), e a possibilidade de insuficiência hepática pós-operatória irreversível, que é o maior temor, especialmente em pacientes cirróticos (22).

Nesse contexto, a volumetria hepática deve ser realizada no planejamento pré-operatório (25). Ela pode ser realizada no mesmo exame de tomografia computadorizada utilizado para o diagnóstico e tem como objetivo calcular o volume do fígado residual após a ressecção hepática planejada. Estudos demonstram que, em fígados normais, pode-se realizar uma ressecção hepática de até $75-80 \%$, de modo que um fígado remanescente de 20-25\% é suficiente para evitar a insuficiência hepática pós-operatória irreversível. Em pacientes com doença hepática intermediária ou cirrose, é necessário pelo menos $40 \%$ de fígado remanescente para evitar a insuficiência hepática (25).

Obviamente esses números não sinalizam a função dos hepatócitos, mas, em conjunto com outros fatores pré-operatórios já citados acima, servem para orientar o cirurgião quanto à possibilidade de uma ressecção cirúrgica em determinado paciente. Quando a volumetria mostra um fígado remanescente menor do que o necessário, pode-se proceder a uma embolização seletiva de ramo portal do lado que será ressecado no pré-operatório, por radiologia intervencionista, para permitir um crescimento do fígado remanescente e possibilitar a realização da cirurgia com segurança (25).

A análise da função hepática no pré-operatório revela que os melhores candidatos à ressecção hepática são os pacientes CHILD A, com MELD <10 e sem hipertensão portal $(22,24)$. Obviamente, a minoria dos pacientes se enquadra nessas variáveis. Pacientes CHILD B, com MELD entre 10 e 15 ou com hipertensão portal também podem ser operados, especialmente aqueles 
com tumores pequenos e periféricos, mas sempre com cautela e com ciência de um risco maior (22).

Ishizawa et al., do Japão, vivendo em uma realidade onde a oferta de órgãos para transplante é muito escassa, demonstraram a aplicabilidade da ressecção hepática também em pacientes com múltiplos tumores ou com hipertensão portal, de forma segura e com resultados similares ao grupo ideal, descrito no parágrafo anterior (23).

Outras opções de tratamento, para pacientes que não se enquadram nessas condições ou com tumores em localizações de difícil acesso cirúrgico, são os procedimentos ablativos, incluindo a alcoolização e a radiofrequência (36). Em pacientes com múltiplas lesões e sem possibilidade de tratamento curativo, pode-se ainda recorrer à quimioembolização arterial, visando promover a necrose do $\mathrm{CHC}$ e a melhora da qualidade de vida do paciente (36).

Apesar de todas essas opções, o que se observa (36) é que apenas 30 a $40 \%$ dos pacientes se beneficiam dos tratamentos ditos curativos (cirurgia e transplante) e, mesmo entre esses pacientes, a sobrevida em cinco anos continua baixa, em torno de 60 a $70 \%$, com taxa de recidiva do tumor ao redor de $50 \%$ em três anos, chegando a até $72 \%$ em pacientes cuja etiologia do $\mathrm{CHC}$ é viral $(33,36)$.

\subsection{Justificativa}

Todos esses aspectos enfatizam a constatação da alta letalidade do $\mathrm{CHC}$, fato este que por si só deve motivar a realização de novos estudos para tentar conhecer melhor a patogenia e evolução da doença, visando diminuir o número de casos novos, adicionar medidas preventivas, aumentar a taxa de sobrevida e diminuir a sua recorrência.

Cada vez mais as doenças e terapias precisam ser individualizadas. Podem ser observadas as diferenças entre pacientes classificados com a mesma doença e cada vez mais nos deparamos com comportamentos biológicos diferentes em um mesmo tumor, muito agressivo em um paciente e insidioso em outro (16). 
Atualmente, terapias moleculares, como o sorafenib, visam atuar na hepatocarcinogênese e já vêm obtendo resultados satisfatórios em pacientes com tumores avançados (39).

Isso nos leva à questão da qualidade de tratamento para o paciente. Não basta oferecermos o que acreditamos ser o melhor tratamento possível naquele momento, devemos também constantemente reavaliar a nossa casuística de forma ativa, visando sempre a melhora dos resultados e a obtenção de novos padrões que possam ser superiores aos atuais.

Alguns estudos demonstraram um pior prognóstico para os pacientes cuja etiologia do $\mathrm{CHC}$ foi a infecção por vírus B ou C (40-42), sugerindo inclusive a preferência pelo transplante nesses pacientes $(40,41)$.

Chirica et al. observaram uma pior sobrevida e maior recidiva em uma amostra de 75 pacientes com $\mathrm{CHC}$ de etiologia $\mathrm{VHC}$ que foram submetidos a ressecção hepática, indicando a preferência por transplante hepático como tratamento primário nesses pacientes (40).

Uma metanálise de Zhou et al., com 20 estudos, revelou um pior prognóstico para pacientes com etiologia viral (VHC e VHB) submetidos a ressecção hepática (41). Outra metanálise reforçou esses dados, mas demonstrou a possibilidade de melhora do prognóstico com o tratamento pósoperatório dos vírus B e C (43).

Um outro estudo foi além e observou que, não apenas há diferença no prognóstico de pacientes com etiologia viral e não viral, mas também há diferença nos fatores prognósticos pré-operatórios de pacientes com etiologias diferentes (42).

Esses estudos individualizaram de certa forma os pacientes em grupos menores, contribuindo para uma análise mais detalhada, gerando novas informações que puderam ser agregadas à assistência. É preciso, no entanto, salientar que os agrupamentos foram realizados apenas entre pacientes com etiologia viral e não viral.

Em virtude dessa diferença no prognóstico entre a etiologia viral e não viral, propusemos em nosso estudo uma individualização ainda maior, seguindo a tendência atual e dividindo a nossa casuística em grupos conforme a etiologia do $\mathrm{CHC}$ : VHC, VHB, álcool, NASH, etiologia mista (VHC+álcool, 
$\mathrm{VHB}+$ álcool ou $\mathrm{VHC}+\mathrm{VHB}$ ) e outros (hemocromatose, doença autoimune, deficiência de alfa-1-antitripsina, cirrose biliar, colangite esclerosante, doença de Wilson, ingestão de aflatoxinas e outros).

Desta forma, nos propusemos a estudar o grupo de pacientes portadores de $\mathrm{CHC}$ submetidos à ressecção hepática no que se refere aos seus fatores etiológicos, mas também, avaliar os resultados deste tratamento potencialmente curativo, bem como outros fatores que pudessem interferir no prognóstico de sobrevida destes. 


\section{OBJETIVOS}

O objetivo primário desse trabalho é comparar o prognóstico (sobrevida global e livre de doença em cinco anos) de pacientes com $\mathrm{CHC}$ submetidos à hepatectomia com intenção curativa, correlacionando-o às diversas etiologias da hepatopatia.

Como objetivos secundários, podemos apontar:

- Identificar variáveis dentre as características clínicas, da doença e da cirurgia, que acarretem pior prognóstico aos pacientes com $\mathrm{CHC}$ submetidos à hepatectomia com intenção curativa.

- conhecer a curva de sobrevida e intervalo livre de doença dos pacientes com $\mathrm{CHC}$ submetidos à hepatectomia com intenção curativa no Serviço de Cirurgia do Fígado e Hipertensão Portal do Hospital das Clínicas da Faculdade de Medicina da Universidade de São Paulo. 


\section{MÉTODO}

\subsection{Aspectos Éticos}

Este estudo foi aprovado como Protocolo de Pesquisa número 311.780 pela Comissão de Ética para Análise de Projetos de Pesquisa (CAPPesq) do Hospital das Clínicas da Faculdade de Medicina da Universidade de São Paulo (HCFMUSP) em 24 de junho de 2013.

\subsection{Desenho do Estudo}

Trata-se de trabalho retrospectivo com obtenção de dados através dos prontuários médicos e prontuários eletrônicos dos pacientes tratados e acompanhados no Serviço de Cirurgia do Fígado e Hipertensão Portal do Hospital das Clínicas da Faculdade de Medicina da Universidade de São Paulo.

\subsection{Casuística}

Foi realizado um levantamento dos dados de pacientes submetidos à hepatectomia entre agosto de 2000 e julho de 2014 para tratamento de CHC no Serviço de Cirurgia do Fígado e Hipertensão Portal do Hospital das Clínicas da Faculdade de Medicina da Universidade de São Paulo e criado um banco de dados, posteriormente submetido à análise estatística.

\subsubsection{Critérios de Inclusão}

1- Pacientes com diagnóstico de $\mathrm{CHC}$ nódulo único submetidos à hepatectomia com intenção curativa, com confirmação anatomopatológica da doença na peça cirúrgica. 


\subsubsection{Critérios de exclusão}

1- Pacientes com dados incompletos nos prontuários.

2- Pacientes cujo diagnóstico de $\mathrm{CHC}$ não foi confirmado no exame anatomopatológico da peça cirúrgica.

3- Pacientes com CHC operados antes de agosto de 2000 e após julho de 2014.

4- Pacientes com $\mathrm{CHC}$ da variante fibrolamelar.

5- Pacientes com tumores mistos do tipo Hepato-Colangiocarcinoma.

\subsection{Obtenção de dados}

Os dados foram obtidos exclusivamente pela revisão dos prontuários (clínicos e eletrônicos) dos pacientes incluídos inicialmente no estudo. Foram obtidos os seguintes dados:

1- Análise da amostra

Idade, gênero, cor, IMC (índice de massa corpórea), sintomas, classificação ASA (44), função hepática: CHILD (26), MELD (27) e BARCELONA (18), níveis séricos de alfafetoproteína e CA 19.9;

2- Características da doença

Etiologia do $\mathrm{CHC}$, tamanho do tumor, grau de Edmondson-Steiner, preenchimento dos critérios de Milão no período pré-operatório, presença de cápsula e invasão da cápsula, presença de nódulos satélites, presença de invasão vascular, avaliação das margens de ressecção, presença de cirrose;

2- Características da cirurgia Acesso aberto ou laparoscópico, ressecção anatômica ou não, necessidade de transfusão, classificação de complicações pós-operatórias de Clavien-Dindo (45);

4- Análise de mortalidade

Óbito, sobrevida global e intervalo livre de doença (em meses), presença de recidiva e o local da recidiva.

Os pacientes foram divididos em grupos, de acordo com a etiologia da 
hepatopatia, sendo feita uma análise da sobrevida e da taxa de recidiva em cinco anos, para cada etiologia, comparando as curvas, visando estabelecer se a causa da hepatopatia apresentou implicação prognóstica.

Para a análise da sobrevida e do intervalo livre de doença, foi considerado como tempo zero a data da cirurgia e, como evento, a data do óbito para os pacientes que faleceram e a data de 28 de fevereiro de 2015 para os pacientes vivos até aquele momento. A data da recidiva foi considerada como sendo a do primeiro exame de imagem atestando a recidiva da doença.

\subsection{Análise Estatística}

Os pacientes foram divididos em grupos, de acordo com a etiologia da hepatopatia e a presença ou não de cirrose hepática, sendo então realizado o teste de Log-Rank para comparar as curvas de sobrevida global e livre de doença, segundo o tipo de etiologia e a presença de cirrose.

A partir da análise descritiva dos dados e levando-se em conta as informações da literatura e a viabilidade estatística da amostra, foi realizada uma análise univariada, para a identificação de variáveis que poderiam estar relacionadas a um pior prognóstico (pior sobrevida e maior taxa de recidiva em cinco anos). A partir daí, foi tentado realizar o ajuste pelo modelo de Regressão de Cox (análise multivariada), visando estudar a interação dos efeitos das diversas variáveis e procurando identificar os principais fatores relacionados ao prognóstico.

Em todas as conclusões obtidas através das análises inferenciais foi utilizado o nível de significância a igual a 5\%, sendo considerado estatisticamente significante quando o valor de $p<0,05$.

Os dados foram digitados em planilhas do Excel 2010 for Windows para o adequado armazenamento das informações. As análises estatísticas foram realizadas com o programa estatístico $R$ versão 2.15 .2 (46)(47)(48) 


\section{RESULTADOS}

\subsection{Casuística}

A amostra inicialmente foi composta de 111 pacientes. Após a aplicação dos critérios de inclusão e exclusão permaneceram elegíveis para análise 101 pacientes. Foram excluídos desse estudo 10 pacientes: 2 pacientes com $\mathrm{CHC}$ fibrolamelar, 5 com a variante mista hepatocolangiocarcinoma e 3 pacientes com dados de prontuário insuficientes.

\subsection{Análise Descritiva}

A amostra selecionada nesta pesquisa foi composta por 101 pacientes, sendo $35(34,7 \%)$ mulheres e $66(65,3 \%)$ homens (Figura 1).

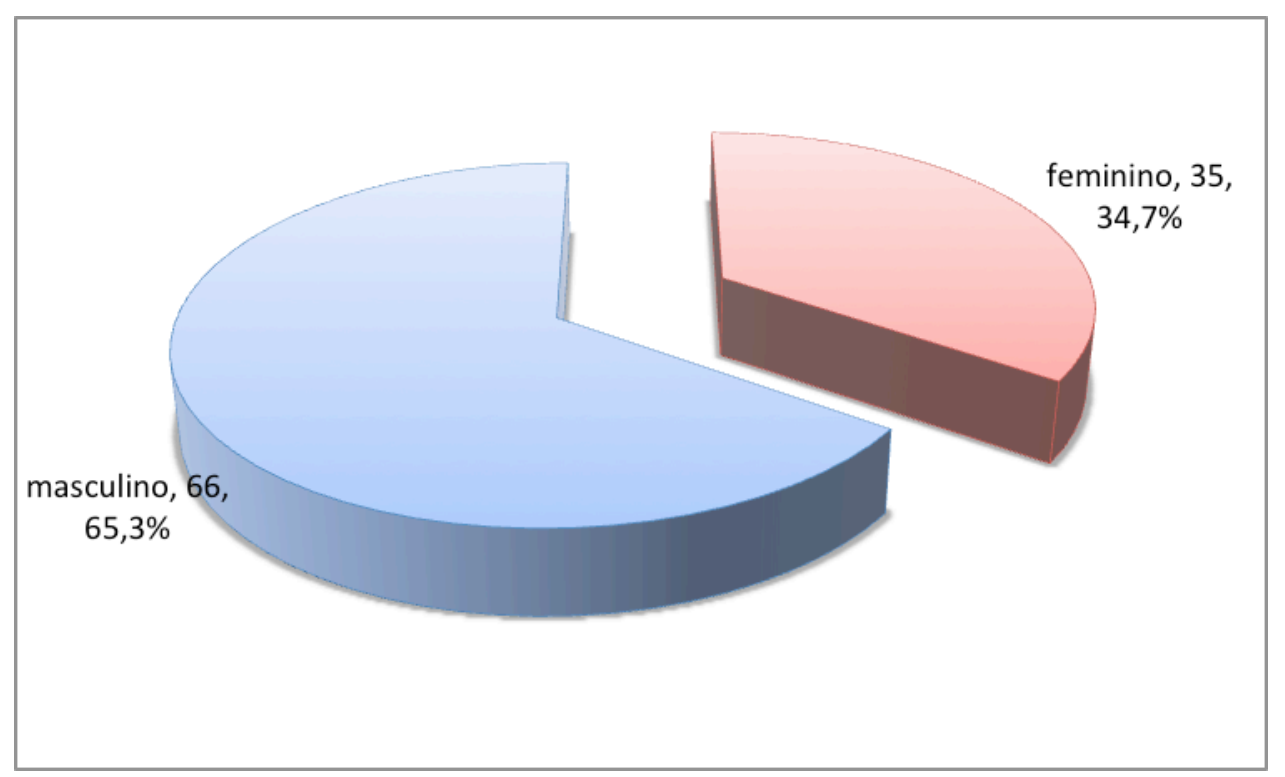

Figura 1 - Distribuição do gênero dos pacientes

A idade média dos pacientes foi de 63,1 anos, variando de 27 a 83 anos, com desvio-padrão de 12,3 anos(Figura 2). A maioria dos pacientes era da cor branca(83 pacientes $=82,2 \%)$ e os demais eram: amarelos (9 pacientes), mulatos (5 pacientes) e negros (4 pacientes)(Figura 3$)$. 0 índice de massa 
corpórea médio de 91 pacientes foi de $25,7 \mathrm{~kg} / \mathrm{m}^{2}$, variando de 15,5 a 36,9 $\mathrm{kg} / \mathrm{m}^{2}$, com desvio-padrão de $4,4 \mathrm{~kg} / \mathrm{m}^{2}$ (Figura 4).

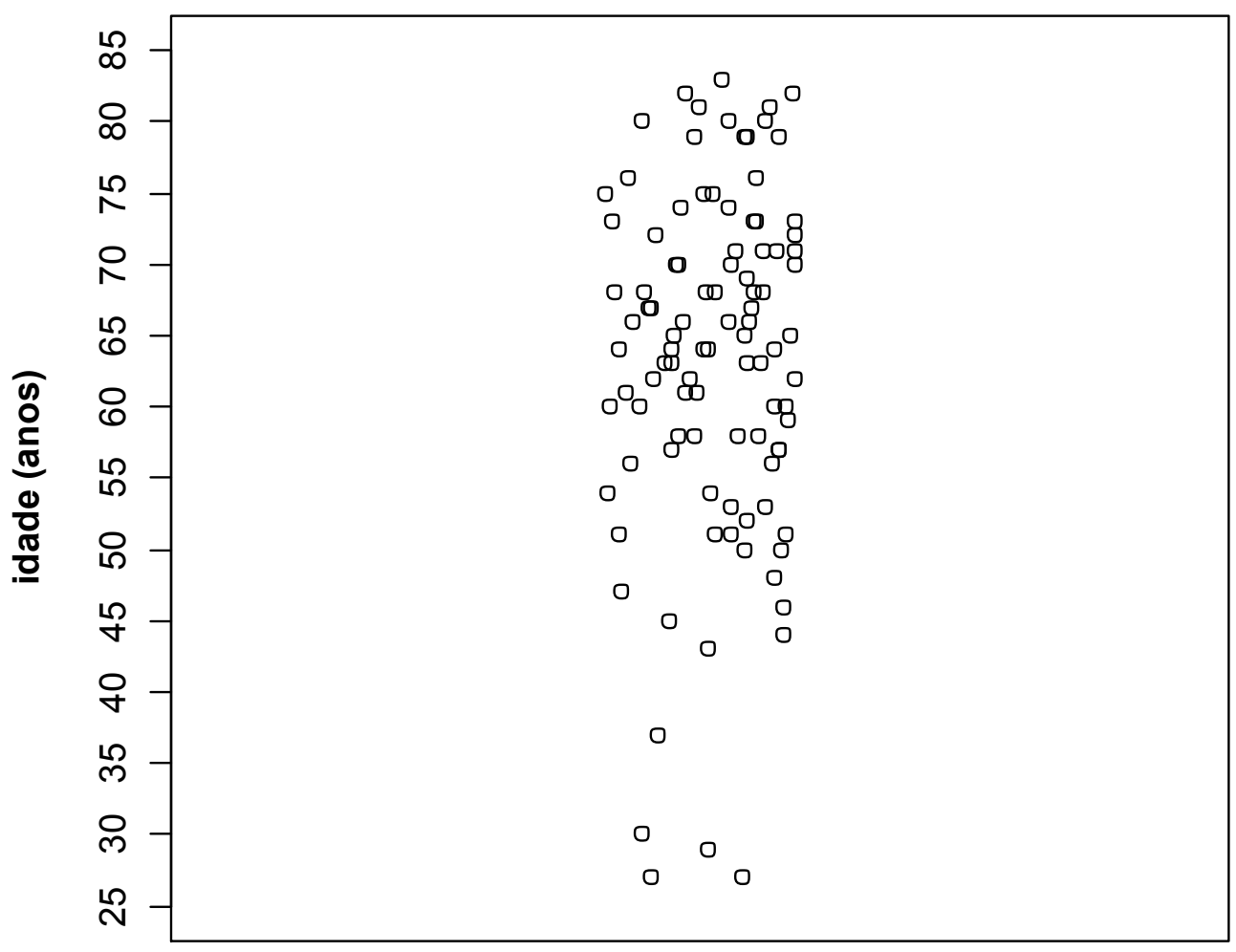

Figura 2 - Diagrama de dispersão unidimensional da idade (anos) dos pacientes

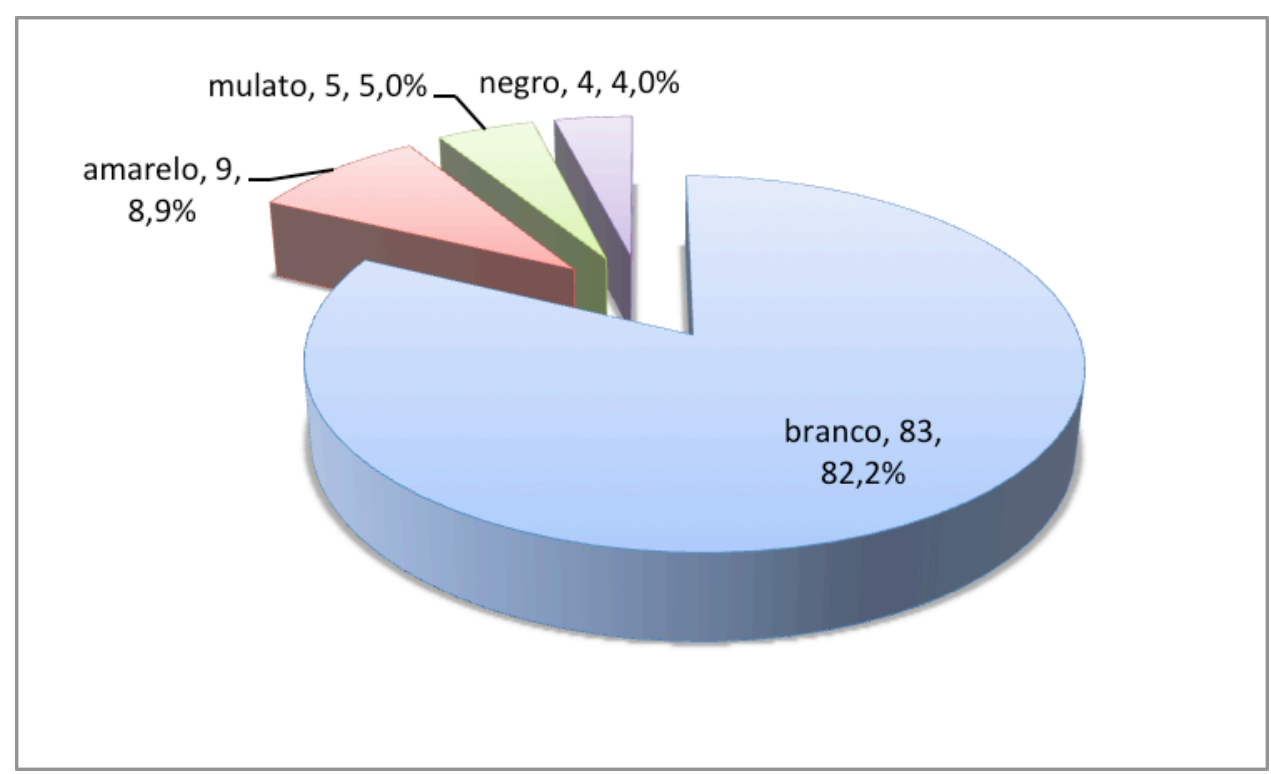

Figura 3 - Distribuição da cor dos pacientes 


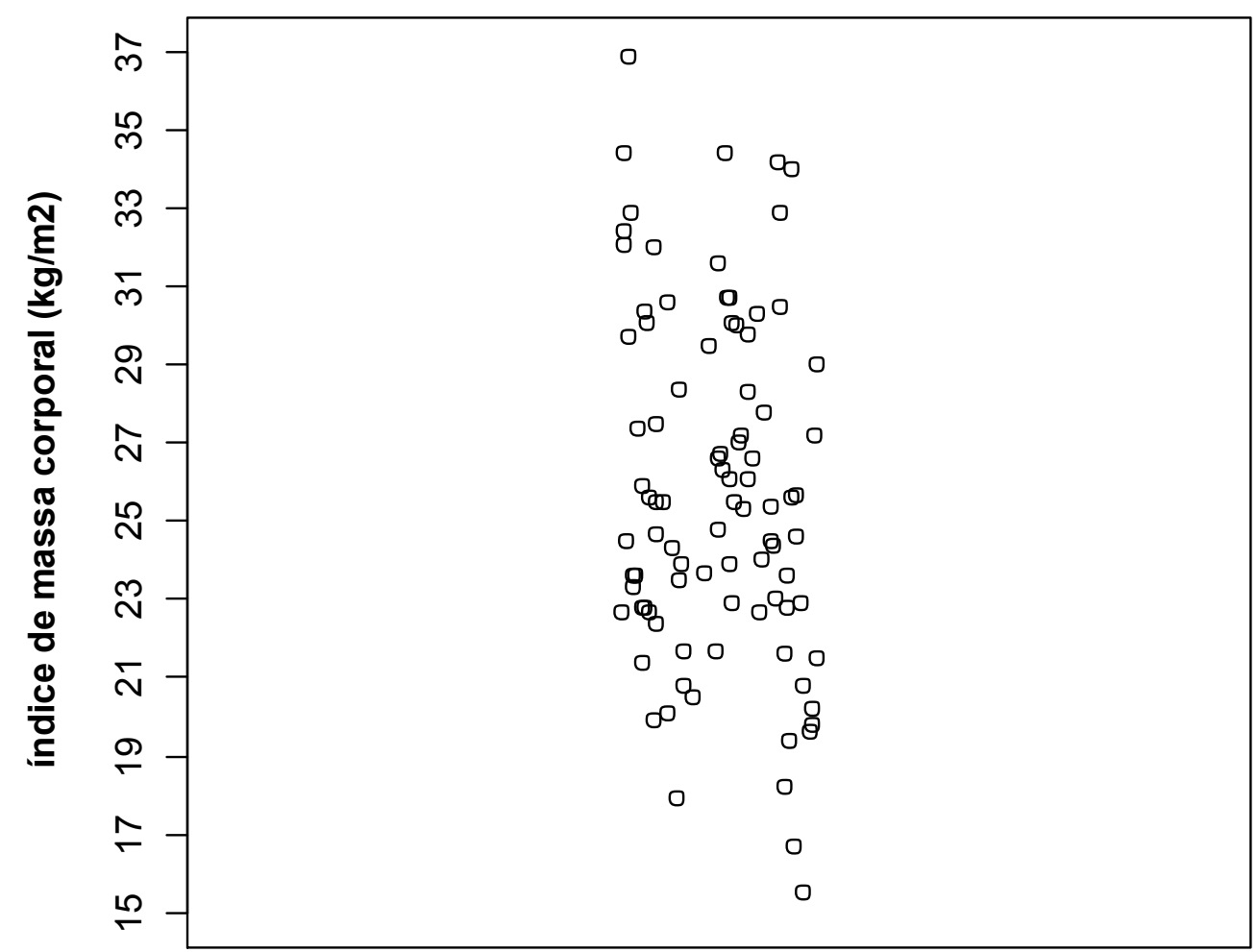

Figura 4 - Diagrama de dispersão unidimensional do índice de massa corporal $\left(\mathrm{kg} / \mathrm{m}^{2}\right)$ dos pacientes

Alguns sintomas, tais como emagrecimento, dor, sangramento digestivo e icterícia, foram observados em 96 pacientes desta amostra e destes, $21(21,9 \%)$ apresentaram emagrecimento. A dor e o sangramento foram relatados, respectivamente por $27(28,1 \%)$ e dois $(2,1 \%)$ pacientes. Seis pacientes(6,3\%) apresentaram icterícia na história clínica(Figura 5). 


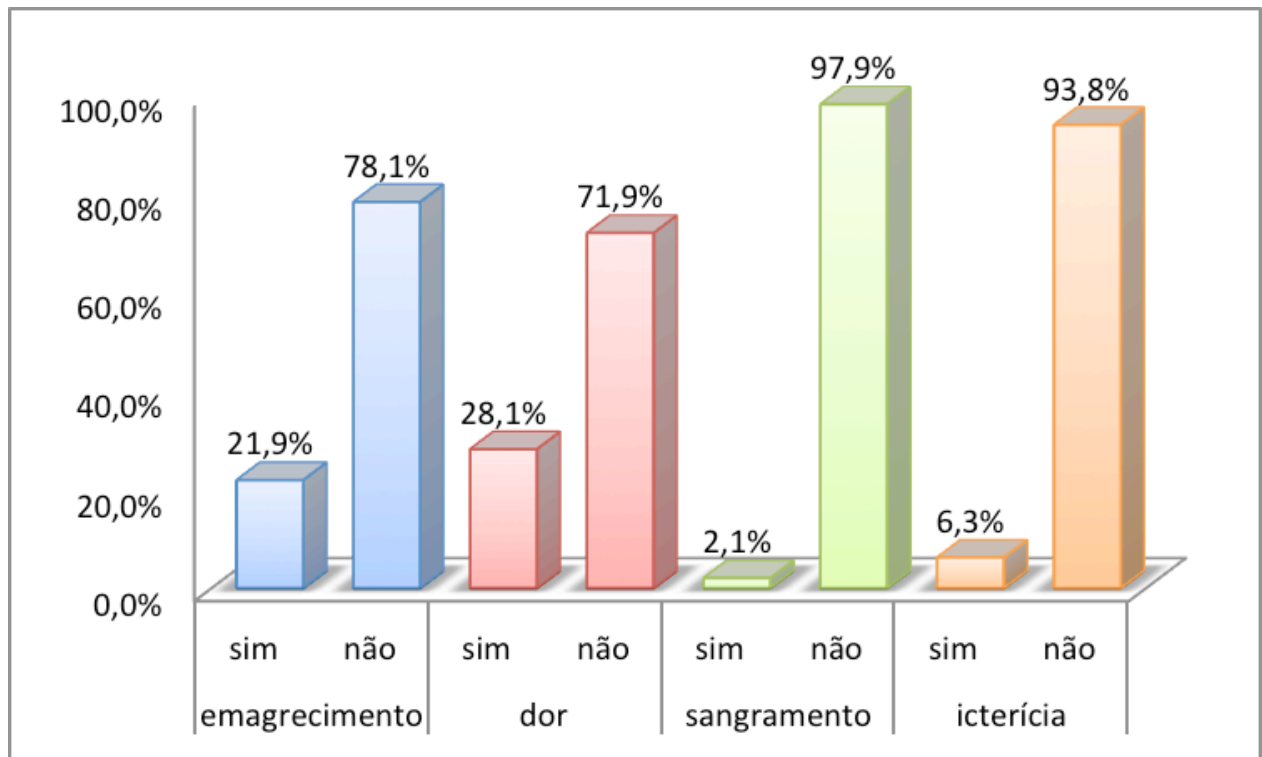

Figura 5 - Distribuição da presença dos principais sintomas dos pacientes com $\mathrm{CHC}$

Quanto à classificação ASA, mensurada também em 96 pacientes, $74(77,1 \%)$ eram ASA II e apenas $1(1,0 \%)$ era ASA IV (Figura 6$).$

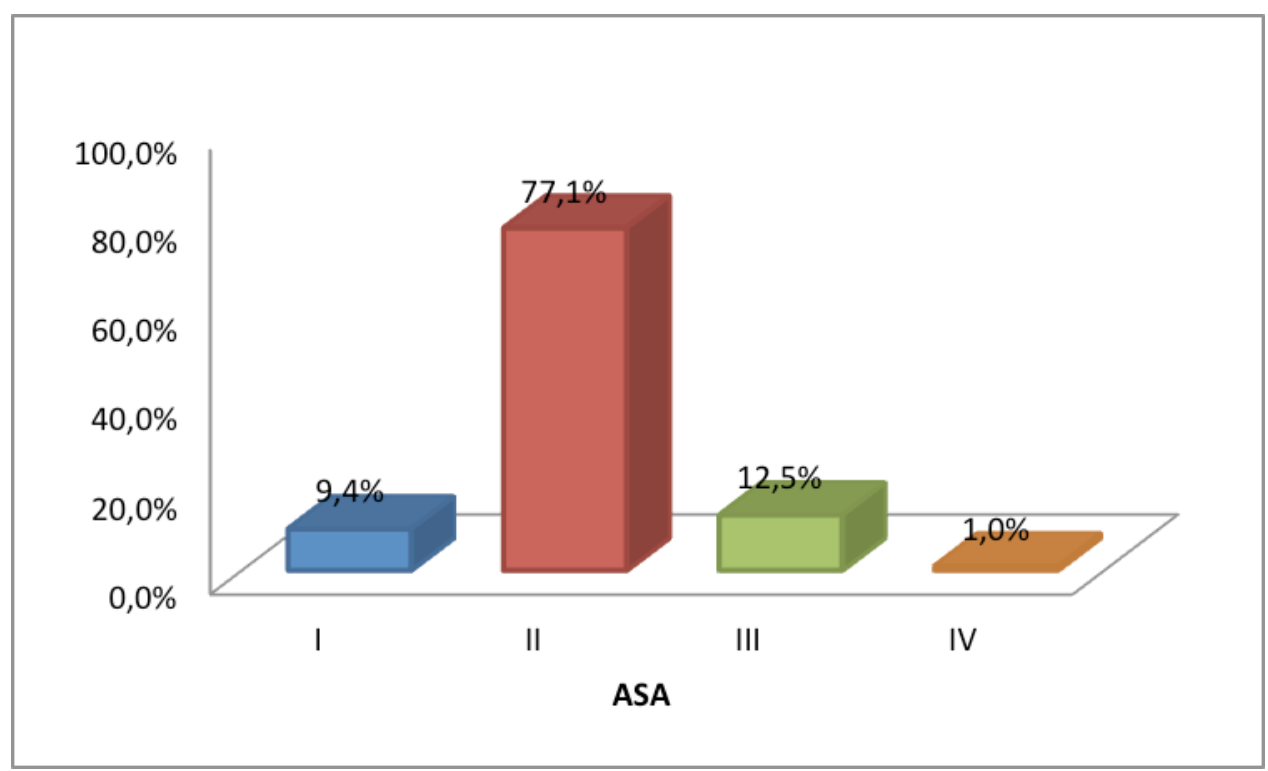

Figura 6 - Distribuição dos pacientes pela classificação ASA

A função hepática pôde ser avaliada em todos os 101 pacientes, sendo que, 98 (97,0\%) destes eram CHILD A(Figura 7). A pontuação média do MELD foi de 8,6, variando de 6 a 26, com desvio-padrão de 3,0(Figura 8). A maioria dos pacientes (95 pacientes $=94,1 \%$ ) enquadrava-se na classificação $A$ de Barcelona(Figura 9). 


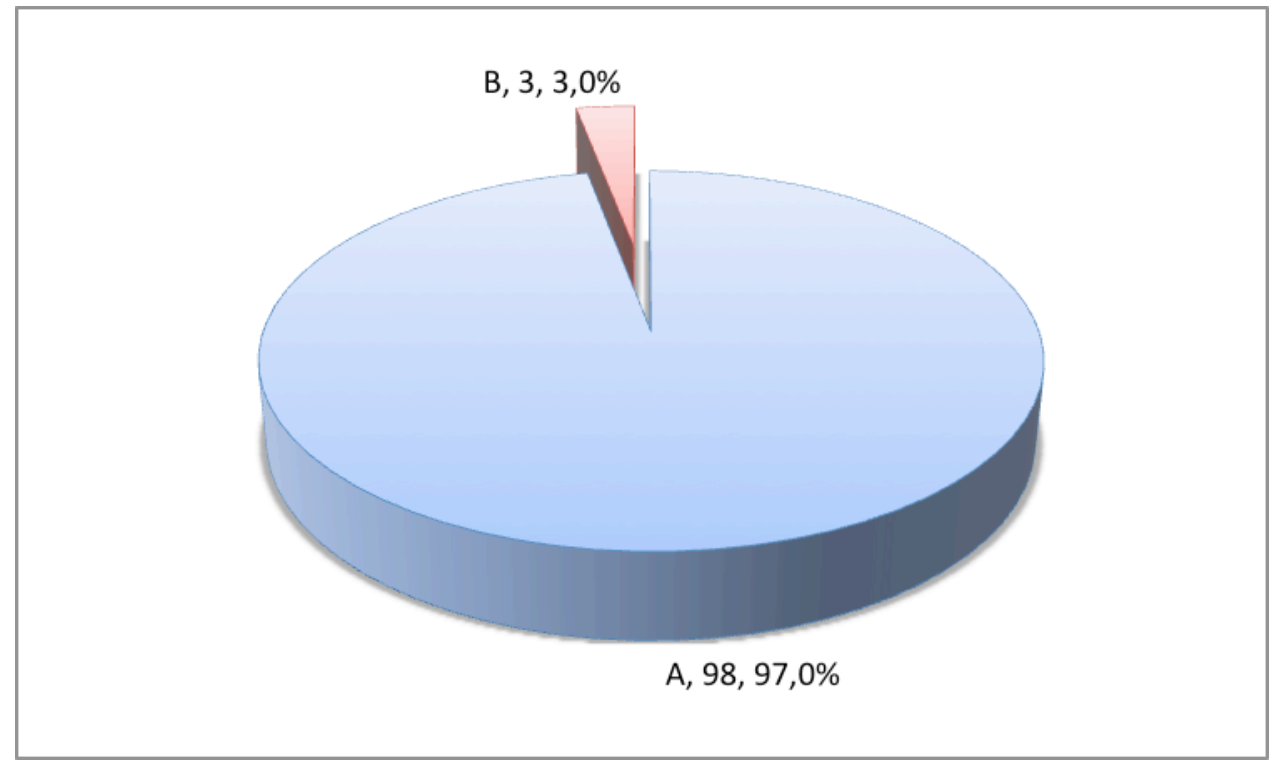

Figura 7 - Distribuição dos pacientes segundo a classificação de CHILD

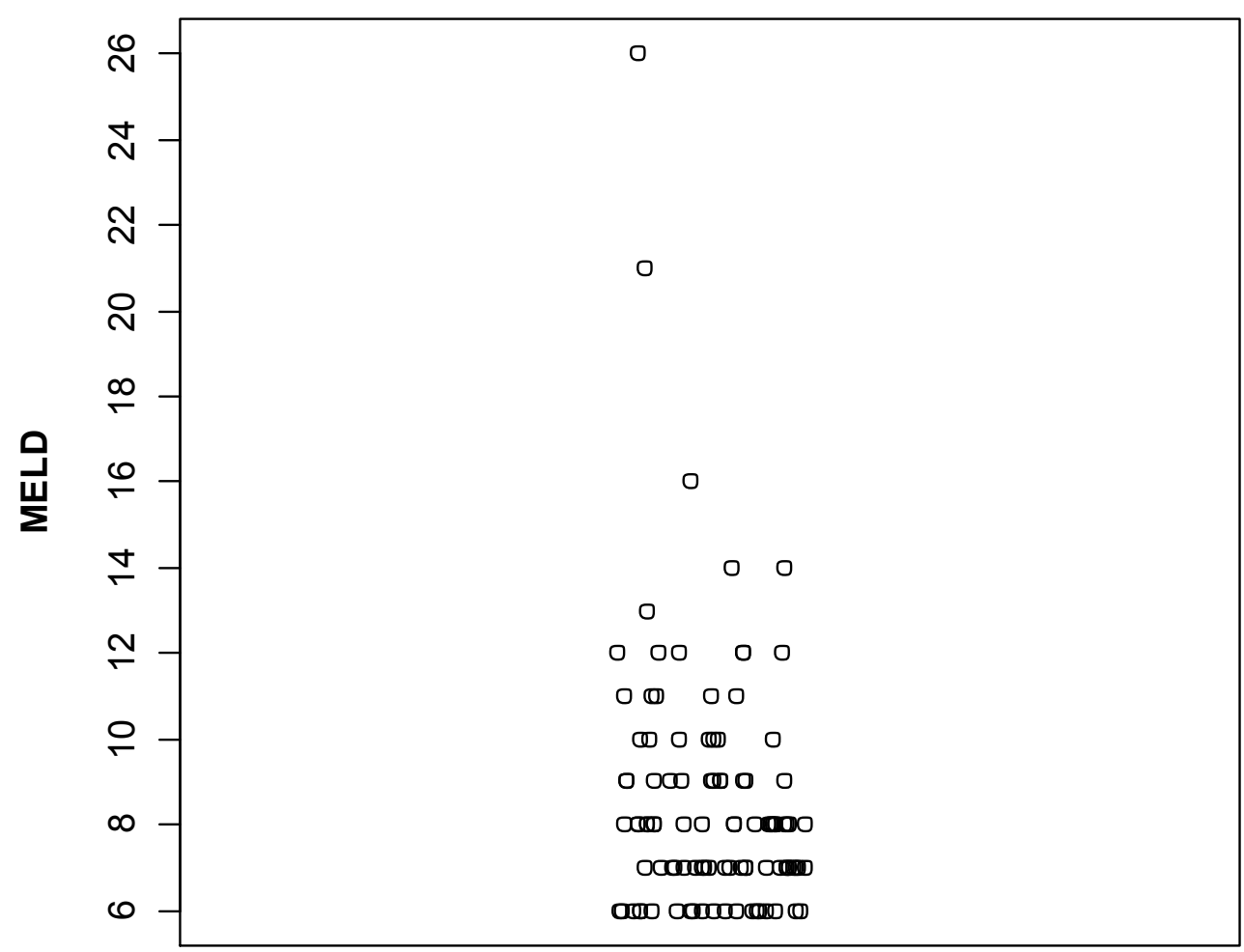

Figura 8 - Diagrama de dispersão unidimensional do MELD dos pacientes 


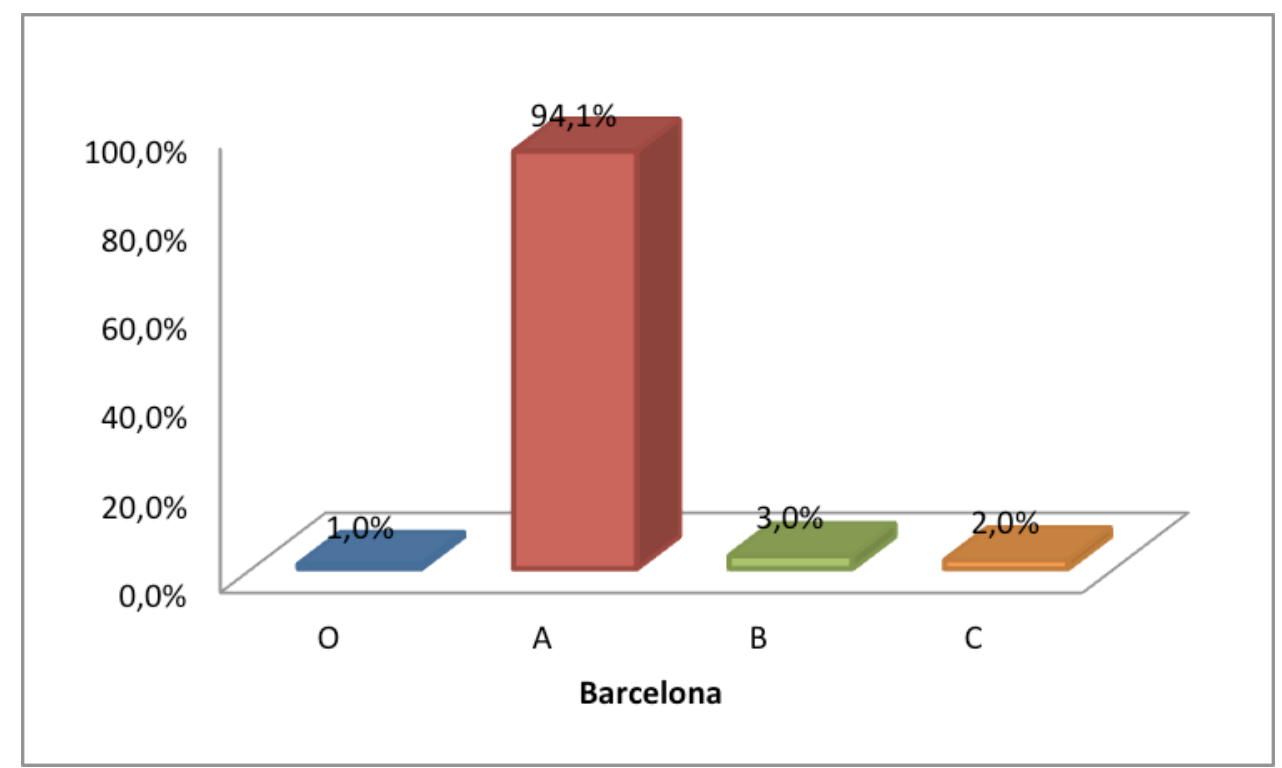

Figura 9 - Distribuição do escore de Barcelona dos pacientes

Dados dos níveis séricos de alfafetoproteína foram obtidos em 91 pacientes, sendo que um deles apresentou valor maior que $60500 \mathrm{ng} / \mathrm{mL}$. Os demais 90 pacientes apresentaram valor mediano de 22,0 ng/mL, variando de 1 a $60500 \mathrm{ng} / \mathrm{mL}$ (Figura 10). Para 58 pacientes foi também avaliado o nível sérico de CA19.9 e quatro pacientes destes tinham medida menor que 0,6 $\mathrm{U} / \mathrm{mL}$. Os demais 54 pacientes apresentaram valor mediano de 26,6 U/mL, variando de 0,6 a 276,1 U/mL(Figura 11). 


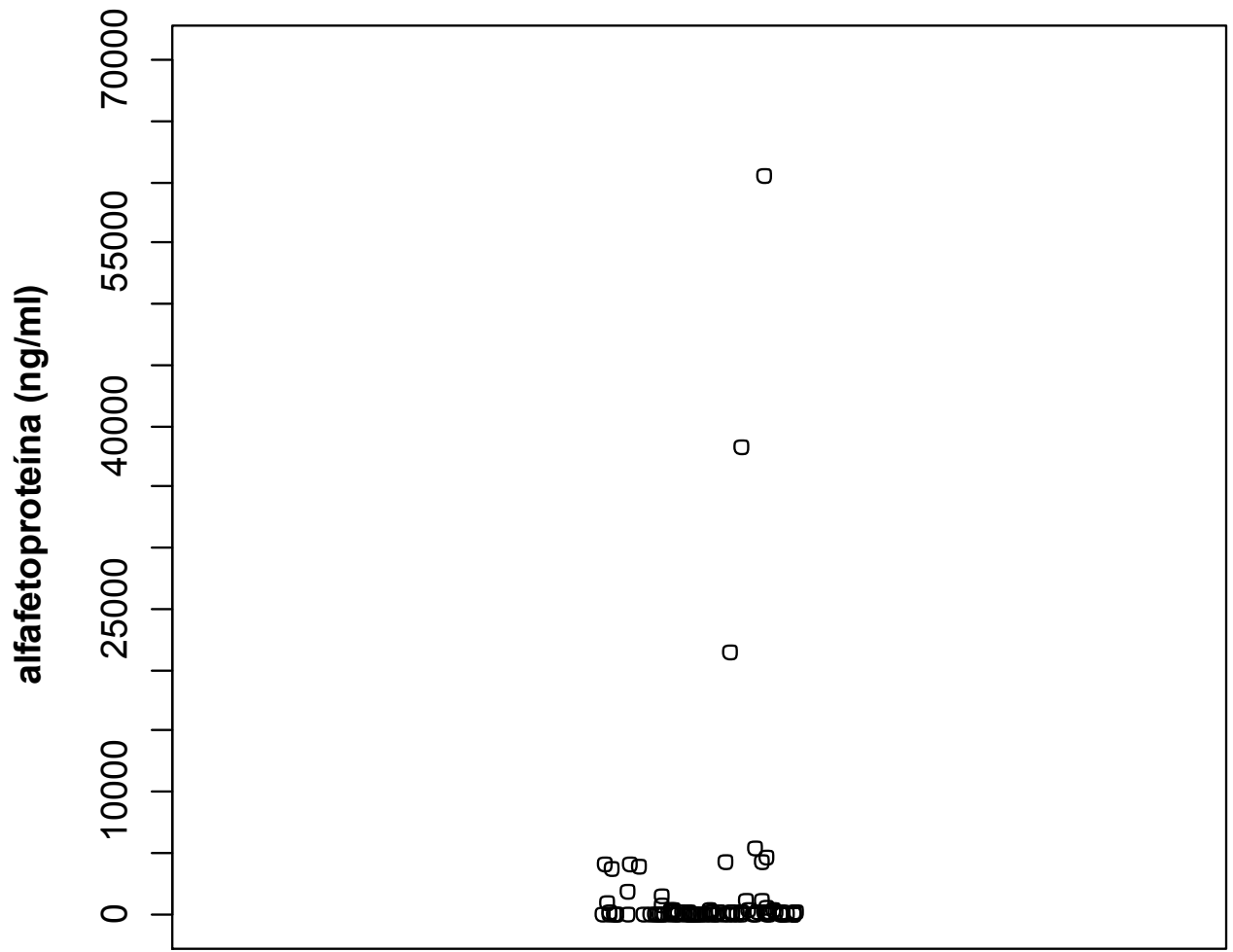

Figura 10 - Diagrama de dispersão unidimensional do nível sérico de alfafetoproteína $(\mathrm{ng} / \mathrm{mL})$ dos pacientes com $\mathrm{CHC}$

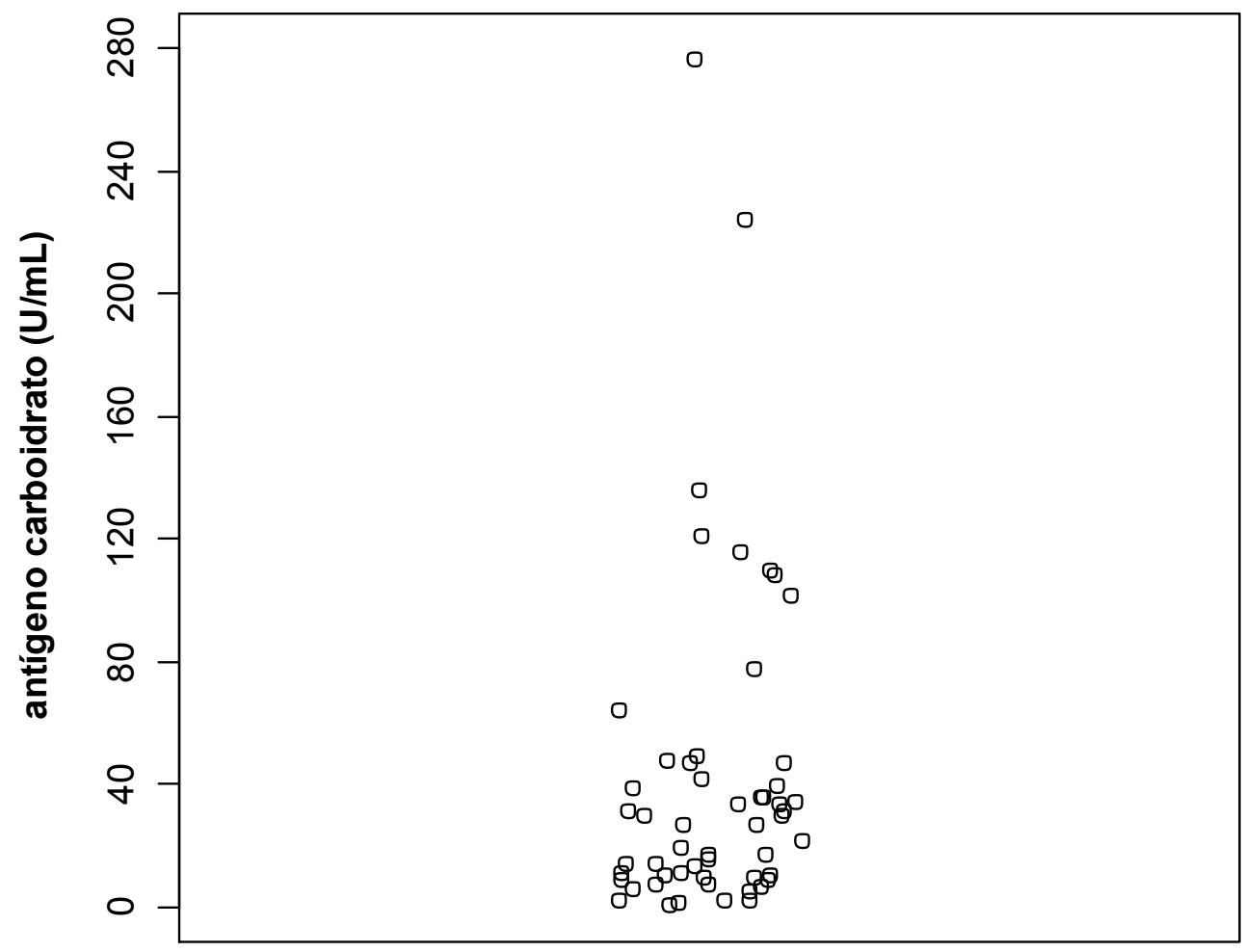

Figura 11 - Diagrama de dispersão unidimensional do nível sérico de CA19.9 $(\mathrm{U} / \mathrm{mL})$ dos pacientes com $\mathrm{CHC}$ 
As Tabelas 1 e 2 resumem as características clínicas dos pacientes da amostra.

Tabela 1 - Distribuição das características gerais, sintomas e ASA dos pacientes com $\mathrm{CHC}$

\begin{tabular}{|c|c|c|c|}
\hline \multirow{4}{*}{ gênero } & & $\mathrm{n}$ & $\%$ \\
\hline & feminino & 35 & $34,7 \%$ \\
\hline & masculino & 66 & $65,3 \%$ \\
\hline & Total & 101 & $100,0 \%$ \\
\hline \multirow[t]{5}{*}{ idade (anos) } & $\mathrm{n}$ & 101 & \\
\hline & média & 63,1 & \\
\hline & mediana & 64,0 & \\
\hline & mínimo-máximo & $27-83$ & \\
\hline & desvio-padrão & 12,3 & \\
\hline \multirow{5}{*}{ 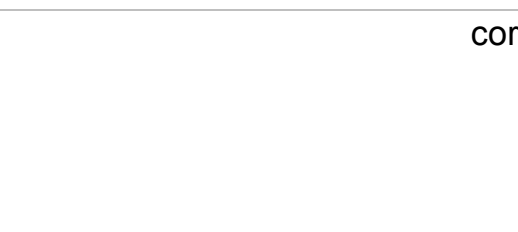 } & branco & 83 & $82,2 \%$ \\
\hline & amarelo & 9 & $8,9 \%$ \\
\hline & mulato & 5 & $5,0 \%$ \\
\hline & negro & 4 & $4,0 \%$ \\
\hline & Total & 101 & $100,0 \%$ \\
\hline \multirow[t]{5}{*}{ índice de massa corporal $\left(\mathrm{kg} / \mathrm{m}^{2}\right)$} & $\mathrm{n}$ & 91 & \\
\hline & média & 25,7 & \\
\hline & mediana & 25,4 & \\
\hline & mínimo-máximo & $15,5-36$ & \\
\hline & desvio-padrão & 4,4 & \\
\hline \multirow[t]{3}{*}{ emagrecimento } & $\operatorname{sim}$ & 21 & $21,9 \%$ \\
\hline & não & 75 & $78,1 \%$ \\
\hline & Total & 96 & $100,0 \%$ \\
\hline \multirow[t]{3}{*}{ dor } & $\operatorname{sim}$ & 27 & $28,1 \%$ \\
\hline & não & 69 & $71,9 \%$ \\
\hline & Total & 96 & $100,0 \%$ \\
\hline \multirow[t]{3}{*}{ sangramento } & $\operatorname{sim}$ & 2 & $2,1 \%$ \\
\hline & não & 94 & $97,9 \%$ \\
\hline & Total & 96 & $100,0 \%$ \\
\hline \multirow[t]{3}{*}{ icterícia } & sim & 6 & $6,3 \%$ \\
\hline & não & 90 & $93,8 \%$ \\
\hline & Total & 96 & $100,0 \%$ \\
\hline \multirow[t]{5}{*}{ ASA } & 1 & 9 & $9,4 \%$ \\
\hline & II & 74 & $77,1 \%$ \\
\hline & III & 12 & $12,5 \%$ \\
\hline & IV & 1 & $1,0 \%$ \\
\hline & Total & 96 & $100,0 \%$ \\
\hline
\end{tabular}


Tabela 2 - Distribuição da classificação de CHILD, MELD, BARCELONA e dos níveis séricos de alfafetoproteína $(\mathrm{ng} / \mathrm{mL})$ e CA $19.9(\mathrm{U} / \mathrm{mL})$ dos pacientes com $\mathrm{CHC}$

\begin{tabular}{rlcc}
\hline \hline & & $\mathrm{n}$ & $\%$ \\
\hline & CHILD & 98 & $97,0 \%$ \\
& $\mathrm{~B}$ & 3 & $3,0 \%$ \\
& Total & 101 & $100,0 \%$ \\
\hline & $\mathrm{n}$ & 101 & \\
& média & 8,6 & \\
& mediana & 8,0 & \\
& mínimo-máximo & $6-26$ & \\
& desvio-padrão & 3,0 & \\
BARCELONA & 0 & 1 & $1,0 \%$ \\
& $\mathrm{~A}$ & 95 & $94,1 \%$ \\
& $\mathrm{~B}$ & $3,0 \%$ \\
& $\mathrm{C}$ & 2 & $2,0 \%$ \\
& Total & 101 & $100,0 \%$ \\
\hline alfafetoproteína $(\mathrm{ng} / \mathrm{ml})$ & $\mathrm{n}$ & 90 & \\
& média & 1833,3 & \\
& mediana & 22,0 & \\
& mínimo-máximo & $1-60500$ & \\
& desvio-padrão & 7814,2 & \\
& $\mathrm{n}$ & 54 & \\
& média & 41,4 & \\
& mediana & 26,6 & \\
& mínimo-máximo & $0,6-276,1$ & \\
& desvio-padrão & 53,6 & \\
\hline \hline
\end{tabular}

As Figuras 12 a 18 apresentam algumas características da doença.

Com relação à etiologia da doença, os pacientes foram divididos em seis grupos: VHC, VHB, Álcool(OH), NASH, mista(VHB, VHC e OH, pelo menos duas de três dessas) e outras( representando doenças como hemocromatose, deficiência de alfa1 antitripsina, aflatoxinas, criptogênica e outras possíveis causas de $\mathrm{CHC}$ ).

Onze (10,9\%) pacientes eram portadores do VHB, 34 (33,7\%) do VHC, 13 pacientes $(12,9 \%)$ de $\mathrm{OH}, 8$ pacientes $(7,9 \%)$ apresentavam NASH, 14 $(13,9 \%)$ pacientes apresentavam etiologia mista e os restantes 21 pacientes $(20,8 \%)$ apresentavam outras etiologias (Figura 12). 


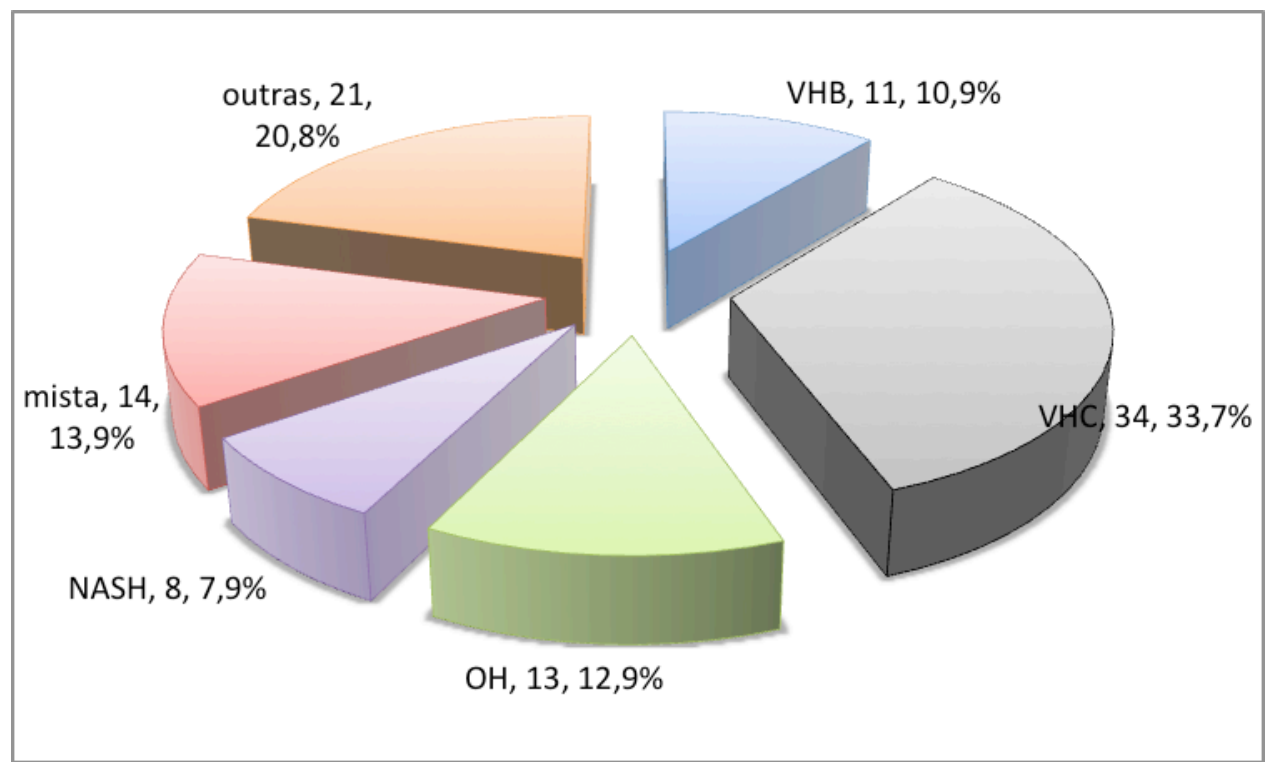

Figura 12 - Distribuição da etiologia da doença dos pacientes com $\mathrm{CHC}$

É importante destacar que 77 (76,2\%) pacientes apresentavam cirrose confirmada e os restantes 24 pacientes $(23,8 \%)$ não apresentavam hepatopatia crônica.

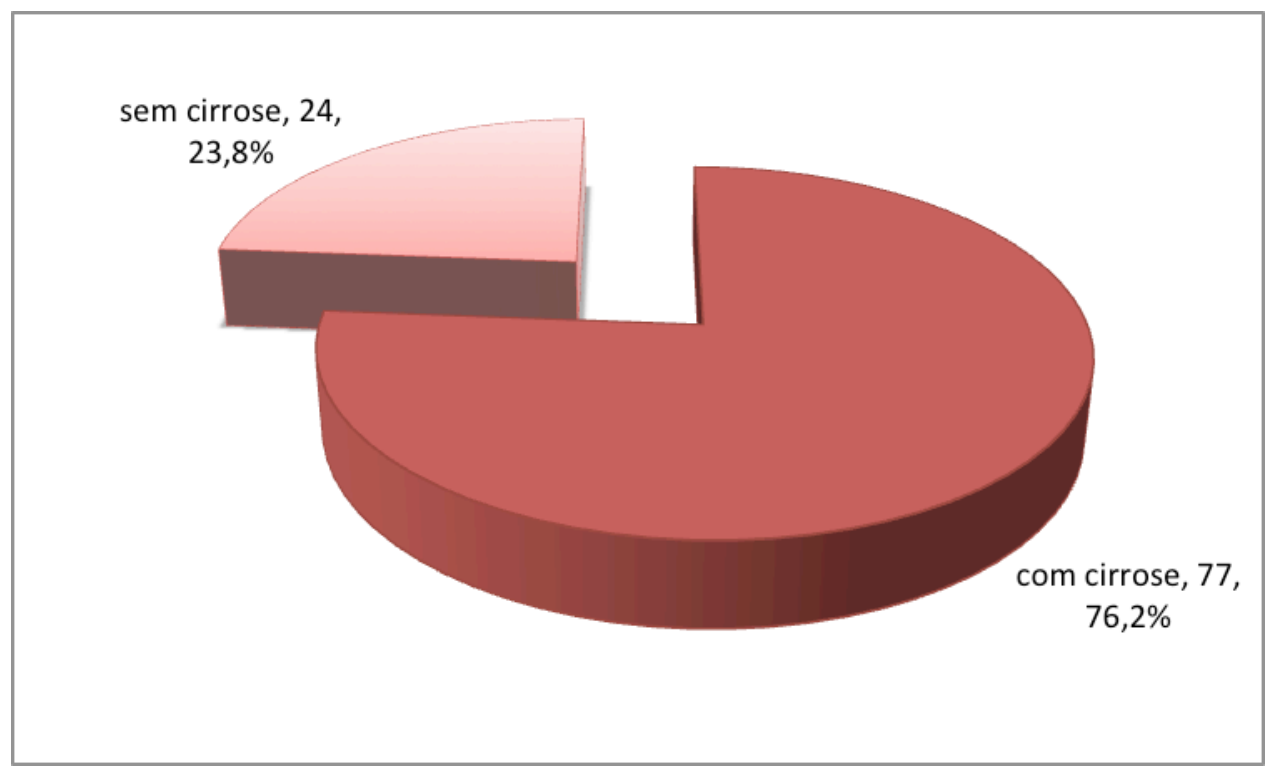

Figura 13 - Distribuição da presença de cirrose entre os pacientes

O tamanho do tumor, grau de Edmondson Steiner, presença ou não de cápsula, nódulos satélites e invasão vascular, bem como a variável margem livre não foram registrados em todos os prontuários. O tamanho mediano do tumor dos pacientes foi de $4,8 \mathrm{~cm}$, variando de 0,5 a $24 \mathrm{~cm}$ (Figura 14). 


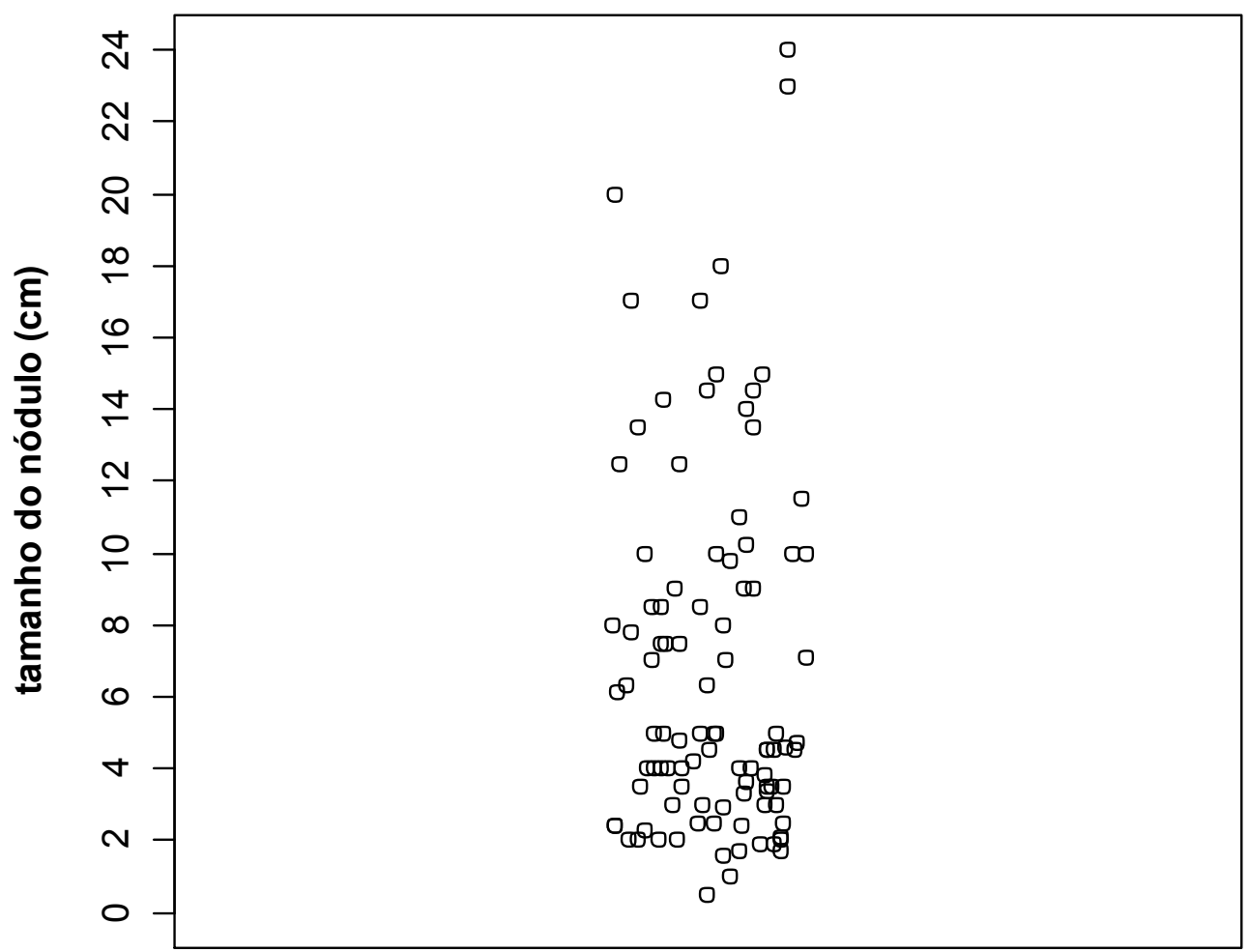

Figura 14 - Diagrama de dispersão unidimensional do tamanho do nódulo $(\mathrm{cm})$ dos pacientes com $\mathrm{CHC}$

Sessenta e cinco pacientes (66,3\%) apresentaram grau III de Edmondson Steiner, sendo este o grau mais frequentemente encontrado, seguido pelo grau II em 26 (26,5\%) pacientes (Figura 15).

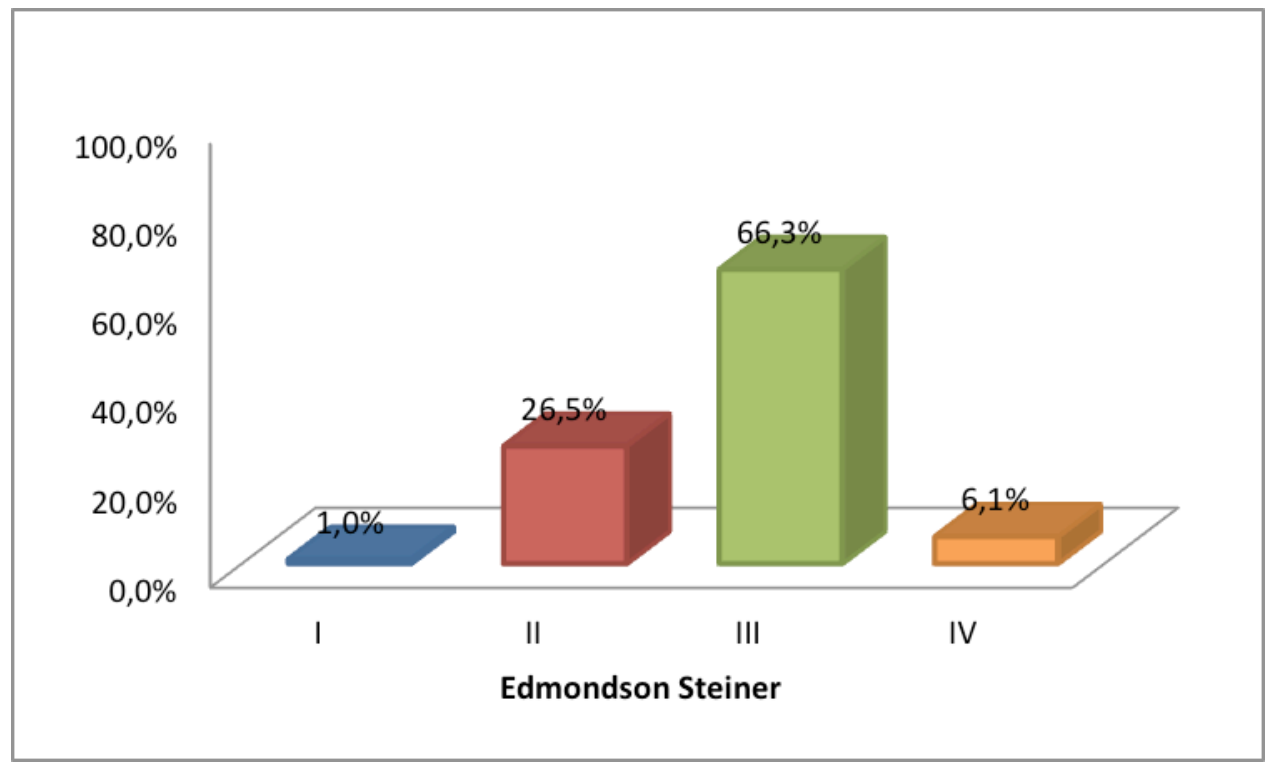

Figura 15 - Distribuição do grau de Edmondson Steiner para o CHC 
A presença de cápsula foi confirmada em 63 pacientes $(64,3 \%)$, sendo que destes, apenas 11 (17,5\%) apresentaram invasão da mesma (Figura 16).

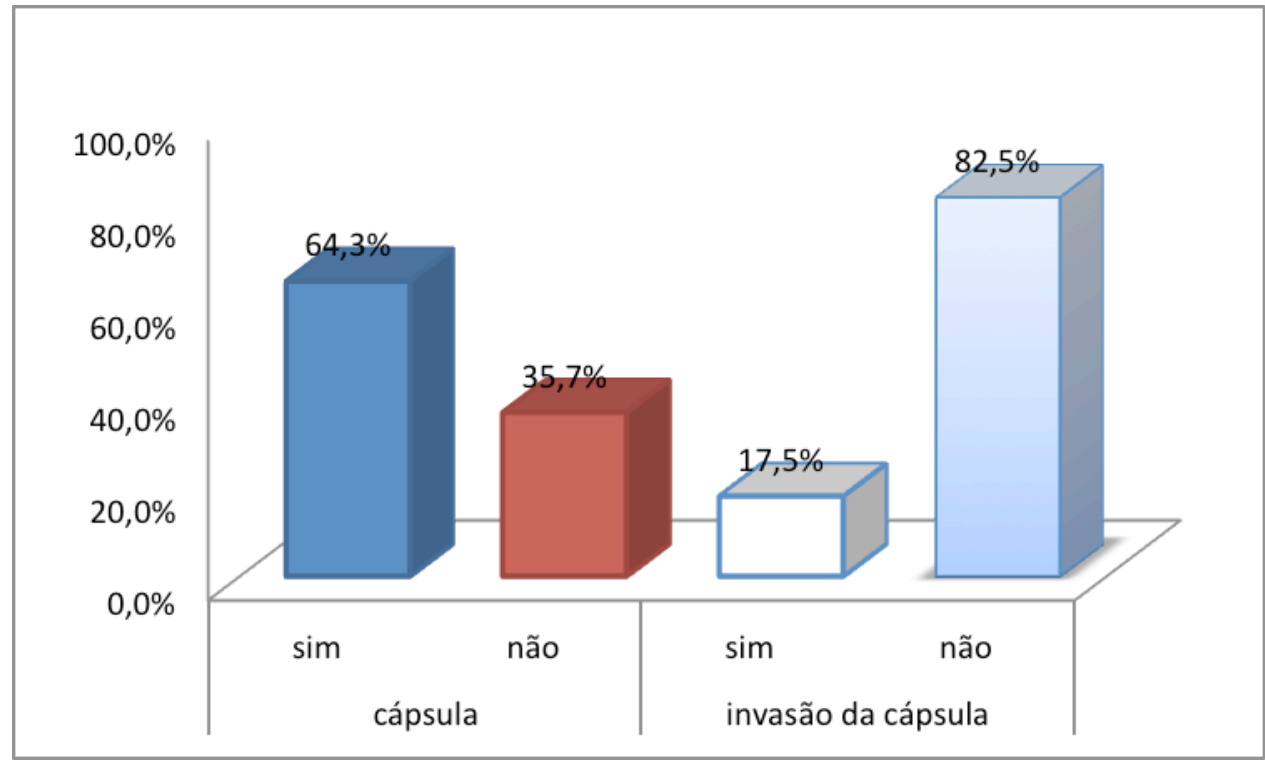

Figura 16 - Distribuição da presença de cápsula e sua invasão entre os pacientes com $\mathrm{CHC}$

Nódulos satélites foram encontrados em 13 pacientes $(13,4 \%)$ e invasão vascular em 52 pacientes (53,6\%). Em oitenta e nove pacientes (92,7\%) as margens de ressecção estavam livres de neoplasia (Figura 17).

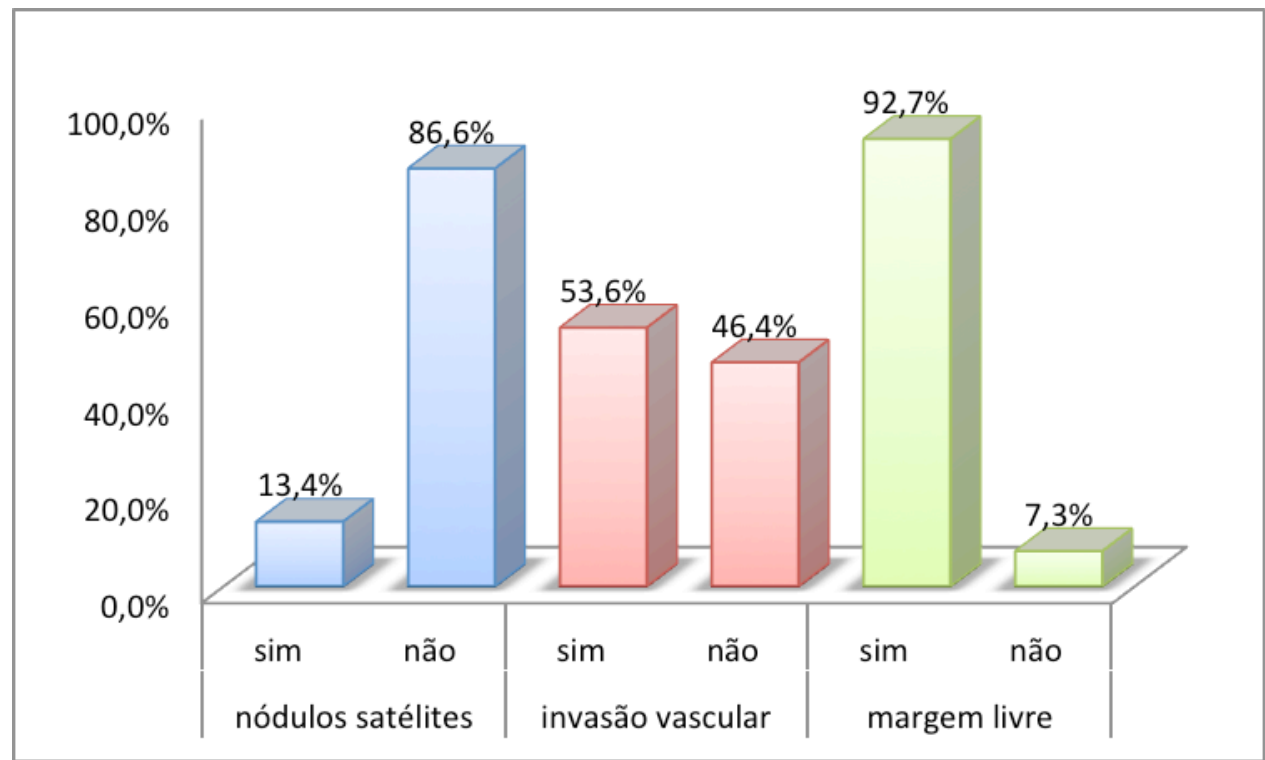

Figura 17 - Distribuição da presença de nódulos satélites, invasão vascular e margem livre entre os pacientes com $\mathrm{CHC}$ 
Cinquenta e sete pacientes $(58,2 \%)$ preenchiam os critérios de Milão: neste estudo apenas um nódulo de até $5 \mathrm{~cm}$ e sem invasão vascular, já que foram operados apenas os pacientes com nódulo único (Figura 18).

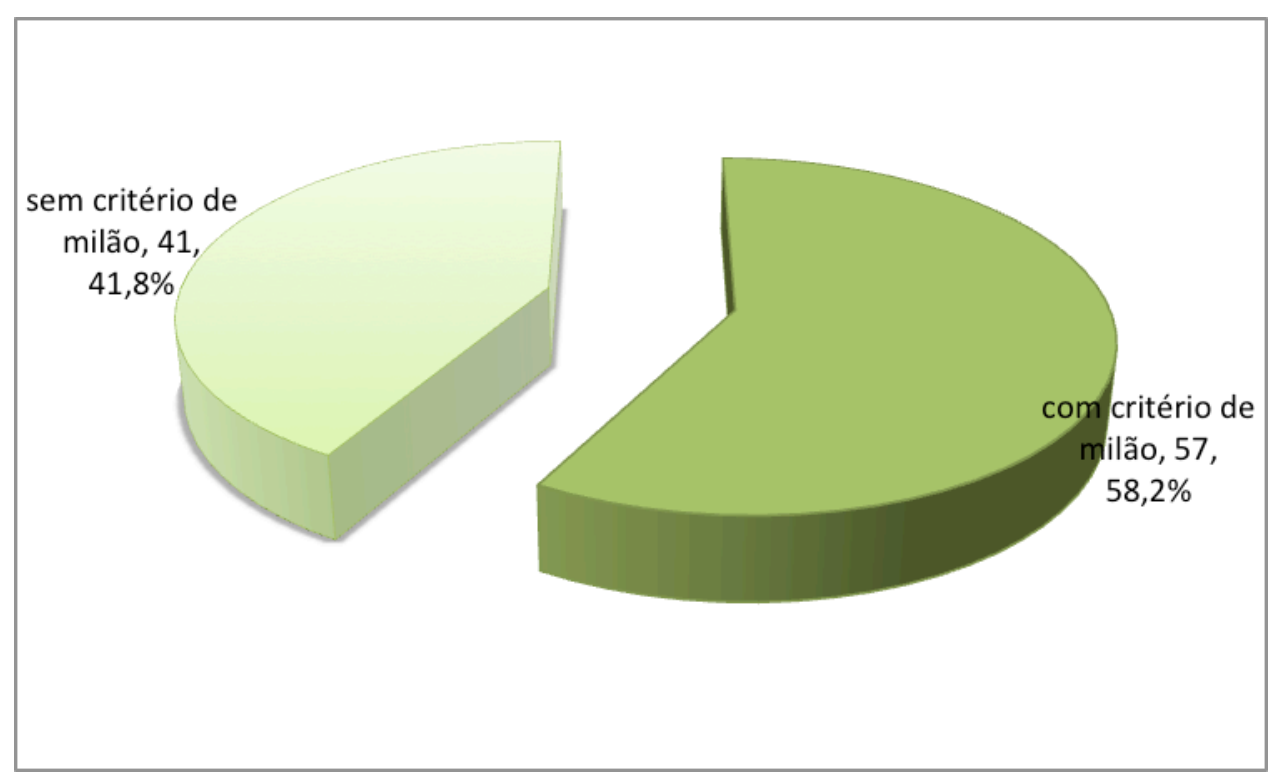

Figura 18 - Distribuição da presença de critérios de Milão entre os pacientes com $\mathrm{CHC}$

A Tabela 3 resume as características da doença nos pacientes da amostra. 
Tabela 3 - Distribuição das características da doença nos pacientes com CHC

\begin{tabular}{|c|c|c|c|}
\hline & & $\mathrm{n}$ & $\%$ \\
\hline \multirow[t]{7}{*}{ etiologia } & VHB & 11 & $10,9 \%$ \\
\hline & VHC & 34 & $33,7 \%$ \\
\hline & $\mathrm{OH}$ & 13 & $12,9 \%$ \\
\hline & $\mathrm{NASH}$ & 8 & $7,9 \%$ \\
\hline & mista & 14 & $13,9 \%$ \\
\hline & outras & 21 & $20,8 \%$ \\
\hline & Total & 101 & $100,0 \%$ \\
\hline \multirow[t]{3}{*}{ cirrose } & $\operatorname{sim}$ & 77 & $76,2 \%$ \\
\hline & não & 24 & $23,8 \%$ \\
\hline & Total & 101 & $100,0 \%$ \\
\hline \multirow[t]{5}{*}{ tamanho do nódulo $(\mathrm{cm})$} & $\mathrm{n}$ & 98 & \\
\hline & média & 6,8 & \\
\hline & mediana & 4,8 & \\
\hline & mínimo-máximo & $0,5-24,0$ & \\
\hline & desvio-padrão & 5,1 & \\
\hline \multirow[t]{5}{*}{ grau de Edmondson Steiner } & 1 & 1 & $1,0 \%$ \\
\hline & II & 26 & $26,5 \%$ \\
\hline & III & 65 & $66,3 \%$ \\
\hline & IV & 6 & $6,1 \%$ \\
\hline & Total & 98 & $100,0 \%$ \\
\hline \multirow[t]{3}{*}{ critério de milão } & $\operatorname{sim}$ & 57 & $58,2 \%$ \\
\hline & não & 41 & $41,8 \%$ \\
\hline & Total & 98 & $100,0 \%$ \\
\hline \multirow[t]{3}{*}{ cápsula } & $\operatorname{sim}$ & 63 & $64,3 \%$ \\
\hline & não & 35 & $35,7 \%$ \\
\hline & Total & 98 & $100,0 \%$ \\
\hline \multirow[t]{3}{*}{ invasão da cápsula } & $\operatorname{sim}$ & 11 & $17,5 \%$ \\
\hline & não & 52 & $82,5 \%$ \\
\hline & Total & 63 & $100,0 \%$ \\
\hline \multirow[t]{3}{*}{ nódulos satélites } & $\operatorname{sim}$ & 13 & $13,4 \%$ \\
\hline & não & 84 & $86,6 \%$ \\
\hline & Total & 97 & $100,0 \%$ \\
\hline \multirow[t]{3}{*}{ invasão vascular } & $\operatorname{sim}$ & 52 & $53,6 \%$ \\
\hline & não & 45 & $46,4 \%$ \\
\hline & Total & 97 & $100,0 \%$ \\
\hline \multirow[t]{3}{*}{ margem livre } & $\operatorname{sim}$ & 89 & $92,7 \%$ \\
\hline & não & 7 & $7,3 \%$ \\
\hline & Total & 96 & $100,0 \%$ \\
\hline
\end{tabular}


Com respeito às principais características da cirurgia, novamente temos que, pelo inadequado registro nos prontuários, não foi possível a completa descrição de todos os 101 pacientes (Figuras 19 a 21).

A maioria dos pacientes (73 pacientes $=75,3 \%$ ) realizou cirurgia aberta, enquanto $24(24,7 \%)$ realizaram cirurgia por via laparoscópica (Figura 19).

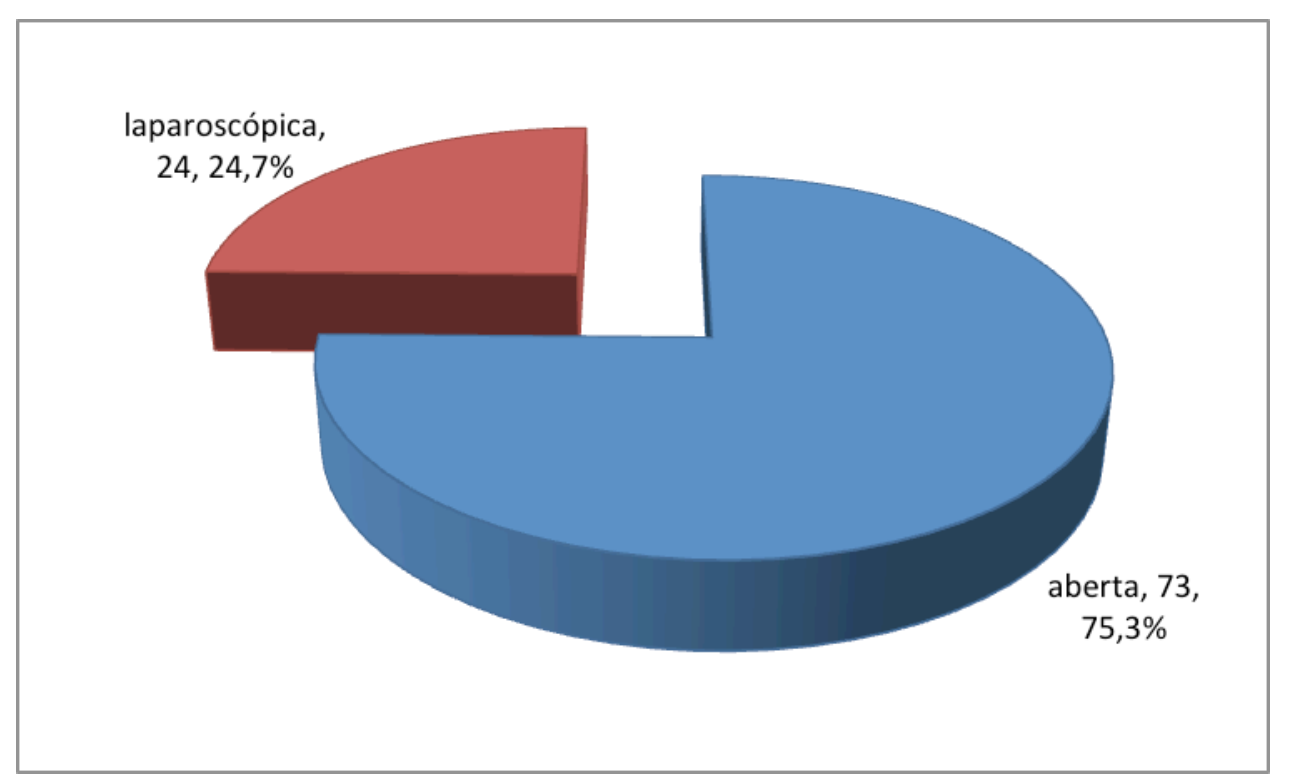

Figura 19 - Distribuição do tipo de cirurgia realizada em pacientes com $\mathrm{CHC}$

A ressecção anatômica foi realizada em 69 pacientes $(69,7 \%)$ e a transfusão de sangue foi necessária em 20 pacientes (21,3\%) (Figura 20).

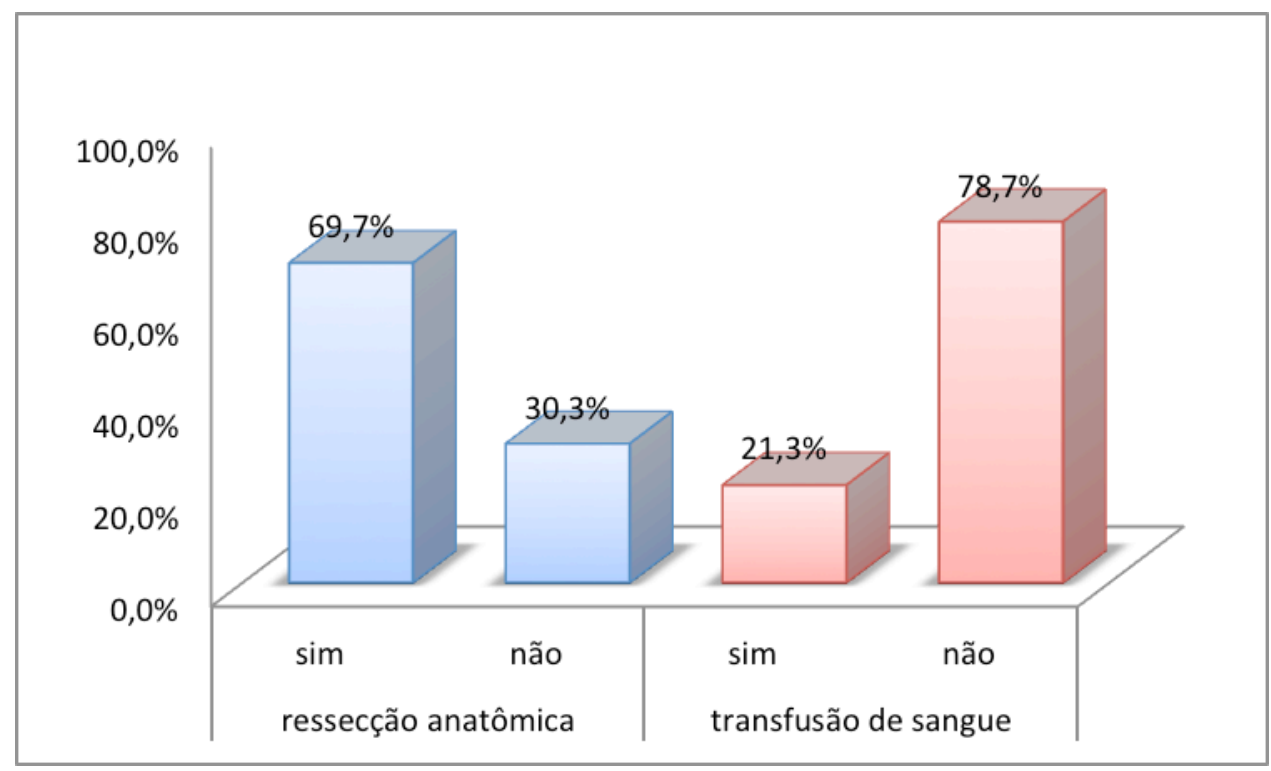

Figura 20 - Distribuição do tipo de ressecção e necessidade de transfusão de sangue dos pacientes com $\mathrm{CHC}$ 
Quanto às complicações pós-operatórias, segundo a classificação de Clavien, 52 pacientes $(55,3 \%)$ apresentaram complicações grau I, e 19 pacientes $(20,2 \%)$ grau II (Figura 21). Complicações como ascite, íleo paralítico, infecções, renais e pulmonares estiveram entre as mais frequentes (Tabela 4). A Tabela 5 mostra a distribuição das causas de reoperações e óbitos hospitalares dos pacientes submetidos à ressecção de $\mathrm{CHC}$.

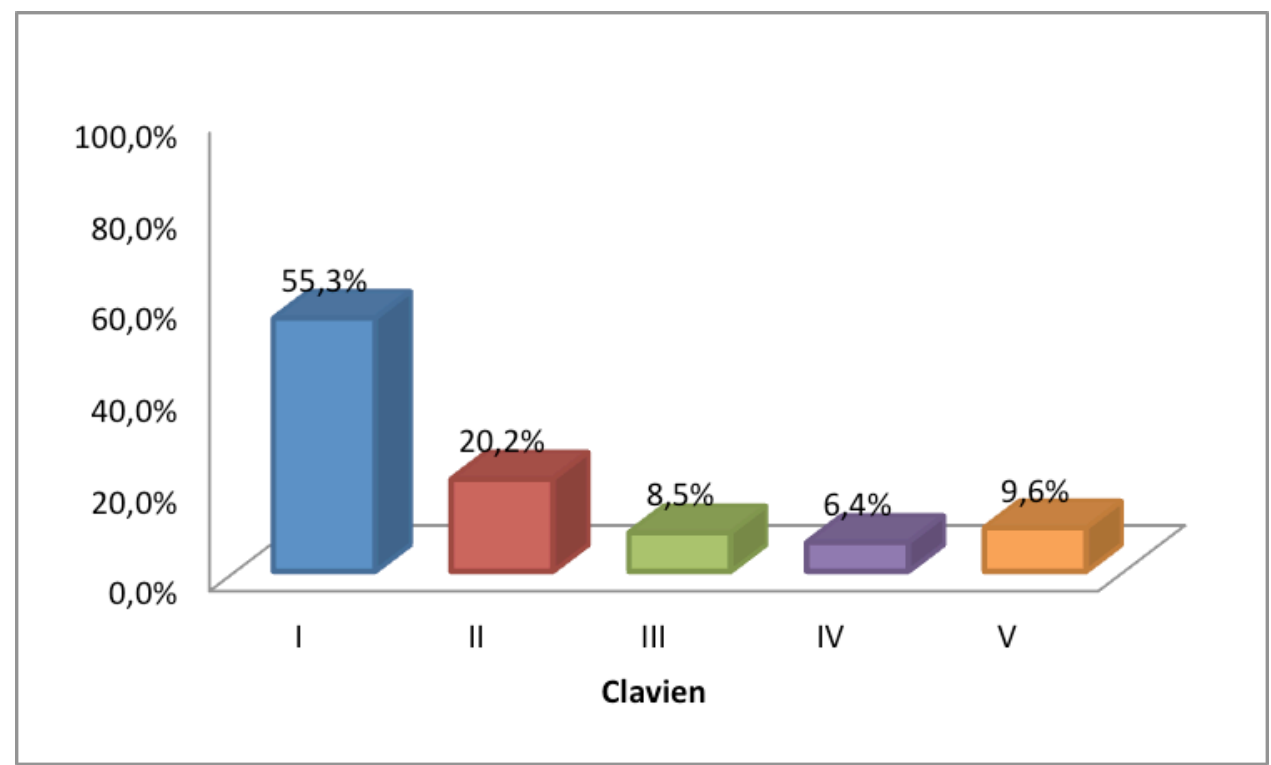

Figura 21 - Distribuição das complicações pós-operatórias segundo a classificação de Clavien-Dindo dos pacientes com CHC

Tabela 4- Distribuição das complicações pós-operatórias dos pacientes submetidos à ressecção de $\mathrm{CHC}$

\begin{tabular}{lcc}
\hline \hline complicação & $\mathrm{n}$ & $\%$ \\
\hline sim & 48 & 47,5 \\
\hline complicações clínicas(IRA,BCP, TEP, IAM e outras) & 16 & 33,3 \\
abscesso intra-abdominal & 10 & 20,8 \\
ascite & 8 & 16,7 \\
fistula biliar & 8 & 16,7 \\
infecção FO & 7 & 14,6 \\
sangramento & 6 & 12,5 \\
reoperação & 5 & 10,4 \\
íleo & 5 & 10,4 \\
\end{tabular}


Tabela 5- Distribuição das causas de reoperações e óbitos hospitalares dos pacientes submetidos à ressecção de $\mathrm{CHC}$

\begin{tabular}{lcr}
\hline complicação & $\mathrm{n}$ & $\%$ \\
\hline reoperação & 5 & 100 \\
\hline drenagem de coleção abdominal & 3 & 60 \\
sangramento & 1 & 20 \\
fistula entérica & 1 & 20 \\
\hline & & \\
\hline óbito hospitalar & 9 & 8,9 \\
choque séptico & 4 & 44,4 \\
choque cardiogênico-IAM & 3 & 33,3 \\
choque hemorrágico & 2 & 22,2 \\
\end{tabular}

A Tabela 6 resume as características da cirurgia dos pacientes.

Tabela 6 - Distribuição das características cirúrgicas dos pacientes com $\mathrm{CHC}$

\begin{tabular}{rlcc}
\hline \hline & & $\mathrm{n}$ & $\%$ \\
\hline tipo de cirurgia & aberta & 73 & $75,3 \%$ \\
& & 24 & $24,7 \%$ \\
& Iaparoscópica & 97 & $100,0 \%$ \\
& Total & 69 & $69,7 \%$ \\
ressecção anatômica & sim & 30 & $30,3 \%$ \\
& não & 99 & $100,0 \%$ \\
& Total & 20 & $21,3 \%$ \\
transfusão de sangue & sim & 74 & $78,7 \%$ \\
& não & 94 & $100,0 \%$ \\
& Total & 52 & $55,3 \%$ \\
Clavien (morbidade) & I & 19 & $20,2 \%$ \\
& II & 8 & $8,5 \%$ \\
& III & 6 & $6,4 \%$ \\
& IV & 9 & $9,6 \%$ \\
& V & 94 & $100,0 \%$ \\
\hline \hline
\end{tabular}

\subsection{Análise da Sobrevida Global, Intervalo Livre de Doença e Recidiva}

Foi importante objeto de investigação desta pesquisa o estudo da sobrevida global e livre de doença dos pacientes. Vale ressaltar que seis dos 101 pacientes faleceram no período entre o pós-operatório imediato e até um mês após a cirurgia e por este motivo foram excluídos da análise de sobrevida global e livre de doença (Tabela 5). 
Do total de 95 pacientes avaliados, houve 44 óbitos (46,3\%) e 51 pacientes $(53,7 \%)$ estavam vivos até o final do tempo de seguimento da pesquisa. Quarenta e seis pacientes $(48,4 \%)$ apresentaram recidiva da doença (Figura 22).

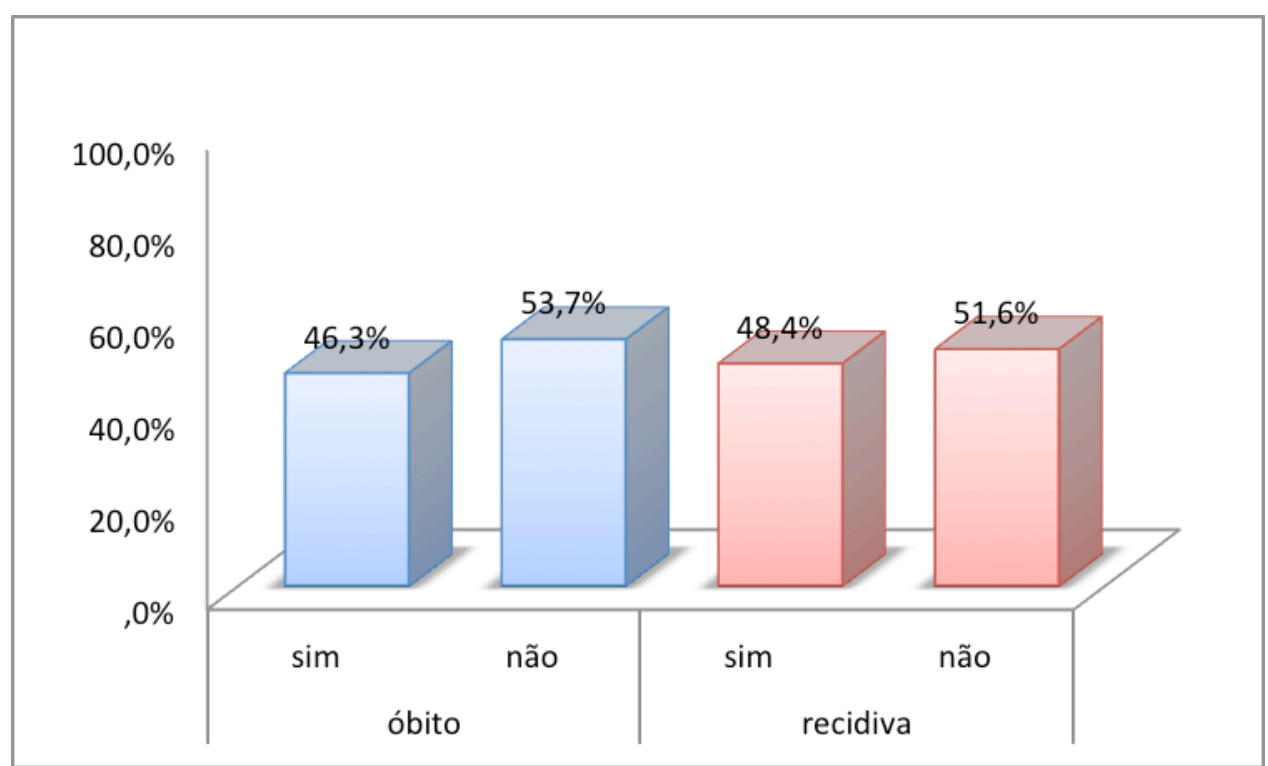

Figura 22 - Ocorrência de óbito e recidiva entre os pacientes com CHC

Por ordem de frequência, a região em que mais ocorreu a recidiva foi a intra-hepática (40 pacientes), sendo que em 12 pacientes a recidiva intrahepática se deu na margem; em seguida ficaram as recidivas em outras regiões (11 pacientes), seguida da recidiva pulmonar (sete pacientes) e por fim, a nodal (quatro pacientes) foi a região com menor número de recidivas (Figura 23). 


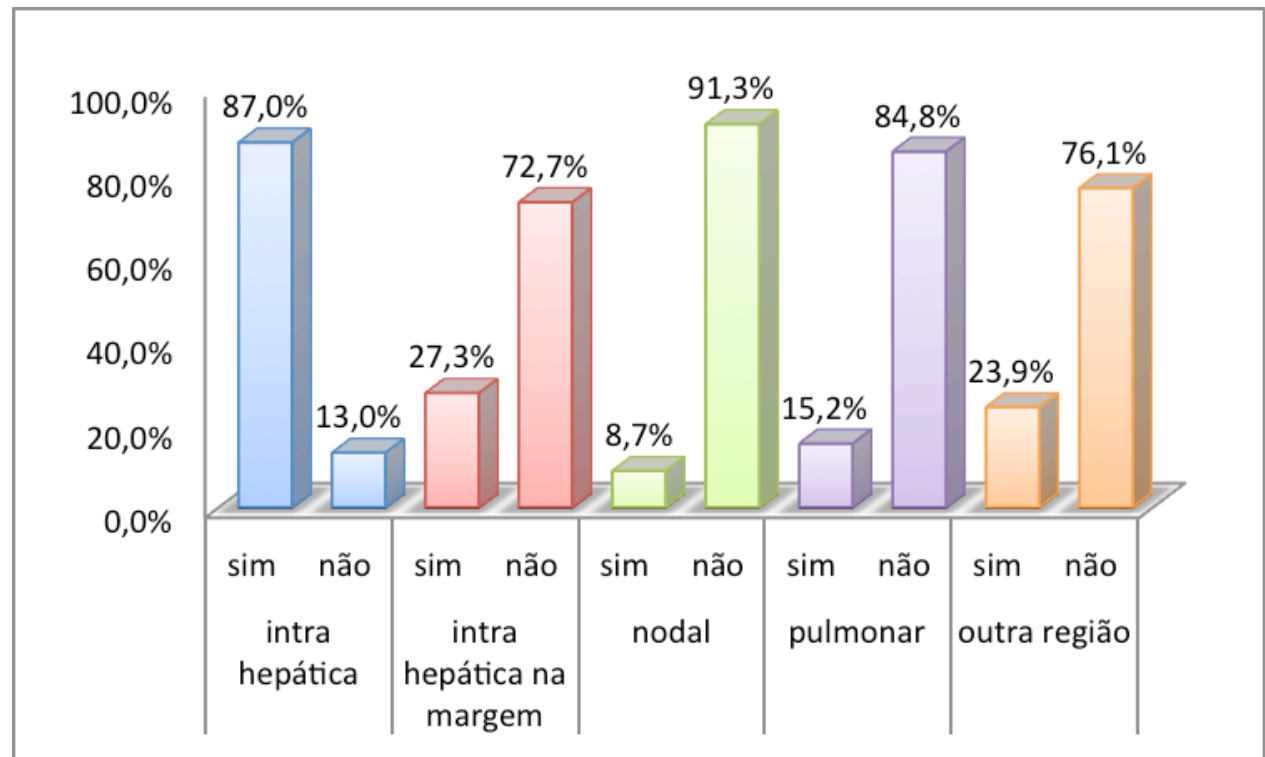

Figura 23 - Distribuição do local da recidiva entre os pacientes com $\mathrm{CHC}$

A Tabela 7 resume a análise de sobrevida global e recidiva dos pacientes avaliados no estudo.

Tabela 7 - Distribuição da sobrevida, , presença e local da recidiva entre os pacientes submetidos à ressecção de $\mathrm{CHC}$

\begin{tabular}{|c|c|c|c|}
\hline & & $\mathrm{n}$ & $\%$ \\
\hline \multirow[t]{3}{*}{ óbito } & $\operatorname{sim}$ & 44 & $46,3 \%$ \\
\hline & não & 51 & $53,7 \%$ \\
\hline & Total & 95 & $100,0 \%$ \\
\hline \multirow[t]{3}{*}{ recidiva } & $\operatorname{sim}$ & 46 & $48,4 \%$ \\
\hline & não & 49 & $51,6 \%$ \\
\hline & Total & 95 & $100,0 \%$ \\
\hline \multirow[t]{3}{*}{ recidiva na região intra hepática } & $\operatorname{sim}$ & 40 & $87,0 \%$ \\
\hline & não & 6 & $13,0 \%$ \\
\hline & Total & 46 & $100,0 \%$ \\
\hline \multirow[t]{3}{*}{ recidiva na região intra hepática na margem } & $\operatorname{sim}$ & 12 & $27,3 \%$ \\
\hline & não & 32 & $72,7 \%$ \\
\hline & Total & 46 & $100,0 \%$ \\
\hline \multirow[t]{3}{*}{ recidiva na região nodal } & $\operatorname{sim}$ & 4 & $8,7 \%$ \\
\hline & não & 42 & $91,3 \%$ \\
\hline & Total & 46 & $100,0 \%$ \\
\hline \multirow[t]{3}{*}{ recidiva na região pulmonar } & $\operatorname{sim}$ & 7 & $15,2 \%$ \\
\hline & não & 39 & $84,8 \%$ \\
\hline & Total & 46 & $100,0 \%$ \\
\hline \multirow[t]{3}{*}{ recidiva em outra região } & $\operatorname{sim}$ & 11 & $23,9 \%$ \\
\hline & não & 35 & $76,1 \%$ \\
\hline & Total & 46 & $100,0 \%$ \\
\hline
\end{tabular}


Conforme se pode observar na curva de sobrevida global ilustrada na Figura 24, em até cinco anos (60 meses) de seguimento, 49,9\% dos pacientes permaneceram vivos. O tempo médio de sobrevida global dos pacientes que faleceram foi de 24,6 meses, variando de 1 a 100 meses.

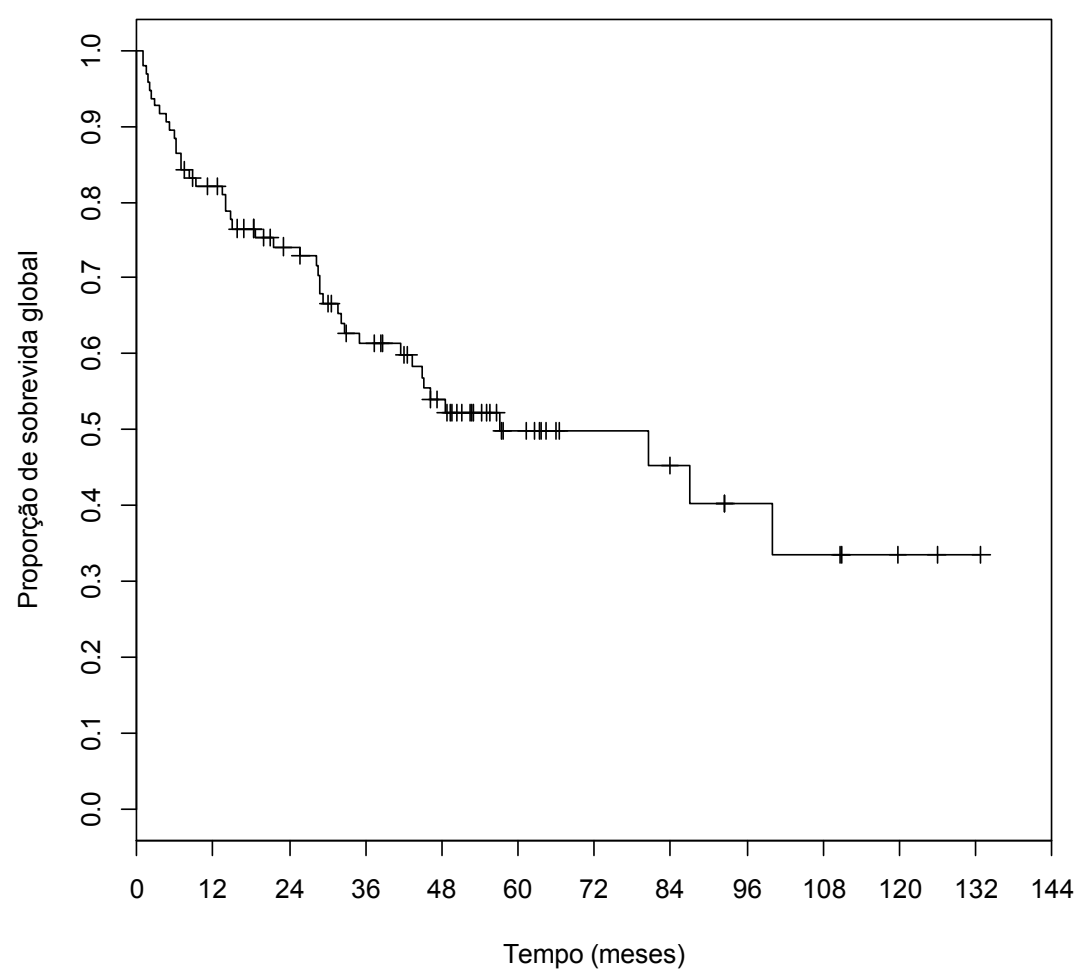

Figura 24 - Curva de sobrevida global dos pacientes submetidos à ressecção de $\mathrm{CHC}$

Quanto ao intervalo livre de doença até cinco anos (60 meses) de seguimento, 40,7\% dos pacientes não apresentaram recidiva (Figura 25). 0 tempo médio de sobrevida livre de doença dos pacientes que recidivaram foi de 17,2 meses, variando de 1,1 a 60,6 meses 


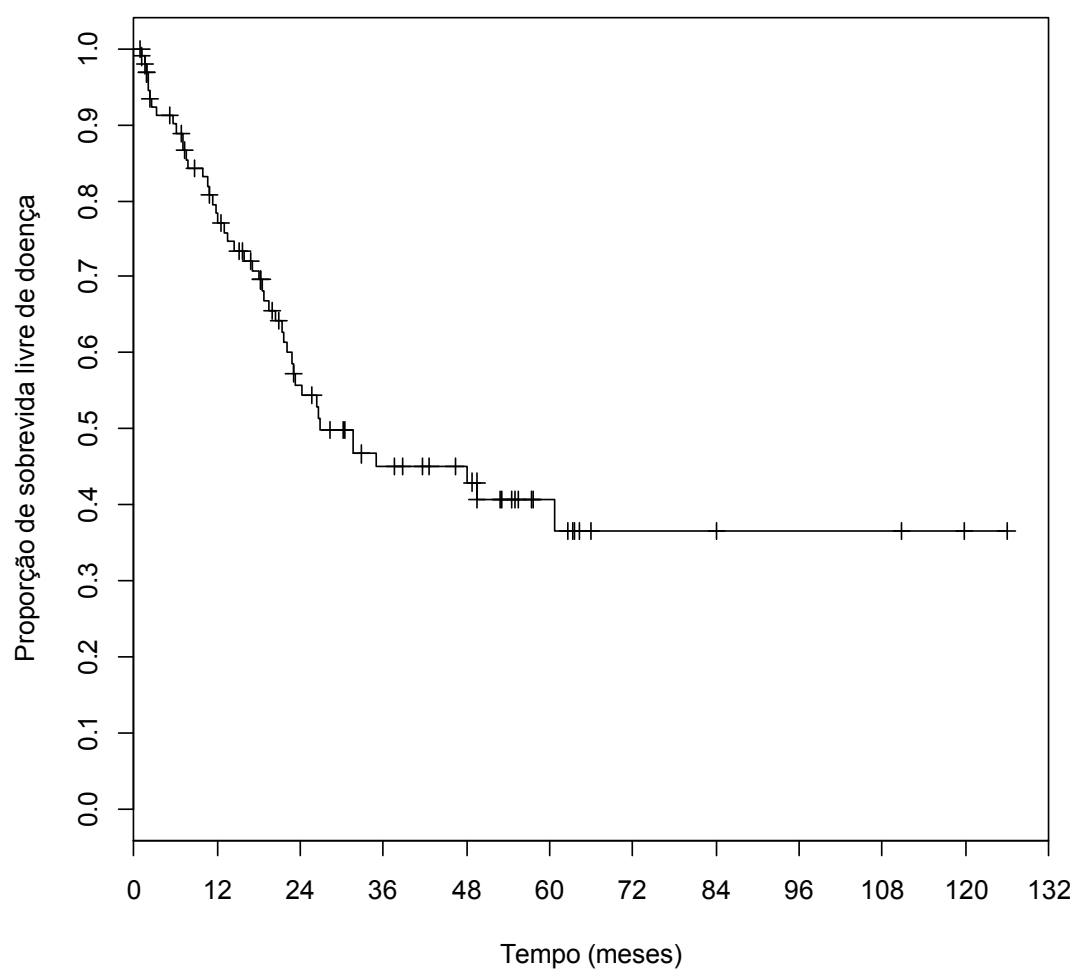

Figura 25 - Curva de sobrevida livre de doença dos pacientes submetidos à ressecção de $\mathrm{CHC}$

\subsection{Análise da Sobrevida Global, Intervalo Livre de Doença e Recidiva com relação à etiologia do $\mathrm{CHC}$}

O estudo da sobrevida global e livre de doença também foi realizado considerando a etiologia da doença.

Conforme está resumido na Figura 26, em três anos (36 meses) de seguimento, o grupo com etiologia NASH apresentou $50,0 \%$ de sobrevida, seguido do VHC (53,0\%), mista $(61,5 \%)$, outras $(66,0 \%)$, VHB $(67,5 \%)$ e OH $(80,8 \%)$. Em cinco anos (60 meses) de seguimento, a sobrevida dos pacientes, segundo a sua etiologia em ordem crescente, foi: VHC $(34,8 \%)$, mista $(46,2 \%)$, NASH $(50,0 \%)$, outras $(52,8 \%)$, OH $(67,3 \%)$ e VHB $(67,5 \%)$ 


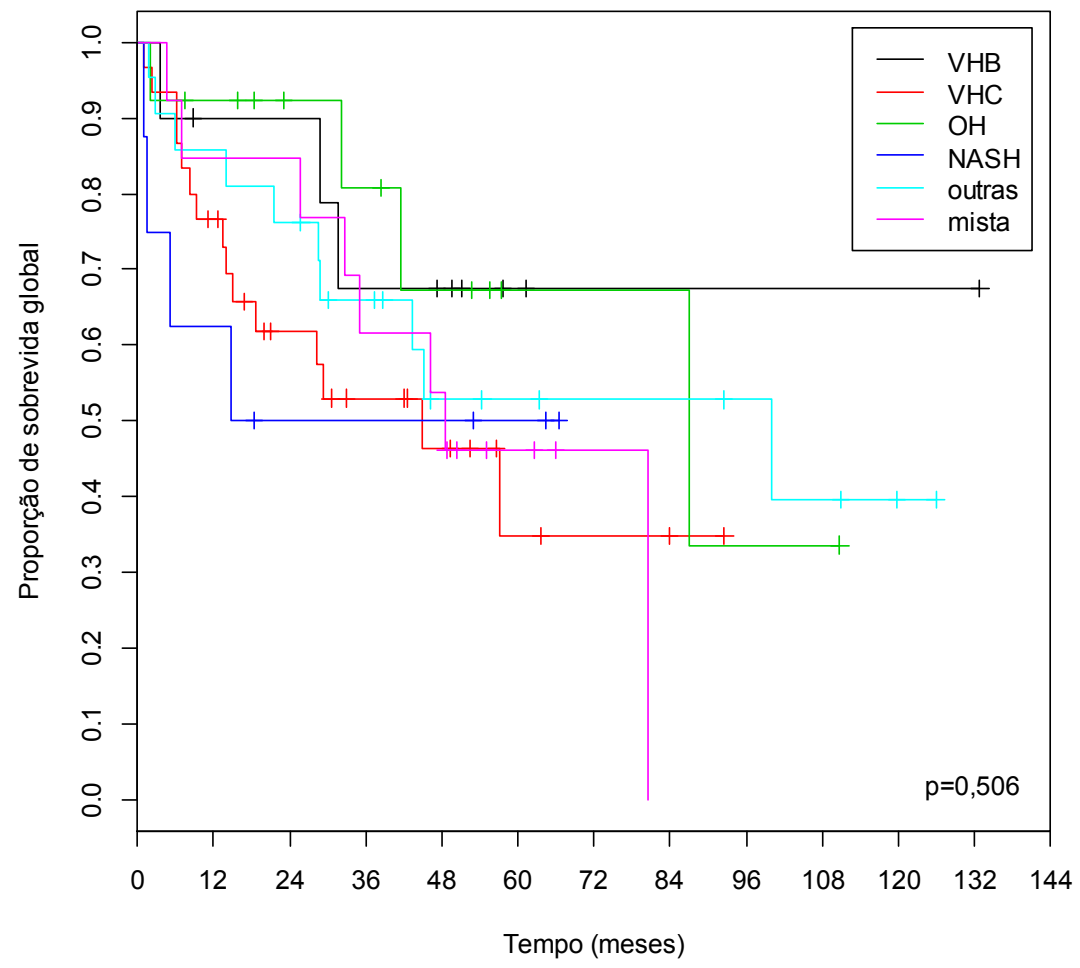

Figura 26 - Curva de sobrevida global dos pacientes submetidos à ressecção de $\mathrm{CHC}$, segundo etiologia da hepatopatia

Com relação à sobrevida livre de doença em três anos (36 meses), a etiologia mista foi a que apresentou menor sobrevida $(33,6 \%)$, seguida das etiologias VHB (34,3\%), VHC (41,9\%), outras (49,6\%), NASH $(53,3 \%)$ e OH $(66,3 \%)$. Em cinco anos (60 meses) de seguimento, a sobrevida livre de doença, segundo a sua etiologia em ordem crescente, foi: VHB $(22,9 \%)$,VHC $(27,9 \%)$, mista $(33,6 \%)$, outras $(37,2 \%)$, NASH $(53,3 \%)$ e $\mathrm{OH}(66,3 \%)$ (Figura 27). 


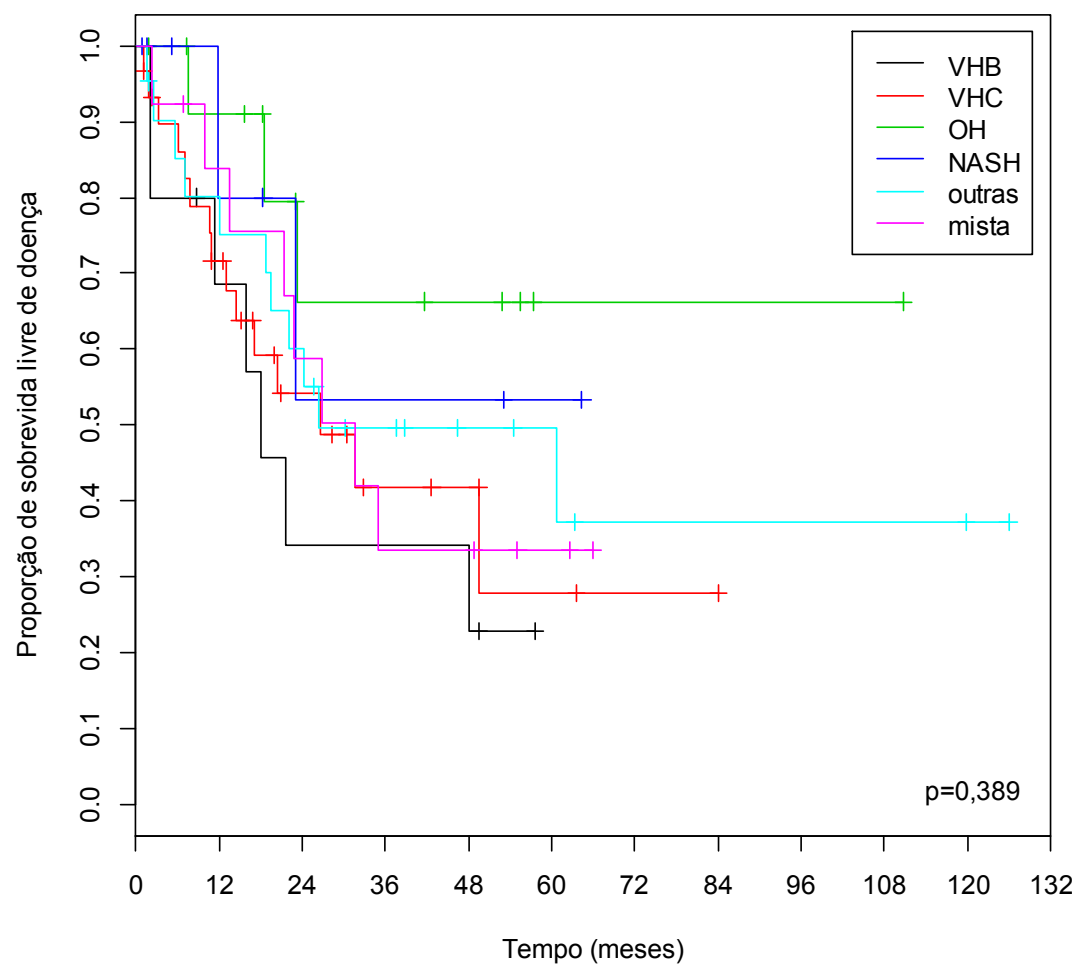

Figura 27 - Curva de sobrevida livre de doença dos pacientes submetidos à ressecção de $\mathrm{CHC}$, segundo a etiologia da hepatopatia

Quando procedemos à mesma análise, mas com a divisão das etiologias apenas em viral e não viral, temos como resultados as curvas das Figuras 28 e 29, que demonstram que em até três anos (36 meses) de seguimento o grupo de pacientes com etiologia viral apresentou $57,1 \%$ de sobrevida enquanto o grupo não viral apresentou 66,9\%. Em cinco anos (60meses) de seguimento a sobrevida do grupo viral foi de $44,3 \%$ e do grupo não viral de 56,3\% (Figura 28). 


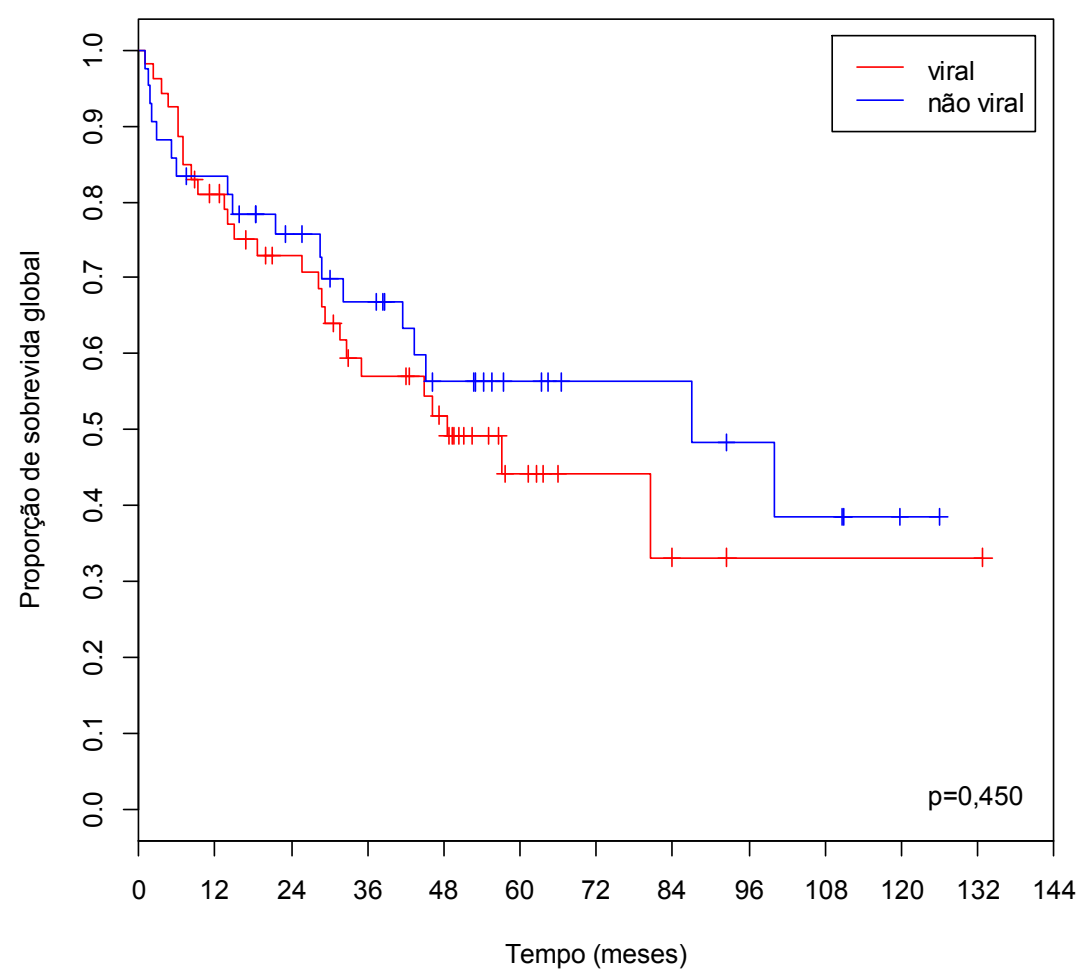

Figura 28 - Curva de sobrevida global dos pacientes submetidos à ressecção de $\mathrm{CHC}$, segundo etiologia(viral/não viral) da hepatopatia

Com relação à sobrevida livre de doença, também para os grupos de pacientes divididos em etiologias viral e não viral, temos que, em três anos (36 meses) de seguimento o grupo etiologia viral apresentou 36,8\% de sobrevida livre de doença e o grupo etiologia não viral 55,5\%. Em cinco anos (60 meses) de seguimento esses valores foram de $29,3 \%$ e $55,5 \%$ respectivamente (Figura 29). 


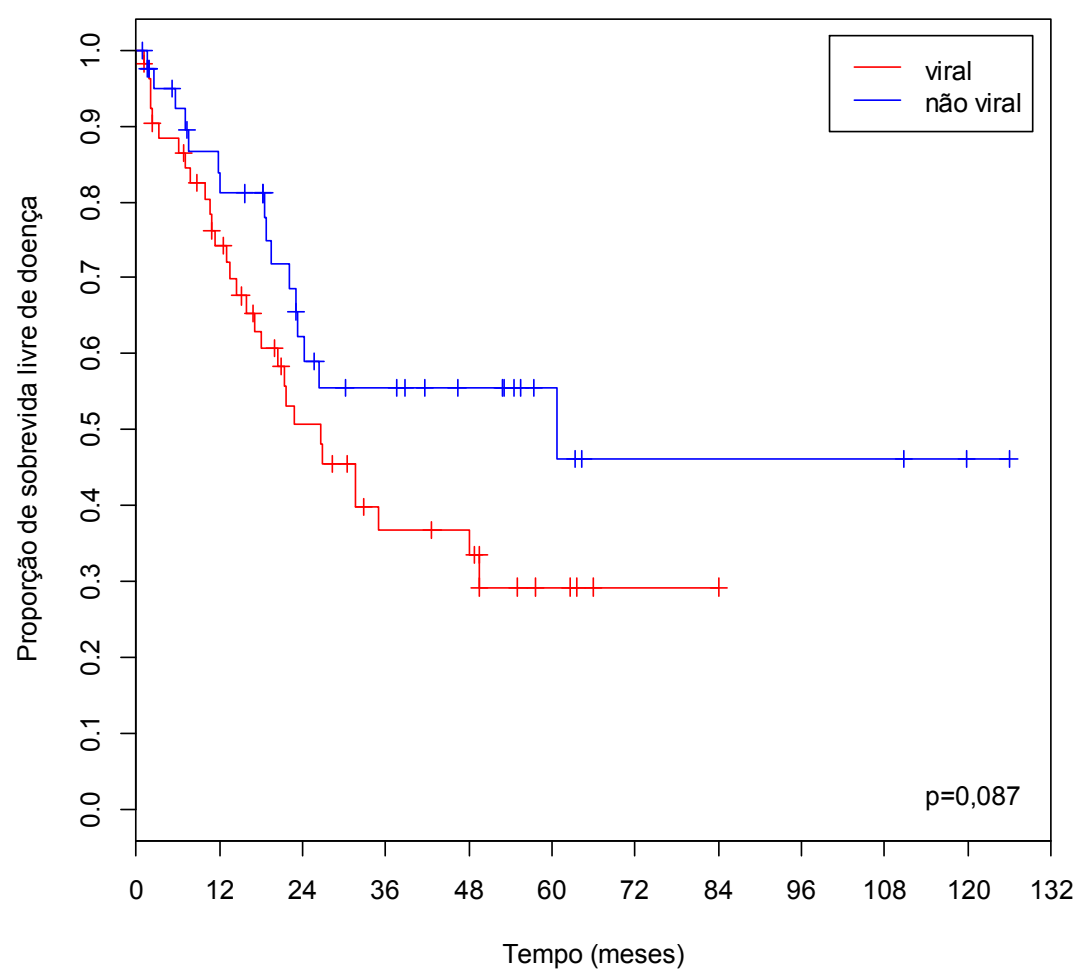

Figura 29 - Curva de sobrevida livre de doença dos pacientes submetidos à ressecção de $\mathrm{CHC}$, segundo a etiologia (viral/não viral) da hepatopatia

\subsection{Análise da Sobrevida Global, Intervalo Livre de Doença e Recidiva com relação à presença ou não de cirrose hepática}

Em cinco anos (60 meses) de seguimento, a sobrevida dos pacientes com cirrose foi de $45,9 \%$ e dos pacientes sem cirrose foi de 59,7\% (Figura 30).

O tempo médio de sobrevida global dos pacientes cirróticos que faleceram foi de 24 meses, variando de 1 a 86,9 meses. Entre os pacientes falecidos não cirróticos, o tempo médio de sobrevida global foi de 26,8 meses, variando de 1,8 a 100,0 meses. 


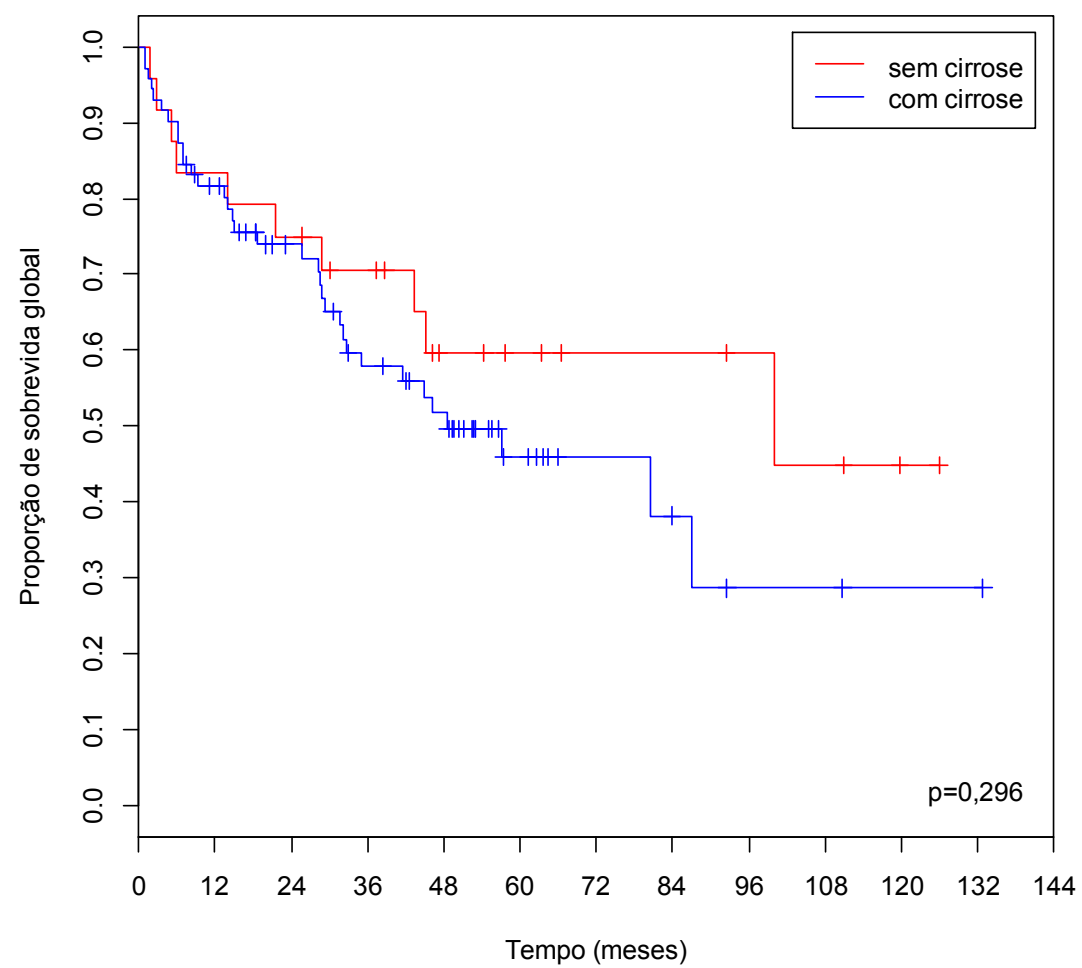

Figura 30 - Curva de sobrevida global dos pacientes submetidos à ressecção de $\mathrm{CHC}$, segundo a presença de cirrose

Em cinco anos (60 meses) de seguimento, a sobrevida livre de doença dos pacientes cirróticos foi de $37,5 \%$ e dos pacientes não cirróticos foi de $37,4 \%$ (Figura 31).

O tempo médio de sobrevida livre de doença dos pacientes cirróticos que apresentaram recidiva foi de 16,5 meses, variando de 1,1 a 49,5 meses. Entre os pacientes com recidiva e não cirróticos, o tempo médio de sobrevida livre de doença foi de 19,0 meses, variando de 1,5 a 60,6 meses. 


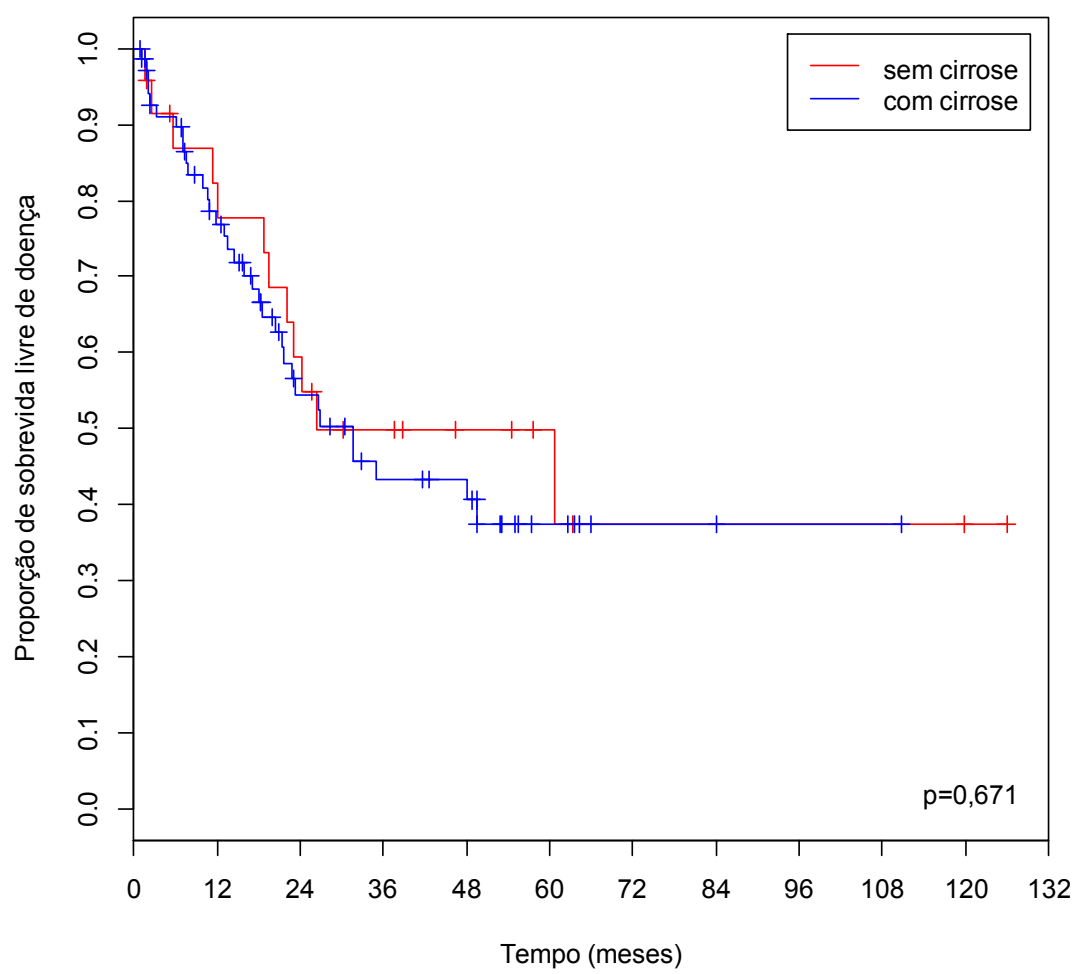

Figura 31 - Sobrevida livre de doença dos pacientes submetidos à ressecção de $\mathrm{CHC}$, segundo a presença de cirrose

\subsection{Análise de fatores prognósticos}

Os resultados inferenciais (teste univariado de Log-Rank) não evidenciaram diferença estatisticamente significante do tempo de sobrevida global com relação às variáveis: faixa etária $(p=0,842)$, gênero $(p=0,396)$, cor $(p=0,982)$, faixa de IMC $(p=0,202)$, ASA $(p=0,295)$, CHILD $(p=0,320)$, MELD $(p=0,111)$, BARCELONA $(p=0,361)$, etiologia $(p=0,506)$, etiologia viral/não viral $(p=0,450)$, tamanho do nódulo $(p=0,284)$, grau de Edmondson Steiner $(p=0,765)$, critérios de Milão $(p=0,494)$, presença de cápsula $(p=0,922)$, presença de cirrose $(p=0,296)$, tipo de cirurgia $(p=0,085)$, ressecção anatômica $(p=0,930)$ e transfusão de sangue $(p=0,165)$.

Foi observada diferença estatisticamente significante para as variáveis: nível sérico de alfafetoproteína $(p=0,043)$, nível sérico de CA19.9 $(p=0,028)$, invasão da cápsula tumoral $(p=0,030)$, margem livre $(p=0,004)$ e para complicações pós-operatórias segundo a classificação de Clavien-DIndo $(p<0,001)$, sendo que a sobrevida foi maior no grupo dos pacientes que não 
tiveram invasão da cápsula tumoral, apresentaram margens livres, alfafetoproteína menor que 100 (ng/ml), CA19.9 menor que 26,6 U/mL e grau baixo de Clavien (I e II).

Apesar das diferenças descritas nas curvas de sobrevida global e livre de doença em relação à etiologia da doença (Figuras 26 e 27), não foi possível evidenciar diferença estatisticamente significante no tempo de sobrevida global $(p=0,506)$ e livre de doença $(p=0,389)$ entre os grupos de pacientes das diferentes etiologias analisadas, hipótese principal desta dissertação. Quando realizamos o agrupamento dos pacientes em etiologias viral/não viral (Figuras 28 e 29) também não obtivemos diferença estatisticamente significante.

As Tabelas 8 e 9 resumem a análise univariada dos fatores prognósticos com seus respectivos valores de $p$. 
Tabela 8 - Distribuição das características gerais dos pacientes (em meses), segundo óbito

\begin{tabular}{|c|c|c|c|c|c|c|c|c|c|c|c|c|c|c|}
\hline & & \multicolumn{6}{|c|}{ óbito } & \multicolumn{6}{|c|}{ vivo } & \multirow[b]{2}{*}{$p^{a}$} \\
\hline & & $\mathrm{n}$ & média & mediana & mínimo & máximo & desvio-padrão & $\mathrm{n}$ & média & mediana & mínimo & máximo & desvio-padrão & \\
\hline \multirow[t]{2}{*}{ faixa etária (anos) } & até 64 & 22 & 24,3 & 23,6 & 1,0 & 80,6 & 19,2 & 26 & 46,3 & 50,0 & 7,4 & 132,9 & 27,6 & 0,843 \\
\hline & acima de 64 & 22 & 24,9 & 13,8 & 1,1 & 100,0 & 28,1 & 25 & 57,7 & 52,8 & 11,0 & 125,9 & 32,8 & \\
\hline \multirow[t]{2}{*}{ gênero } & feminino & 14 & 27,1 & 25,0 & 2,7 & 100,0 & 24,8 & 19 & 56,6 & 55,5 & 11,0 & 132,9 & 31,6 & 0,396 \\
\hline & masculino & 30 & 23,4 & 15,0 & 1,0 & 86,9 & 23,6 & 32 & 49,1 & 49,1 & 7,4 & 125,9 & 30,0 & \\
\hline \multirow[t]{4}{*}{ cor } & branco & 36 & 22,1 & 13,8 & 1,0 & 100,0 & 23,4 & 44 & 54,2 & 52,6 & 7,4 & 132,9 & 31,7 & 0,982 \\
\hline & negro & 1 & 35,0 & 35,0 & 35,0 & 35,0 & - & 2 & 16,3 & 16,3 & 12,6 & 20,0 & 5,2 & \\
\hline & amarelo & 4 & 36,1 & 21,8 & 14,1 & 86,9 & 34,5 & 3 & 47,7 & 49,6 & 38,4 & 55,1 & 8,5 & \\
\hline & mulato & 3 & 35,6 & 29,4 & 28,7 & 48,6 & 11,3 & 2 & 44,0 & 44,0 & 37,5 & 50,4 & 9,1 & \\
\hline \multirow[t]{2}{*}{ faixa de IMC $(\mathrm{kg} / \mathrm{m} 2)$} & até 25,4 & 18 & 29,4 & 21,2 & 1,6 & 100,0 & 28,5 & 24 & 53,4 & 49,5 & 15,7 & 132,9 & 25,8 & 0,202 \\
\hline & acima de 25,4 & 25 & 21,9 & 18,7 & 1,0 & 86,9 & 19,9 & 19 & 63,0 & 55,5 & 16,8 & 125,9 & 32,3 & \\
\hline \multirow[t]{4}{*}{ ASA } & I & 6 & 39,9 & 30,4 & 14,1 & 100,0 & 31,0 & 3 & 59,6 & 25,8 & 20,0 & 132,9 & 63,6 & 0,295 \\
\hline & II & 34 & 23,7 & 15,0 & 1,0 & 86,9 & 22,5 & 35 & 53,4 & 50,4 & 15,7 & 125,9 & 27,4 & \\
\hline & III & 3 & 3,4 & 3,5 & 1,6 & 5,1 & 1,8 & 9 & 61,9 & 62,6 & 30,1 & 110,8 & 24,1 & \\
\hline & IV & 1 & 25,8 & 25,8 & 25,8 & 25,8 & - & - & - & - & - & - & - & \\
\hline \multirow[t]{2}{*}{ CHILD } & A & 43 & 24,1 & 15,1 & 1,0 & 100,0 & 23,8 & 49 & 49,9 & 49,6 & 7,4 & 132,9 & 29,3 & 0,320 \\
\hline & $\mathrm{B}$ & 1 & 45,0 & 45,0 & 45,0 & 45,0 & - & 2 & 101,7 & 101,7 & 92,6 & 110,8 & 12,9 & \\
\hline \multirow[t]{2}{*}{ MELD } & menor que 10 & 32 & 27,2 & 24,9 & 1,0 & 100,0 & 26,0 & 42 & 53,0 & 50,0 & 7,4 & 132,9 & 32,8 & 0,111 \\
\hline & 10 ou mais & 12 & 17,7 & 14,6 & 1,1 & 45,0 & 15,0 & 9 & 46,6 & 51,1 & 20,0 & 63,6 & 15,8 & \\
\hline \multirow[t]{4}{*}{ BARCELONA } & 0 & - & - & - & - & - & - & 1 & 84,0 & 84,0 & 84,0 & 84,0 & . & 0,361 \\
\hline & $A$ & 40 & 24,3 & 16,9 & 1,0 & 100,0 & 24,3 & 49 & 49,8 & 49,6 & 7,4 & 132,9 & 29,1 & \\
\hline & B & 2 & 30,5 & 30,5 & 14,8 & 46,2 & 22,2 & 1 & 119,8 & 119,8 & 119,8 & 119,8 & - & \\
\hline & $C$ & 2 & 25,6 & 25,6 & 6,2 & 45,0 & 27,4 & - & - & - & - & - & - & \\
\hline \multirow[t]{2}{*}{ alfafetoproteína (ng/ml) } & menor que 100 & 20 & 22,5 & 15,0 & 1,1 & 86,9 & 22,6 & 37 & 53,4 & 51,1 & 7,4 & 132,9 & 31,1 & 0,043 \\
\hline & 100 ou mais & 17 & 23,5 & 14,1 & 2,7 & 100,0 & 25,1 & 12 & 49,1 & 46,6 & 12,6 & 110,9 & 30,2 & \\
\hline \multirow[t]{2}{*}{ CA19.9 (U/mL) } & até 26,6 & 7 & 36,2 & 9,4 & 1,9 & 100,0 & 41,7 & 18 & 52,8 & 50,4 & 7,4 & 132,9 & 34,3 & 0,028 \\
\hline & acima de 26,6 & 14 & 21,4 & 15,0 & 1,6 & 57,2 & 18,5 & 12 & 47,3 & 45,4 & 11,0 & 119,8 & 26,7 & \\
\hline
\end{tabular}

${ }^{\mathrm{a}}$ Log-Rank 
Tabela 9 - Distribuição das características gerais dos pacientes (em meses), segundo óbito

\begin{tabular}{|c|c|c|c|c|c|c|c|c|c|c|c|c|c|c|}
\hline & & \multicolumn{6}{|c|}{ óbito } & \multicolumn{6}{|c|}{ vivo } & \multirow[b]{2}{*}{$p^{a}$} \\
\hline & & $\mathrm{n}$ & média & mediana & mínimo & máximo & desvio-padrão & $\mathrm{n}$ & média & mediana & mínimo & máximo & desvio-padrão & \\
\hline \multirow[t]{6}{*}{ etiologia } & VHB & 3 & 21,3 & 28,7 & 3,5 & 31,7 & 15,5 & 7 & 58,3 & 51,1 & 8,8 & 132,9 & 37,1 & 0,506 \\
\hline & $\mathrm{VHC}$ & 15 & 17,4 & 13,4 & 1,1 & 57,2 & 16,1 & 15 & 41,9 & 42,0 & 11,0 & 92,6 & 25,0 & \\
\hline & $\mathrm{OH}$ & 4 & 40,6 & 36,9 & 1,9 & 86,9 & 35,2 & 9 & 42,2 & 38,4 & 7,4 & 110,8 & 31,8 & \\
\hline & $\mathrm{NASH}$ & 4 & 5,6 & 3,4 & 1,0 & 14,8 & 6,4 & 4 & 50,6 & 58,7 & 18,4 & 66,5 & 22,3 & \\
\hline & mista & 10 & 29,2 & 25,0 & 1,8 & 100,0 & 29,3 & 11 & 67,8 & 54,4 & 25,8 & 125,9 & 37,6 & \\
\hline & outras & 8 & 35,1 & 33,9 & 4,6 & 80,6 & 24,5 & 5 & 56,6 & 55,1 & 48,7 & 66,0 & 7,5 & \\
\hline \multirow[t]{2}{*}{ tamanho do nódulo (cm) } & até 5 & 21 & 25,3 & 15,1 & 1,0 & 86,9 & 25,3 & 32 & 50,9 & 49,5 & 7,4 & 132,9 & 29,2 & 0,284 \\
\hline & acima de 5 & 21 & 23,5 & 14,8 & 1,8 & 100,0 & 23,9 & 19 & 53,6 & 51,1 & 8,8 & 125,9 & 33,3 & \\
\hline \multirow[t]{4}{*}{ grau Edmondson Steiner } & I & - & - & - & - & - & - & 1 & 84,0 & 84,0 & 84,0 & 84,0 & - & 0,765 \\
\hline & II & 11 & 30,4 & 15,1 & 1,1 & 100,0 & 34,4 & 13 & 60,9 & 56,6 & 8,8 & 119,8 & 31,1 & \\
\hline & III & 29 & 21,5 & 14,8 & 1,0 & 80,6 & 19,9 & 32 & 52,2 & 50,8 & 7,4 & 132,9 & 30,0 & \\
\hline & IV & 2 & 30,2 & 30,2 & 14,1 & 46,2 & 22,7 & 4 & 20,9 & 20,5 & 16,8 & 25,8 & 3,7 & \\
\hline \multirow[t]{2}{*}{ critério de milão } & não & 20 & 24,5 & 18,1 & 1,8 & 100,0 & 24,0 & 20 & 52,0 & 50,8 & 8,8 & 125,9 & 33,1 & 0,494 \\
\hline & $\operatorname{sim}$ & 22 & 24,3 & 14,6 & 1,0 & 86,9 & 25,1 & 31 & 51,8 & 49,6 & 7,4 & 132,9 & 29,3 & \\
\hline \multirow[t]{2}{*}{ cápsula } & não & 18 & 51,7 & 49,6 & 7,4 & 132,9 & 32,6 & 16 & 26,2 & 20,5 & 1,8 & 100,0 & 26,0 & 0,922 \\
\hline & $\operatorname{sim}$ & 32 & 51,7 & 50,4 & 8,8 & 125,9 & 30,3 & 26 & 22,5 & 14,5 & 1,0 & 86,9 & 23,2 & \\
\hline \multirow[t]{2}{*}{ invasão da cápsula } & não & 19 & 26,4 & 21,4 & 1,0 & 86,9 & 24,7 & 29 & 50,3 & 49,6 & 8,8 & 125,9 & 28,6 & 0,030 \\
\hline & $\operatorname{sim}$ & 7 & 11,8 & 5,9 & 1,1 & 43,3 & 15,0 & 3 & 65,3 & 53,0 & 23,1 & 119,8 & 49,5 & \\
\hline \multirow[t]{2}{*}{ margem livre } & não & 6 & 24,3 & 27,2 & 1,1 & 46,2 & 15,1 & - & - & - & - & - & - & 0,004 \\
\hline & $\operatorname{sim}$ & 36 & 24,2 & 14,1 & 1,0 & 100,0 & 25,6 & 48 & 52,1 & 50,0 & 7,4 & 132,9 & 30,5 & \\
\hline \multirow[t]{2}{*}{ cirrose } & não & 10 & 26,8 & 17,8 & 1,8 & 100,0 & 30,3 & 14 & 65,5 & 56,0 & 25,8 & 125,9 & 33,5 & 0,296 \\
\hline & $\operatorname{sim}$ & 34 & 24,0 & 16,9 & 1,0 & 86,9 & 22,0 & 37 & 46,7 & 49,6 & 7,4 & 132,9 & 28,1 & \\
\hline \multirow[t]{2}{*}{ tipo de cirurgia } & aberta & 38 & 26,4 & 20,1 & 1,1 & 100,0 & 24,6 & 30 & 59,8 & 52,9 & 15,7 & 132,9 & 28,8 & 0,085 \\
\hline & laparoscópica & 6 & 13,3 & 7,6 & 1,0 & 32,1 & 13,8 & 18 & 45,6 & 45,4 & 7,4 & 125,9 & 29,6 & \\
\hline \multirow[t]{2}{*}{ ressecção anatômica } & não & 13 & 24,3 & 25,8 & 1,1 & 48,6 & 16,2 & 15 & 55,3 & 46,3 & 11,0 & 132,9 & 35,0 & 0,930 \\
\hline & $\operatorname{sim}$ & 30 & 24,5 & 14,1 & 1,0 & 100,0 & 26,9 & 35 & 51,6 & 52,8 & 7,4 & 125,9 & 28,4 & \\
\hline \multirow[t]{2}{*}{ transfusão de sangue } & não & 31 & 27,9 & 25,8 & 1,0 & 100,0 & 26,3 & 40 & 52,5 & 50,0 & 7,4 & 132,9 & 29,8 & 0,165 \\
\hline & $\operatorname{sim}$ & 11 & 16,5 & 14,1 & 1,6 & 48,6 & 14,2 & 7 & 66,1 & 55,5 & 38,4 & 119,8 & 30,1 & \\
\hline \multirow[t]{5}{*}{ Clavien (morbidade) } & I & 22 & 30,4 & 27,1 & 1,9 & 100,0 & 26,1 & 30 & 53,4 & 49,2 & 15,7 & 132,9 & 34,0 & $<0,001$ \\
\hline & II & 8 & 23,3 & 14,5 & 3,5 & 80,6 & 25,4 & 11 & 61,7 & 63,4 & 38,4 & 92,6 & 16,3 & \\
\hline & III & 5 & 31,7 & 32,8 & 6,9 & 48,6 & 15,9 & 3 & 61,5 & 49,4 & 42,7 & 92,5 & 27,0 & \\
\hline & IV & 4 & 7,1 & 4,1 & 1,6 & 18,7 & 7,9 & 2 & 32,5 & 32,5 & 7,4 & 57,6 & 35,5 & \\
\hline & V & 4 & 2,3 & 1,5 & 1,0 & 5,1 & 1,9 & - & - & - & - & - & - & \\
\hline
\end{tabular}

${ }^{\mathrm{a}}$ Log-Rank 


\subsection{Análise Multivariada}

O passo seguinte para finalizar a análise estatística sobre a sobrevida global seria o ajuste do modelo de Regressão de Cox (análise multivariada). Contudo, considerando as variáveis significantes na análise univariada (CA19.9, invasão da cápsula, margem livre e classificação de Clavien) nos deparamos com o obstáculo do tamanho amostral dessas variáveis: CA19.9 (51 pacientes), invasão da cápsula (58 pacientes), margem livre (90 pacientes) e Clavien (89 pacientes).

É sabido que no processo de ajuste do modelo de Regressão de Cox participam somente os pacientes que tiverem todas as informações concomitantemente. Desta forma, optou-se por não ajustar este modelo, uma vez que, aproximadamente apenas metade da amostra participaria do processo, o que influenciaria nos resultados.

\subsection{Análise de risco (odds-ratio)}

Uma outra forma de análise dos fatores prognósticos é o cálculo da chamada Razão de Risco(Odds-ratio).

Os resultados inferenciais (teste univariado de Qui-quadrado ou Exato de Fisher) não evidenciaram diferença estatisticamente significante em relação à presença ou não de óbito segundo faixa etária $(p=0,924)$, gênero $(p=0,579)$, cor $(p=0,851)$, faixa de IMC $(p=0,196)$, ASA $(p=0,157)$, CHILD $(p>0,999)$, MELD $(p=0,260)$, BARCELONA $(p=0,358)$, CA19.9 $(p=0,061)$, etiologia $(p=0,607)$, etiologia viral/não viral $(p=0,547)$, tamanho do nódulo $(p=0,217)$, grau de Edmondson Steiner $(p=0,908)$, critérios de Milão $(p=0,415)$, cápsula $(p=0,836)$, invasão da cápsula $(p=0,095)$, cirrose $(p=0,597)$, ressecção anatômica $(p=0,981)$, transfusão de sangue $(p=0,185)$ e classificação de complicações pós-operatórias de Clavien-Dindo $(p=0,156)$.

Houve diferença estatisticamente significante nas variáveis nível sérico de alfafetoproteína $(p=0,037)$, margem livre $(p=0,008)$ e tipo de cirurgia $(p=0,009)$, sendo que no grupo dos pacientes que faleceram há uma porcentagem maior de casos com nível sérico de alfafetoproteína maior ou 
igual a $100(45,9 \%)$, quando comparado ao grupo dos pacientes vivos $(24,5 \%)$. A margem livre $(100,0 \%)$ e a cirurgia laparoscópica $(37,5 \%)$ foram mais frequentes no grupo dos pacientes vivos, quando comparado ao grupo dos pacientes que faleceram.

As Tabelas 10 a 13 mostram os detalhes dessa análise de risco.

Tabela 10 - Distribuição das características gerais dos pacientes submetidos à ressecção de $\mathrm{CHC}$, segundo óbito

\begin{tabular}{|c|c|c|c|c|c|c|c|c|c|}
\hline & & óbito & & vivo & & Total & $\mathrm{p}$ & OR & $\mathrm{IC}(\mathrm{OR})^{\star *}$ \\
\hline \multicolumn{10}{|l|}{ faixa etária (anos) } \\
\hline até 64 & 22 & $50,0 \%$ & 26 & $51,0 \%$ & 48 & $50,5 \%$ & $0,924^{a}$ & 0,962 & 0,$429 ; 2,154$ \\
\hline acima de 64 & 22 & $50,0 \%$ & 25 & $49,0 \%$ & 47 & $49,5 \%$ & & & \\
\hline Total & 44 & $100,0 \%$ & 51 & $100,0 \%$ & 95 & $100,0 \%$ & & & \\
\hline \multicolumn{10}{|c|}{ 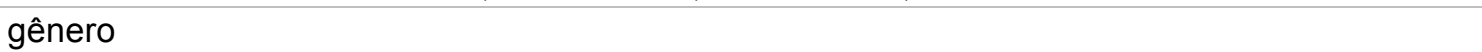 } \\
\hline feminino & 14 & $31,8 \%$ & 19 & $37,3 \%$ & 33 & $34,7 \%$ & $0,579^{a}$ & 0,786 & 0,$336 ; 1,841$ \\
\hline masculino & 30 & $68,2 \%$ & 32 & $62,7 \%$ & 62 & $65,3 \%$ & & & \\
\hline Total & 44 & $100,0 \%$ & 51 & $100,0 \%$ & 95 & $100,0 \%$ & & & \\
\hline \multicolumn{10}{|l|}{ cor } \\
\hline branco $^{c}$ & 36 & $81,8 \%$ & 44 & $86,3 \%$ & 80 & $84,2 \%$ & $0,851^{\mathrm{b}}$ & & \\
\hline negro & 1 & $2,3 \%$ & 2 & $3,9 \%$ & 3 & $3,2 \%$ & & 1,636 & 0,$143 ; 18,785$ \\
\hline amarelo & 4 & $9,1 \%$ & 3 & $5,9 \%$ & 7 & $7,4 \%$ & & 0,614 & 0,$129 ; 2,921$ \\
\hline mulato & 3 & $6,8 \%$ & 2 & $3,9 \%$ & 5 & $5,3 \%$ & & 0,545 & 0,$086 ; 3,444$ \\
\hline Total & 44 & $100,0 \%$ & 51 & $100,0 \%$ & 95 & $100,0 \%$ & & & \\
\hline \multicolumn{10}{|l|}{ faixa de IMC $\left(\mathrm{kg} / \mathrm{m}^{2}\right)$} \\
\hline até 25,4 & 18 & $41,9 \%$ & 24 & $55,8 \%$ & 42 & $48,8 \%$ & $0,196^{a}$ & 0,570 & 0,$243 ; 1,339$ \\
\hline acima de 25,4 & 25 & $58,1 \%$ & 19 & $44,2 \%$ & 44 & $51,2 \%$ & & & \\
\hline Total & 43 & $100,0 \%$ & 43 & $100,0 \%$ & 86 & $100,0 \%$ & & & \\
\hline \multicolumn{10}{|l|}{ ASA } \\
\hline $1^{\mathrm{c}}$ & 6 & $13,6 \%$ & 3 & $6,4 \%$ & 9 & $9,9 \%$ & $0,157^{b}$ & & \\
\hline II & 34 & $77,3 \%$ & 35 & $74,5 \%$ & 69 & $75,8 \%$ & & 2,059 & 0,$476 ; 8,902$ \\
\hline III & 3 & $6,8 \%$ & 9 & $19,1 \%$ & 12 & $13,2 \%$ & & 6,000 & 0,$893 ; 40,307$ \\
\hline IV & 1 & $2,3 \%$ & - & - & 1 & $1,1 \%$ & & & \\
\hline Total & 44 & $100,0 \%$ & 47 & $100,0 \%$ & 91 & $100,0 \%$ & & & \\
\hline \multicolumn{10}{|l|}{ CHILD } \\
\hline A & 43 & $97,7 \%$ & 49 & $96,1 \%$ & 92 & $96,8 \%$ & $>0,999^{b}$ & 1,755 & 0,$154 ; 20,040$ \\
\hline B & 1 & $2,3 \%$ & 2 & $3,9 \%$ & 3 & $3,2 \%$ & & & \\
\hline Total & 44 & $100,0 \%$ & 51 & $100,0 \%$ & 95 & $100,0 \%$ & & & \\
\hline \multicolumn{10}{|c|}{ 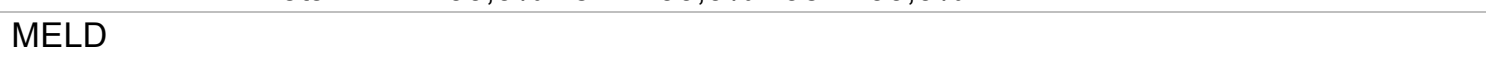 } \\
\hline menor que 10 & 32 & $72,7 \%$ & 42 & $82,4 \%$ & 74 & $77,9 \%$ & $0,260^{a}$ & 0,571 & 0,$215 ; 1,521$ \\
\hline 10 ou mais & 12 & $27,3 \%$ & 9 & $17,6 \%$ & 21 & $22,1 \%$ & & & \\
\hline Total & 44 & $100,0 \%$ & 51 & $100,0 \%$ & 95 & $100,0 \%$ & & & \\
\hline \multicolumn{10}{|l|}{ BARCELONA } \\
\hline 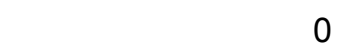 & - & - & 1 & $2,0 \%$ & 1 & $1,1 \%$ & $0,358^{\mathrm{b}}$ & & \\
\hline$A^{c}$ & 40 & $90,9 \%$ & 49 & $96,1 \%$ & 89 & $93,7 \%$ & & & \\
\hline $\mathrm{B}$ & 2 & $4,5 \%$ & 1 & $2,0 \%$ & 3 & $3,2 \%$ & & 0,408 & 0,$036 ; 4,667$ \\
\hline C & 2 & $4,5 \%$ & - & - & 2 & $2,1 \%$ & & & \\
\hline Total & 44 & $100,0 \%$ & 51 & $100,0 \%$ & 95 & $100,0 \%$ & & & \\
\hline
\end{tabular}


Tabela 11 - Distribuição das características gerais dos pacientes submetidos à ressecção de $\mathrm{CHC}$, segundo óbito

\begin{tabular}{|c|c|c|c|c|c|c|c|c|c|}
\hline & & óbito & & vivo & & Total & $\mathrm{p}$ & $\mathrm{OR}^{*}$ & $\mathrm{IC}(\mathrm{OR})^{\star *}$ \\
\hline \multicolumn{10}{|l|}{ alfafetoproteína (ng/ml) } \\
\hline menor que 100 & 20 & $54,1 \%$ & 37 & $75,5 \%$ & 57 & $66,3 \%$ & $0,037^{\mathrm{a}}$ & 0,382 & 0,$152 ; 0,955$ \\
\hline 100 ou mais & 17 & $45,9 \%$ & 12 & $24,5 \%$ & 29 & $33,7 \%$ & & & \\
\hline Total & 37 & $100,0 \%$ & 49 & $100,0 \%$ & 86 & $100,0 \%$ & & & \\
\hline \multicolumn{10}{|l|}{ CA19.9 } \\
\hline até 26,6 & 7 & $33,3 \%$ & 18 & $60,0 \%$ & 25 & $49,0 \%$ & $0,061^{a}$ & 0,333 & 0,$104 ; 1,068$ \\
\hline acima de 26,6 & 14 & $66,7 \%$ & 12 & $40,0 \%$ & 26 & $51,0 \%$ & & & \\
\hline Total & 21 & $100,0 \%$ & 30 & $100,0 \%$ & 51 & $100,0 \%$ & & & \\
\hline \multicolumn{10}{|l|}{ etiologia } \\
\hline $\mathrm{VHB}^{\mathrm{c}}$ & 3 & $6,8 \%$ & 7 & $13,7 \%$ & 10 & $10,5 \%$ & $0,607^{b}$ & & \\
\hline $\mathrm{VHC}$ & 15 & $34,1 \%$ & 15 & $29,4 \%$ & 30 & $31,6 \%$ & & 0,429 & 0,$093 ; 1,980$ \\
\hline $\mathrm{OH}$ & 4 & $9,1 \%$ & 9 & $17,6 \%$ & 13 & $13,7 \%$ & & 0,964 & 0,$160 ; 5,796$ \\
\hline $\mathrm{NASH}$ & 4 & $9,1 \%$ & 4 & $7,8 \%$ & 8 & $8,4 \%$ & & 0,429 & 0,$062 ; 2,972$ \\
\hline mista & 10 & $22,7 \%$ & 11 & $21,6 \%$ & 21 & $22,1 \%$ & & 0,471 & 0,$095 ; 2,337$ \\
\hline outras & 8 & $18,2 \%$ & 5 & $9,8 \%$ & 13 & $13,7 \%$ & & 0,268 & 0,$046 ; 1,548$ \\
\hline Total & 44 & $100,0 \%$ & 51 & $100,0 \%$ & 95 & $100,0 \%$ & & & \\
\hline \multicolumn{10}{|l|}{ tamanho do nódulo (cm) } \\
\hline até 5 & 21 & $50,0 \%$ & 32 & $62,7 \%$ & 53 & $57,0 \%$ & $0,217^{\mathrm{a}}$ & 0,594 & 0,$259 ; 1,361$ \\
\hline acima de 5 & 21 & $50,0 \%$ & 19 & $37,3 \%$ & 40 & $43,0 \%$ & & & \\
\hline Total & 42 & $100,0 \%$ & 51 & $100,0 \%$ & 93 & $100,0 \%$ & & & \\
\hline \multicolumn{10}{|l|}{ grau Edmondson Steiner } \\
\hline 1 & - & - & 1 & $2,0 \%$ & 1 & $1,1 \%$ & $0,908^{b}$ & & \\
\hline$\|^{\mathrm{c}}$ & 11 & $26,2 \%$ & 13 & $26,0 \%$ & 24 & $26,1 \%$ & & & \\
\hline III & 29 & $69,0 \%$ & 32 & $64,0 \%$ & 61 & $66,3 \%$ & & 0,934 & 0,$362 ; 2,408$ \\
\hline IV & 2 & $4,8 \%$ & 4 & $8,0 \%$ & 6 & $6,5 \%$ & & 1,692 & 0,$259 ; 11,066$ \\
\hline Total & 42 & $100,0 \%$ & 50 & $100,0 \%$ & 92 & $100,0 \%$ & & & \\
\hline \multicolumn{10}{|l|}{ critérios de Milão } \\
\hline não & 20 & $47,6 \%$ & 20 & $39,2 \%$ & 40 & $43,0 \%$ & $0,415^{\mathrm{a}}$ & 1,409 & 0,$617 ; 3,219$ \\
\hline $\operatorname{sim}$ & 22 & $52,4 \%$ & 31 & $60,8 \%$ & 53 & $57,0 \%$ & & & \\
\hline Total & 42 & $100,0 \%$ & 51 & $100,0 \%$ & 93 & $100,0 \%$ & & & \\
\hline
\end{tabular}

Tabela 12- Distribuição da etiologia (viral/não viral) dos pacientes submetidos à ressecção de $\mathrm{CHC}$, segundo óbito

\begin{tabular}{|c|c|c|c|c|c|c|c|c|c|c|}
\hline & & & óbito & & vivo & & Total & $p$ & $\mathrm{OR}^{*}$ & $\mathrm{IC}(\mathrm{OR})^{\star *}$ \\
\hline \multicolumn{11}{|l|}{ etiologia } \\
\hline & viral & 26 & $59,1 \%$ & 27 & $52,9 \%$ & 53 & $55,8 \%$ & $0,547^{a}$ & 1,284 & 0,$569 ; 2,899$ \\
\hline & não viral & 18 & $40,9 \%$ & 24 & $47,1 \%$ & 42 & $44,2 \%$ & & & \\
\hline & Total & 44 & $100,0 \%$ & 51 & $100,0 \%$ & 95 & $100,0 \%$ & & & \\
\hline
\end{tabular}

*razão de chances (odds-ratio), ${ }^{\star *}$ intervalo com 95\% de confiança para razão de chances

${ }^{a}$ Qui-quadrado de Pearson 
Tabela 13 - Distribuição das características gerais dos pacientes submetidos à ressecção de $\mathrm{CHC}$, segundo óbito

\begin{tabular}{|c|c|c|c|c|c|c|c|c|c|}
\hline & & óbito & & vivo & & Total & $\mathrm{p}$ & OR & $\mathrm{IC}(\mathrm{OR})^{\star *}$ \\
\hline \multicolumn{10}{|l|}{ cápsula } \\
\hline não & 16 & $38,1 \%$ & 18 & $36,0 \%$ & 34 & $37,0 \%$ & $0,836^{\mathrm{a}}$ & 1,094 & 0,$468 ; 2,558$ \\
\hline $\operatorname{sim}$ & 26 & $61,9 \%$ & 32 & $64,0 \%$ & 58 & $63,0 \%$ & & & \\
\hline Total & 42 & $100,0 \%$ & 50 & $100,0 \%$ & 92 & $100,0 \%$ & & & \\
\hline \multicolumn{10}{|c|}{ invasão da cápsula } \\
\hline não & 19 & $73,1 \%$ & 29 & $90,6 \%$ & 48 & $82,8 \%$ & $0,095^{b}$ & 0,281 & 0,$064 ; 1,222$ \\
\hline $\operatorname{sim}$ & 7 & $26,9 \%$ & 3 & $9,4 \%$ & 10 & $17,2 \%$ & & & \\
\hline Total & 26 & $100,0 \%$ & 32 & $100,0 \%$ & 58 & $100,0 \%$ & & & \\
\hline \multicolumn{10}{|l|}{ Margem livre } \\
\hline não & 6 & $14,3 \%$ & - & - & 6 & $6,7 \%$ & $0,008^{b}$ & & \\
\hline $\operatorname{sim}$ & 36 & $85,7 \%$ & 48 & $100,0 \%$ & 84 & $93,3 \%$ & & & \\
\hline Total & 42 & $100,0 \%$ & 48 & $100,0 \%$ & 90 & $100,0 \%$ & & & \\
\hline \multicolumn{10}{|l|}{ cirrose } \\
\hline não & 10 & $22,7 \%$ & 14 & $27,5 \%$ & 24 & $25,3 \%$ & $0,597^{\mathrm{a}}$ & 0,777 & 0,$305 ; 1,981$ \\
\hline $\operatorname{sim}$ & 34 & $77,3 \%$ & 37 & $72,5 \%$ & 71 & $74,7 \%$ & & & \\
\hline Total & 44 & $100,0 \%$ & 51 & $100,0 \%$ & 95 & $100,0 \%$ & & & \\
\hline \multicolumn{10}{|l|}{ tipo de cirurgia } \\
\hline aberta & 38 & $86,4 \%$ & 30 & $62,5 \%$ & 68 & $73,9 \%$ & $0,009^{a}$ & 3,800 & 1,$342 ; 10,757$ \\
\hline laparoscópica & 6 & $13,6 \%$ & 18 & $37,5 \%$ & 24 & $26,1 \%$ & & & \\
\hline Total & 44 & $100,0 \%$ & 48 & $100,0 \%$ & 92 & $100,0 \%$ & & & \\
\hline \multicolumn{10}{|c|}{ ressecção anatômica } \\
\hline não & 13 & $30,2 \%$ & 15 & $30,0 \%$ & 28 & $30,1 \%$ & $0,981^{\mathrm{a}}$ & 1,011 & 0,$416 ; 2,458$ \\
\hline $\operatorname{sim}$ & 30 & $69,8 \%$ & 35 & $70,0 \%$ & 65 & $69,9 \%$ & & & \\
\hline Total & 43 & $100,0 \%$ & 50 & $100,0 \%$ & 93 & $100,0 \%$ & & & \\
\hline \multicolumn{10}{|l|}{ transfusão de sangue } \\
\hline não & 31 & $73,8 \%$ & 40 & $85,1 \%$ & 71 & $79,8 \%$ & $0,185^{\mathrm{a}}$ & 0,493 & 0,$171 ; 1,420$ \\
\hline $\operatorname{sim}$ & 11 & $26,2 \%$ & 7 & $14,9 \%$ & 18 & $20,2 \%$ & & & \\
\hline Total & 42 & $100,0 \%$ & 47 & $100,0 \%$ & 89 & $100,0 \%$ & & & \\
\hline \multicolumn{10}{|c|}{ Clavien (morbidade) } \\
\hline $1^{\mathrm{c}}$ & 22 & $51,2 \%$ & 30 & $65,2 \%$ & 52 & $58,4 \%$ & $0,156^{\mathrm{b}}$ & & \\
\hline 2 & 8 & $18,6 \%$ & 11 & $23,9 \%$ & 19 & $21,3 \%$ & & 1,008 & 0,$348 ; 2,922$ \\
\hline 3 & 5 & $11,6 \%$ & 3 & $6,5 \%$ & 8 & $9,0 \%$ & & 0,440 & 0,$095 ; 2,039$ \\
\hline 4 & 4 & $9,3 \%$ & 2 & $4,3 \%$ & 6 & $6,7 \%$ & & 0,367 & 0,$062 ; 2,184$ \\
\hline 5 & 4 & $9,3 \%$ & - & - & 4 & $4,5 \%$ & & & \\
\hline Total & 43 & $100,0 \%$ & 46 & $100,0 \%$ & 89 & $100,0 \%$ & & & \\
\hline
\end{tabular}

*razão de risco (odds-ratio), **intervalo com 95\% de confiança para razão de risco

${ }^{\mathrm{a}} \mathrm{Qui}$-quadrado de Pearson, ${ }^{\mathrm{b}}$ Exato de Fisher ou sua extensão

classe de referência

Com relação à análise dos fatores prognósticos para a sobrevida livre de doença, os resultados inferenciais (teste univariado de Qui-quadrado ou Exato de Fisher) não evidenciaram diferença estatisticamente significante entre recidiva e faixa etária $(p=0,123)$, gênero $(p=0,083)$, cor $(p=0,292)$, faixa de IMC $(p=0,992)$, CHILD $(p=0,609)$, MELD $(p=0,563)$, BARCELONA $(p=0,370)$, CA19.9 $(p=0,867)$, etiologia $(p=0,073)$, tamanho do nódulo $(p=0,652)$, grau 
Edmondson Steiner $(p=0,554)$, critério de Milão $(p=0,975)$, presença de cápsula $(p=0,962)$, invasão da cápsula $(p=0,737)$, margem livre $(p=0,429)$, cirrose $(p=0,858)$, tipo de cirurgia $(p=0,058)$, ressecção anatômica $(p=0,838)$, transfusão de sangue $(p=0,081)$ e complicações pós-operatórias de ClavienDindo $(p=0,293)$.

Houve diferença estatisticamente significante nas variáveis ASA $(p=0,014)$ e nível sérico de alfafetoproteína $(p=0,012)$.

As Tabelas 14 a 16 resumem os detalhes dessa análise. 
Tabela 14 - Distribuição das características gerais dos pacientes submetidos à ressecção de $\mathrm{CHC}$, segundo recidiva

\begin{tabular}{|c|c|c|c|c|c|c|c|c|c|}
\hline \multirow{2}{*}{ faixa etária (anos) } & \multicolumn{2}{|c|}{ com recidiva } & \multicolumn{2}{|c|}{ sem recidiva } & \multicolumn{2}{|r|}{ Total } & \multirow[t]{2}{*}{$\mathrm{p}$} & \multirow[t]{2}{*}{$\mathrm{OR}^{*}$} & \multirow[t]{2}{*}{$\mathrm{IC}(\mathrm{OR})^{* *}$} \\
\hline & & & & & & & & & \\
\hline até 64 & 27 & $58,7 \%$ & 21 & $42,9 \%$ & 48 & $50,5 \%$ & $0,123^{a}$ & 1,895 & 0,$838 ; 4,282$ \\
\hline acima de 64 & 19 & $41,3 \%$ & 28 & $57,1 \%$ & 47 & $49,5 \%$ & & & \\
\hline Total & 46 & $100,0 \%$ & 49 & $100,0 \%$ & 95 & $100,0 \%$ & & & \\
\hline \multicolumn{10}{|l|}{ gênero } \\
\hline feminino & 20 & $43,5 \%$ & 13 & $26,5 \%$ & 33 & $34,7 \%$ & $0,083^{a}$ & 2,130 & 0,$900 ; 5,041$ \\
\hline masculino & 26 & $56,5 \%$ & 36 & $73,5 \%$ & 62 & $65,3 \%$ & & & \\
\hline Total & 46 & $100,0 \%$ & 49 & $100,0 \%$ & 95 & $100,0 \%$ & & & \\
\hline \multicolumn{10}{|l|}{ cor } \\
\hline branco $^{c}$ & 36 & $78,3 \%$ & 44 & $89,8 \%$ & 80 & $84,2 \%$ & $0,292^{b}$ & 1 & \\
\hline negro & 1 & $2,2 \%$ & 2 & $4,1 \%$ & 3 & $3,2 \%$ & & 1,636 & 0,$143 ; 18,785$ \\
\hline amarelo & 5 & $10,9 \%$ & 2 & $4,1 \%$ & 7 & $7,4 \%$ & & 0,327 & 0,$060 ; 1,788$ \\
\hline mulato & 4 & $8,7 \%$ & 1 & $2,0 \%$ & 5 & $5,3 \%$ & & 0,205 & 0,$022 ; 1,912$ \\
\hline Total & 46 & $100,0 \%$ & 49 & $100,0 \%$ & 95 & $100,0 \%$ & & & \\
\hline \multicolumn{10}{|c|}{ faixa de IMC $\left(\mathrm{kg} / \mathrm{m}^{2}\right)$} \\
\hline até 25,4 & 22 & $48,9 \%$ & 20 & $48,8 \%$ & 42 & $48,8 \%$ & $0,992^{a}$ & 1,004 & 0,$431 ; 2,343$ \\
\hline acima de 25,4 & 23 & $51,1 \%$ & 21 & $51,2 \%$ & 44 & $51,2 \%$ & & & \\
\hline Total & 45 & $100,0 \%$ & 41 & $100,0 \%$ & 86 & $100,0 \%$ & & & \\
\hline \multicolumn{10}{|l|}{ ASA } \\
\hline $1^{\mathrm{C}}$ & 7 & $15,2 \%$ & 2 & $4,4 \%$ & 9 & $9,9 \%$ & $0,014^{b}$ & 1 & \\
\hline II & 36 & $78,3 \%$ & 33 & $73,3 \%$ & 69 & $75,8 \%$ & & 3,208 & 0,$622 ; 16,555$ \\
\hline III & 2 & $4,3 \%$ & 10 & $22,2 \%$ & 12 & $13,2 \%$ & & 17,500 & 1,$968 ; 155,598$ \\
\hline IV & 1 & $2,2 \%$ & - & - & 1 & $1,1 \%$ & & - & - \\
\hline Total & 46 & $100,0 \%$ & 45 & $100,0 \%$ & 91 & $100,0 \%$ & & & \\
\hline \multicolumn{10}{|l|}{ CHILD } \\
\hline$A$ & 44 & $95,7 \%$ & 48 & $98,0 \%$ & 92 & $96,8 \%$ & $0,609^{b}$ & 0,458 & 0,$040 ; 5,233$ \\
\hline $\mathrm{B}$ & 2 & $4,3 \%$ & 1 & $2,0 \%$ & 3 & $3,2 \%$ & & & \\
\hline Total & 46 & $100,0 \%$ & 49 & $100,0 \%$ & 95 & $100,0 \%$ & & & \\
\hline \multicolumn{10}{|l|}{ MELD } \\
\hline menor que 10 & 37 & $80,4 \%$ & 37 & $75,5 \%$ & 74 & $77,9 \%$ & $0,563^{a}$ & 1,333 & 0,$502 ; 3,542$ \\
\hline 10 ou mais & 9 & $19,6 \%$ & 12 & $24,5 \%$ & 21 & $22,1 \%$ & & & \\
\hline Total & 46 & $100,0 \%$ & 49 & $100,0 \%$ & 95 & $100,0 \%$ & & & \\
\hline \multicolumn{10}{|l|}{ BARCELONA } \\
\hline 0 & - & - & 1 & $2,0 \%$ & 1 & $1,1 \%$ & $0,370^{b}$ & & \\
\hline$A^{c}$ & 42 & $91,3 \%$ & 47 & $95,9 \%$ & 89 & $93,7 \%$ & & 1 & \\
\hline $\mathrm{B}$ & 2 & $4,3 \%$ & 1 & $2,0 \%$ & 3 & $3,2 \%$ & & 0,447 & 0,$039 ; 5,107$ \\
\hline C & 2 & $4,3 \%$ & - & - & 2 & $2,1 \%$ & & & \\
\hline Total & 46 & $100,0 \%$ & 49 & $100,0 \%$ & 95 & $100,0 \%$ & & & \\
\hline
\end{tabular}

*razão de chances (odds-ratio), **intervalo com 95\% de confiança para razão de chances

${ }^{a}$ Qui-quadrado de Pearson, ${ }^{b}$ Exato de Fisher ou sua extensão

classe de referência 
Tabela 15 - Distribuição das características gerais dos pacientes submetidos à ressecção de $\mathrm{CHC}$, segundo recidiva

\begin{tabular}{|c|c|c|c|c|c|c|c|c|c|}
\hline \multirow{2}{*}{ alfafetoproteína (ng/ml) } & \multicolumn{2}{|c|}{ com recidiva } & \multicolumn{2}{|c|}{ sem recidiva } & \multicolumn{2}{|r|}{ Total } & \multirow[t]{2}{*}{$\mathrm{p}$} & \multirow[t]{2}{*}{$\mathrm{OR}^{*}$} & \multirow[t]{2}{*}{$\mathrm{IC}(\mathrm{OR})^{* *}$} \\
\hline & & & & & & & & & \\
\hline menor que 100 & 21 & $52,5 \%$ & 36 & $78,3 \%$ & 57 & $66,3 \%$ & $0,012^{a}$ & 0,307 & 0,$120 ; 0,783$ \\
\hline 100 ou mais & 19 & $47,5 \%$ & 10 & $21,7 \%$ & 29 & $33,7 \%$ & & & \\
\hline Total & 40 & $100,0 \%$ & 46 & $100,0 \%$ & 86 & $100,0 \%$ & & & \\
\hline \multicolumn{10}{|l|}{ CA19.9 } \\
\hline até 26,6 & 10 & $47,6 \%$ & 15 & $50,0 \%$ & 25 & $49,0 \%$ & $0,867^{a}$ & 0,909 & 0,$298 ; 2,775$ \\
\hline acima de 26,6 & 11 & $52,4 \%$ & 15 & $50,0 \%$ & 26 & $51,0 \%$ & & & \\
\hline Total & 21 & $100,0 \%$ & 30 & $100,0 \%$ & 51 & $100,0 \%$ & & & \\
\hline \multicolumn{10}{|l|}{ etiologia } \\
\hline viral & 30 & $65,2 \%$ & 23 & $46,9 \%$ & 53 & $55,8 \%$ & $0,073^{a}$ & 2,120 & 0,$928 ; 4,843$ \\
\hline não viral & 16 & $34,8 \%$ & 26 & $53,1 \%$ & 42 & $44,2 \%$ & & & \\
\hline Total & 46 & $100,0 \%$ & 49 & $100,0 \%$ & 95 & $100,0 \%$ & & & \\
\hline \multicolumn{10}{|l|}{ tamanho do nódulo (cm) } \\
\hline até 5 & 24 & $54,5 \%$ & 29 & $59,2 \%$ & 53 & $57,0 \%$ & $0,652^{a}$ & 0,828 & 0,$364 ; 1,884$ \\
\hline acima de 5 & 20 & $45,5 \%$ & 20 & $40,8 \%$ & 40 & $43,0 \%$ & & & \\
\hline Total & 44 & $100,0 \%$ & 49 & $100,0 \%$ & 93 & $100,0 \%$ & & & \\
\hline \multicolumn{10}{|l|}{ grau Edmondson Steiner } \\
\hline 1 & - & - & 1 & $2,1 \%$ & 1 & $1,1 \%$ & $0,554^{b}$ & & \\
\hline${ } \mathrm{I}^{\mathrm{C}}$ & 10 & $22,7 \%$ & 14 & $29,2 \%$ & 24 & $26,1 \%$ & & 1 & \\
\hline III & 32 & $72,7 \%$ & 29 & $60,4 \%$ & 61 & $66,3 \%$ & & 0,647 & 0,$249 ; 1,681$ \\
\hline IV & 2 & $4,5 \%$ & 4 & $8,3 \%$ & 6 & $6,5 \%$ & & 1,429 & 0,$218 ; 9,376$ \\
\hline Total & 44 & $100,0 \%$ & 48 & $100,0 \%$ & 92 & $100,0 \%$ & & & \\
\hline \multicolumn{10}{|l|}{ critério de milão } \\
\hline não & 19 & $43,2 \%$ & 21 & $42,9 \%$ & 40 & $43,0 \%$ & $0,975^{a}$ & 1,013 & 0,$445 ; 2,306$ \\
\hline $\operatorname{sim}$ & 25 & $56,8 \%$ & 28 & $57,1 \%$ & 53 & $57,0 \%$ & & & \\
\hline Total & 44 & $100,0 \%$ & 49 & $100,0 \%$ & 93 & $100,0 \%$ & & & \\
\hline
\end{tabular}

*razão de chances (odds-ratio), ${ }^{* *}$ intervalo com $95 \%$ de confiança para razão de chances

${ }^{a}$ Qui-quadrado de Pearson, ${ }^{b}$ Exato de Fisher ou sua extensão

${ }^{\mathrm{c}}$ classe de referência 
Tabela 16 - Distribuição das características gerais dos pacientes submetidos à ressecção de $\mathrm{CHC}$, segundo recidiva

\begin{tabular}{|c|c|c|c|c|c|c|c|c|c|}
\hline \multirow{2}{*}{ cápsula } & \multicolumn{2}{|c|}{ com recidiva } & \multicolumn{2}{|c|}{ sem recidiva } & \multicolumn{2}{|r|}{ Total } & \multirow[t]{2}{*}{$p$} & \multirow[t]{2}{*}{$\mathrm{OR}^{*}$} & \multirow[t]{2}{*}{$\mathrm{IC}(\mathrm{OR})^{\star \star}$} \\
\hline & & & & & & & & & \\
\hline não & 16 & $37,2 \%$ & 18 & $36,7 \%$ & 34 & $37,0 \%$ & $0,962^{a}$ & 1,021 & 0,$437 ; 2,384$ \\
\hline $\operatorname{sim}$ & 27 & $62,8 \%$ & 31 & $63,3 \%$ & 58 & $63,0 \%$ & & & \\
\hline Total & 43 & $100,0 \%$ & 49 & $100,0 \%$ & 92 & $100,0 \%$ & & & \\
\hline \multicolumn{10}{|l|}{ invasão da cápsula } \\
\hline não & 23 & $85,2 \%$ & 25 & $80,6 \%$ & 48 & $82,8 \%$ & $0,737^{\mathrm{b}}$ & 1,380 & 0,$345 ; 5,519$ \\
\hline $\operatorname{sim}$ & 4 & $14,8 \%$ & 6 & $19,4 \%$ & 10 & $17,2 \%$ & & & \\
\hline Total & 27 & $100,0 \%$ & 31 & $100,0 \%$ & 58 & $100,0 \%$ & & & \\
\hline \multicolumn{10}{|l|}{ margem livre } \\
\hline não & 4 & $9,1 \%$ & 2 & $4,3 \%$ & 6 & $6,7 \%$ & $0,429^{b}$ & 2,200 & 0,$382 ; 12,668$ \\
\hline $\operatorname{sim}$ & 40 & $90,9 \%$ & 44 & $95,7 \%$ & 84 & $93,3 \%$ & & & \\
\hline Total & 44 & $100,0 \%$ & 46 & $100,0 \%$ & 90 & $100,0 \%$ & & & \\
\hline \multicolumn{10}{|l|}{ cirrose } \\
\hline não & 12 & $26,1 \%$ & 12 & $24,5 \%$ & 24 & $25,3 \%$ & $0,858^{a}$ & 1,088 & 0,$431 ; 2,747$ \\
\hline $\operatorname{sim}$ & 34 & $73,9 \%$ & 37 & $75,5 \%$ & 71 & $74,7 \%$ & & & \\
\hline Total & 46 & $100,0 \%$ & 49 & $100,0 \%$ & 95 & $100,0 \%$ & & & \\
\hline \multicolumn{10}{|l|}{ tipo de cirurgia } \\
\hline aberta & 38 & $82,6 \%$ & 30 & $65,2 \%$ & 68 & $73,9 \%$ & $0,058^{a}$ & 2,533 & 0,$956 ; 6,712$ \\
\hline laparoscópica & 8 & $17,4 \%$ & 16 & $34,8 \%$ & 24 & $26,1 \%$ & & & \\
\hline Total & 46 & $100,0 \%$ & 46 & $100,0 \%$ & 92 & $100,0 \%$ & & & \\
\hline \multicolumn{10}{|l|}{ ressecção anatômica } \\
\hline não & 14 & $31,1 \%$ & 14 & $29,2 \%$ & 28 & $30,1 \%$ & $0,838^{a}$ & 1,097 & 0,$452 ; 2,661$ \\
\hline $\operatorname{sim}$ & 31 & $68,9 \%$ & 34 & $70,8 \%$ & 65 & $69,9 \%$ & & & \\
\hline Total & 45 & $100,0 \%$ & 48 & $100,0 \%$ & 93 & $100,0 \%$ & & & \\
\hline \multicolumn{10}{|l|}{ transfusão de sangue } \\
\hline não & 31 & $72,1 \%$ & 40 & $87,0 \%$ & 71 & $79,8 \%$ & $0,081^{a}$ & 0,388 & 0,$131 ; 1,148$ \\
\hline $\operatorname{sim}$ & 12 & $27,9 \%$ & 6 & $13,0 \%$ & 18 & $20,2 \%$ & & & \\
\hline Total & 43 & $100,0 \%$ & 46 & $100,0 \%$ & 89 & $100,0 \%$ & & & \\
\hline \multicolumn{10}{|l|}{ Clavien (morbidade) } \\
\hline $1^{\mathrm{c}}$ & 27 & $61,4 \%$ & 25 & $55,6 \%$ & 52 & $58,4 \%$ & $0,293^{b}$ & 1 & \\
\hline 2 & 11 & $25,0 \%$ & 8 & $17,8 \%$ & 19 & $21,3 \%$ & & 0,785 & 0,$272 ; 2,269$ \\
\hline 3 & 4 & $9,1 \%$ & 4 & $8,9 \%$ & 8 & $9,0 \%$ & & 1,080 & 0,$244 ; 4,787$ \\
\hline 4 & 2 & $4,5 \%$ & 4 & $8,9 \%$ & 6 & $6,7 \%$ & & 2,160 & 0,$363 ; 12,840$ \\
\hline 5 & - & - & 4 & $8,9 \%$ & 4 & $4,5 \%$ & & - & \\
\hline Total & 44 & $100,0 \%$ & 45 & $100,0 \%$ & 89 & $100,0 \%$ & & & \\
\hline
\end{tabular}

*razão de chances (odds-ratio), **intervalo com 95\% de confiança para razão de chances

${ }^{a}$ Qui-quadrado de Pearson, ${ }^{b}$ Exato de Fisher ou sua extensão

${ }^{c}$ classe de referência 


\section{DISCUSSÃO}

A ressecção cirúrgica surge hoje como a principal modalidade de tratamento para o $\mathrm{CHC}$. Isso ocorre principalmente pelos critérios restritivos e pela oferta insuficiente de fígados para transplante no mundo $(12,38)$.

Fan et al. demonstraram que apenas cerca de $2 \%$ dos pacientes com CHC têm a oportunidade de transplante de fígado, ao passo que a ressecção hepática pode ser realizada em cerca de $25 \%$ desses pacientes (33).

Sabemos que a sobrevida em cinco anos da ressecção hepática por CHC é similar à do transplante hepático, quando se considera a intenção de tratamento, que se situa por volta de 60-70\% (37). Quando falamos de pacientes CHILD A e nódulo único ( $98 \%$ da nossa amostra), a sobrevida em cinco anos após a ressecção pode ser considerada melhor que a do transplante hepático, especialmente se fizermos uma análise por intenção de tratamento, considerando também os pacientes que morreram em lista de transplante (38).

Analisando esses dados parece claro que a ressecção hepática deve ser a terapia de escolha em pacientes com função hepática preservada e nódulo único.

Como demonstrado por Fan et al., essa terapêutica não só pode ser a única chance de cura da maioria dos pacientes com $\mathrm{CHC}$, como também pode possibilitar uma melhor avaliação histológica e molecular da biologia tumoral desses pacientes, selecionando quais seriam melhores candidatos ao transplante hepático de resgate, e poupando pacientes com biologia tumoral favorável, onde a ressecção seria suficiente, ou muito agressiva, onde o transplante não traria benefícios (33).

Com o desenvolvimento da técnica cirúrgica e a melhora dos cuidados peri-operatórios, cada vez mais tumores podem ser ressecados de forma segura e com baixa mortalidade hospitalar, que se situa ao redor de 3 a $7 \% \mathrm{em}$ centros especializados $(31,33)$, com sobrevida global em torno de 60 a $70 \%$ e sobrevida livre de doença ao redor de $50 \%$ em cinco anos $(33,36)$. 
Nosso estudo encontrou dados compatíveis com a literatura com mortalidade hospitalar de 8,9\%, sobrevida global em cinco anos de $49,9 \%$ e sobrevida livre de doença em 5 anos de 40,7\%. Uma possível explicação para a baixa taxa de sobrevida global em nossa série seria o fato da nossa amostra ser composta por mais de $40 \%$ de pacientes fora do critério de Milão, isto é, com nódulos maiores que $5 \mathrm{~cm}$.

A prática clínica mostra que a análise individual dos pacientes é fundamental, devendo-se considerar fatores relacionados à doença hepática de base como função hepática, a presença de hipertensão portal e o volume de fígado residual, e os fatores relacionados ao tumor como o estadiamento da doença. A avaliação individualizada permite cada vez mais ampliar o espectro de pacientes aptos a realizar a cirurgia hepática de maneira segura (36).

Um dos aspectos desfavoráveis à ressecção, quando comparada ao transplante hepático, é a alta taxa de recidiva, podendo chegar a $50 \%$ em cinco anos (38). Isso ocorre porque a ressecção hepática não elimina a doença de base (hepatopatia crônica/cirrose), o que possibilita o surgimento de novos tumores.

Novamente a biologia tumoral aparece como protagonista e nos faz pensar porque alguns tumores de mesmo tipo histológico são mais agressivos do que outros.

Alguns estudos demonstraram uma diferença no prognóstico com relação à etiologia do $\mathrm{CHC}$ de pacientes submetidos à ressecção hepática (4042), enquanto outros não conseguiram chegar a essa mesma conclusão (31).

Chirica et al. demonstraram, em uma amostra de 75 pacientes submetidos à ressecção de $\mathrm{CHC}$, uma pior evolução para pacientes de etiologia viral, especialmente por VHC (40). Essa amostra continha apenas pacientes com $\mathrm{CHC}$ em estágio inicial que foram submetidos à hepatectomia $\mathrm{e}$ demonstrou que pacientes com $\mathrm{CHC}$ de etiologia VHC tiveram pior sobrevida global e livre de doença em cinco anos.

Zhou et al. realizaram uma metanálise com 20 estudos correlacionando etiologia e prognóstico e também chegaram à conclusão que a etiologia viral acarreta pior prognóstico aos pacientes operados (41). Houve uma tendência a 
maior sobrevida global e livre de doença entre os pacientes com etiologia não viral, não havendo diferença entre aqueles portadores do VHB e do VHC.

Miao et al. analisaram diversos estudos sobre prognóstico e etiologia e, através de uma metanálise (43), concluíram que o tratamento antiviral com interferon (IFN) após ressecção hepática melhora a sobrevida global e livre de doença de pacientes com $\mathrm{CHC}$ de etiologia VHC.

Fong et al. não encontraram diferenças no prognóstico entre etiologia viral e não viral em um estudo de 1999, mas eles mesmo acreditavam que isso possa ter ocorrido devido ao pequeno tamanho da amostra e pela presença de poucos casos de alguns fatores etiológicos (31).

A possível associação entre etiologia e prognóstico foi o objetivo principal do presente estudo, já que não há trabalhos analisando essa situação no Brasil e, principalmente, individualizando as etiologias mais especificamente do que apenas nas categorias "viral" e "não viral".

Nosso estudo não encontrou diferença estatisticamente significante entre os grupos das diversas etiologias de $\mathrm{CHC}$. No entanto, as curvas de sobrevida global e livre de doença divididas por etiologia nos mostram algumas tendências que merecem reflexão (Figuras 26 e 27).

Com relação à sobrevida global em cinco anos, observamos que as etiologias álcool e VHB foram as que tiveram melhores resultados com $67,3 \% \mathrm{e}$ $67,5 \%$, respectivamente, ao passo que os pacientes com $\mathrm{CHC}$ de etiologia VHC foram os que tiveram pior resultado, com apenas $34,8 \%$ de sobrevida em cinco anos.

Quando analisamos a curva de sobrevida livre de doença em cinco anos, observamos que as etiologias álcool e NASH apresentaram os melhores resultados, com $66,3 \%$ e 53,3\%, respectivamente, sendo que as etiologias virais (VHC e VHB) apresentaram os piores, com $27,9 \%$ e $22,9 \%$, respectivamente.

Esses dados são compatíveis com a literatura, sempre mostrando um pior prognóstico para as etiologias virais e um melhor prognóstico para a etiologia alcóolica.

Isso é reforçado quando analisamos as curvas de sobrevida divididas por etiologia viral e não viral (Figuras 28 e 29), em que, apesar de não haver 
diferença estatisticamente significante, observamos uma clara tendência a um melhor prognóstico para as etiologias não virais, especialmente no que se refere à sobrevida livre de doença.

Um outro dado interessante nessa análise foi em relação aos pacientes com etiologia VHB, que apresentaram um dos melhores resultados de sobrevida global, juntamente com a etiologia alcoólica, mas que ficaram entre os piores resultados na avaliação de sobrevida livre de doença, juntamente com a etiologia VHC.

Esse fato poderia ser explicado principalmente pelo diferente mecanismo implicado na hepatocarcinogênese do VHB, que tem potencial de se integrar ao DNA do hepatócito, provocando alterações que podem levar ao desenvolvimento tumoral, mesmo sem a presença de cirrose. As outras etiologias parecem agir por agressão direta ao hepatócito, levando inicialmente ao desenvolvimento de cirrose e, depois, de $\mathrm{CHC}$ (41).

Desta forma, poderia ser explicada a possibilidade de desenvolvimento de $\mathrm{CHC}$ em pacientes não cirróticos infectados pelo VHB. Esses pacientes, em teoria, poderiam ter melhor sobrevida global em relação às demais etiologias por terem função hepática preservada e fazerem parte dos programas de rastreamento, o que pode facilitar a detecção da doença em estágios mais precoces, propiciando melhores resultados de sobrevida global, mas também maiores taxas de recidiva.

No entanto, quando avaliamos as curvas de sobrevida com relação à presença de cirrose hepática, não conseguimos encontrar dados estatisticamente significantes que atestem um pior prognóstico para os pacientes com cirrose, como seria de se esperar. A análise da literatura também mostra uma disparidade de resultados, com alguns trabalhos atestando pior prognóstico para pacientes cirróticos submetidos å hepatectomia (33) e outros afirmando que não há diferença estatisticamente significante (31).

A explicação mais provável seria de um viés de seleção para a cirurgia, operando tumores maiores apenas em pacientes não cirróticos e submetendo os cirróticos apenas a pequenas ressecções, devido ao temor de insuficiência hepática pós-operatória (31). Alguns trabalhos mostraram que a estratificação da análise por tamanho do nódulo confirmou o pior prognóstico para pacientes 
com cirrose $(31,42,49)$. Outro argumento para a ausência de diferença significativa é a rigorosa seleção dos pacientes submetidos à hepatectomia que, apesar de cirróticos, tem função hepática preservada.

Um outro ponto importante de nosso estudo foi a análise de outros fatores prognósticos para os pacientes com $\mathrm{CHC}$ submetidos à ressecção hepática.

A literatura é muito variada quanto aos fatores prognósticos para estes pacientes, mas a maioria dos trabalhos concorda em apontar as variáveis presença de invasão vascular, tamanho e número de nódulos, nível sérico de alfafetoproteína (AFP) pré-operatório e margens de ressecção como tendo influência significativa na evolução desses pacientes $(31,36,37,42)$.

Fong et al., analisando uma amostra de 412 pacientes com $\mathrm{CHC}$, encontraram como fatores de bom prognóstico a realização de ressecção hepática, paciente CHILD A e baixos níveis pré-operatórios de AFP. Considerando apenas os 154 pacientes desse estudo submetidos à ressecção hepática, os fatores de bom prognóstico encontrados foram baixos níveis préoperatórios de AFP, margens de ressecção livres de neoplasia, ausência de invasão vascular e tumor menor que $5 \mathrm{~cm}$ (31).

Bruix et al. encontraram como fatores prognósticos a presença de invasão vascular e o tamanho e número de nódulos, que consideraram importantes preditores de recidiva (36).

Silva et al. encontraram como variáveis negativas na análise univariada a presença de invasão vascular e de nódulos satélites na análise univariada, tanto para sobrevida global como para sobrevida livre de doença, sendo apenas a invasão vascular confirmada na análise multivariada (37). Um outro dado interessante nesse trabalho foi que nenhuma variável pré-operatória foi significativa entre aquelas com impacto no prognóstico.

Kondo et al. fizeram uma análise individualizada dos fatores prognósticos segundo a etiologia do $\mathrm{CHC}$ (42), tanto para sobrevida global como para sobrevida livre de doença. Constataram que o tamanho do tumor e a invasão vascular nos grupos de pacientes com etiologia viral e o nível sérico de fosfatase alcalina e o número de tumores em pacientes com etiologia não viral representavam fatores prognósticos para sobrevida global. Com relação à 
sobrevida livre de doença, os fatores prognósticos para o grupo de etiologia VHB foram o número de tumores e a invasão vascular; já para o grupo VHC, o nível sérico de fosfatase alcalina, o tempo de protrombina, o tamanho do tumor e a invasão vascular; e para o grupo de etiologia não viral, o tamanho e o número de tumores e a invasão vascular. Esse estudo foi importante para trazer à tona o fato de que podem haver diferentes fatores prognósticos para pacientes com as diversas etiologias do $\mathrm{CHC}$.

Todos esses estudos reforçam a grande probabilidade de haver diferença prognóstica entre os grupos de pacientes com as diferentes etiologias do $\mathrm{CHC}$, apesar de não termos encontrado diferença estatisticamente significante em nossa análise.

No presente estudo foi realizada a análise de fatores prognósticos para sobrevida global e livre de doença, tanto pelo método Log-Rank, com a comparação de curvas de Kaplan-Meier entre as diversas variáveis, como pelo método de cálculo da razão de risco (odds-ratio).

O teste univariado de Log-Rank evidenciou as variáveis nível sérico de AFP, nível sérico de CA 19.9, invasão da cápsula tumoral, margens de ressecção e complicações pós-operatórias de acordo com a classificação de Clavien-Dindo como sendo estatisticamente significantes.

No entanto, não foi possível realizar a análise multivariada, devido à diferença amostral das variáveis acima. Além disso, esse teste não nos permitiu quantificar essas diferenças entre as variáveis estatisticamente significantes.

Dessa forma, realizamos também o cálculo da razão de risco (oddsratio), através do teste de Qui-quadrado ou do teste exato de Fisher, sendo evidenciadas como estatisticamente significantes para sobrevida global as variáveis nível sérico de AFP, margens de ressecção e tipo de cirurgia.

Considerando o $\mathrm{OR}=0,382$ para a variável $A F P$, podemos dizer que os pacientes com AFP sérica $>100 \mathrm{ng} / \mathrm{ml}$ tiveram 2,6 vezes mais chance de morte do que os pacientes com AFP sérica $<100 \mathrm{ng} / \mathrm{ml}$, o que é um fato interessante, já que é um fator que pode ser analisado no período pré-operatório.

Não foi possível calcular um OR para a variável margens de ressecção, pois não tivemos sobrevida tardia em pacientes com margens comprometidas; 
podemos, no entanto, pressupor que essa variável é um fator prognóstico importante para a sobrevida global.

Com relação ao tipo de cirurgia, o $\mathrm{OR}=3,8$ nos mostra que os pacientes submetidos à cirurgia aberta apresentaram 3,8 vezes mais chance de morte do que os pacientes submetidos à cirurgia laparoscópica. No entanto, é importante observar que, geralmente, os pacientes submetidos à cirurgia laparoscópica são pacientes portadores de doença em estágio inicial, com nódulos menores e em localizações mais favoráveis para uma ressecção. Mesmo assim, não podemos subestimar o menor trauma e a consequente melhor recuperação dos pacientes submetidos a procedimentos laparoscópicos.

Também é interessante notar que algumas variáveis, que representam fatores prognósticos de acordo com a literatura, não se confirmaram em nossa análise. São elas: o tamanho do nódulo, a classificação de CHILD, a pontuação de MELD e a invasão da cápsula tumoral.

No que tange à variável classificação de CHILD, esse achado pode ser explicado pelo fato de que $98 \%$ da amostra foi composta de pacientes CHILD A, com apenas 3 pacientes CHILD B. Obviamente, ao mesmo tempo em que isso torna a amostra extremamente homogênea, impossibilita a avaliação da variável classificação de CHILD como fator prognóstico.

Em relação às outras variáveis mencionadas acima (pontuação de MELD, tamanho do nódulo e invasão da cápsula), esses achados podem ser explicados pelo baixo tamanho da amostra, sendo os dados amplamente favoráveis aos pacientes com MELD $<10$, nódulo $<5 \mathrm{~cm}$ e sem invasão da cápsula tumoral. Essas variáveis tem intervalos de confiança (IC) amplos, o que reforça a possibilidade de que uma amostra maior poderia atingir a significância estatística.

A análise dos fatores prognósticos para a sobrevida livre de doença foi realizada apenas através do teste de Qui-quadrado ou teste exato de Fisher, com o cálculo da razão de risco (odds-ratio).

As variáveis estatisticamente significantes neste quesito foram a classificação de ASA e o nível sérico de AFP. Nesse caso, pacientes com AFP $>100 \mathrm{ng} / \mathrm{ml}$ no período pré-operatório tiveram 3,26 vezes mais chance de recidiva do que pacientes com AFP $<100 \mathrm{ng} / \mathrm{ml}$. 
Parece interessante notar que a variável etiologia não apresentou uma diferença estatisticamente significante, com um $p=0,073$. Poderíamos dizer que a chance de não haver diferença estatisticamente significante entre as etiologias viral e não viral com relação à sobrevida livre de doença foi de apenas $7,3 \%$, de forma que, se adotássemos um nível de significância de $10 \%$, essa análise poderia ser positiva. No entanto, o IC amplo de 0,93 a 4,84 sugere novamente a necessidade de uma amostra maior para consolidar as nossas evidências. $\mathrm{O} O R=2,12$, nessa situação, poderia permitir a inferência de que a chance de recidiva em pacientes com etiologia viral seria aproximadamente 0 dobro da chance dos pacientes com etiologia não viral.

Certamente não podemos deixar de ressaltar a principal limitação desse estudo, que é a sua natureza retrospectiva, o que, infelizmente, nos deixou sem alguns dados relativos a alguns pacientes e dificultou sobremaneira a realização do estudo. Uma das análises prejudicadas por esta razão foi a regressão de Cox (multivariada), que, devido à ausência de alguns dados nos prontuários, não pode ser realizada.

Um outro aspecto já mencionado anteriormente foi o número relativamente pequeno desta amostra, que, apesar de representar uma grande casuística do ponto de vista cirúrgico, ainda não tem o poder de demonstrar diferenças significativas neste estudo.

Dessa forma, esse estudo pode servir de base para outras pesquisas, visando confirmar os achados e avaliar melhor os resultados aqui apontados, prosseguindo na busca por maior conhecimento e melhora na assistência aos pacientes com $\mathrm{CHC}$. 


\section{CONCLUSÕES}

Com base nos resultados obtidos da análise desta casuística com pacientes portadores de carcinoma hepatocelular submetidos à hepatectomia com intenção curativa, pudemos concluir que:

1. Não houve diferença estatisticamente significante na sobrevida global e livre de doença em cinco anos entre os grupos de pacientes das diversas etiologias do $\mathrm{CHC}$ que foram submetidos à hepatectomia com intenção de tratamento curativo.

2. As variáveis nível sérico de alfafetoproteína, nível sérico de CA19.9, invasão da cápsula do tumor, margem livre e presença de complicações pós-operatórias segundo a classificação de Clavien-Dindo podem ser consideradas indicadores de prognóstico.

3. As curvas de sobrevida global e livre de doença demonstram que, em até cinco anos (60 meses) de seguimento, 49,9\% dos pacientes permaneceram vivos e que, $40,7 \%$ deles não apresentaram recidiva. 


\section{REFERÊNCIAS}

1. El Serag HB. Epidemiology of hepatocellular carcinoma in USA. Hepatology Research. 2007;37(s2 Fourth JSH S):S88-S94.

2. International Agency for Research on Cancer. Liver cancer incidence, mortality and prevalence worldwide in 2008 [online], http://globocan.iarc.fr/factsheet.asp (2012).

3. Venook, Papandreou, al Fe. The Incidence and Epidemiology of Hepatocellular Carcinoma: A Global and Regional Perspective. The Oncologist. 2010:1-9.

4. Sherman M. Epidemiology of Hepatocellular Carcinoma. Oncology. 2010;78(1):7-10.

5. Bismuth $\mathrm{H}$, Chiche L, Castaing D. Surgical treatment of hepatocellular carcinomas in noncirrhotic liver: experience with 68 liver resections. World Journal of Surgery. 1995;19(1):35-41.

6. El-Serag HB, Kanwal F. Epidemiology of hepatocellular carcinoma in the United States: where are we? Where do we go? Hepatology. 2014;60(5):176775.

7. El Serag HB, Rudolph KL. Hepatocellular Carcinoma: Epidemiology and Molecular Carcinogenesis. Gastroenterology. 2007;132(7):2557-76.

8. Davila JA, Morgan RO, Shaib Y, McGlynn KA, El-Serag HB. Diabetes increases the risk of hepatocellular carcinoma in the United States: a population based case control study. Gut. 2005;54(4):533-9.

9. Goncalves CS, Pereira FE, Gayotto LC. Hepatocellular carcinoma in Brazil: report of a national survey (Florianopolis, SC, 1995). Revista do Instituto de Medicina Tropical de Sao Paulo. 1997;39(3):165-70.

10. Carrilho FJ, Kikuchi L, Branco F, Goncalves CS, Mattos AAd. Clinical and epidemiological aspects of hepatocellular carcinoma in Brazil. Clinics. 2010;65(12):1285-90.

11. Paranagua-Vezozzo DC, Ono SK, Alvarado-Mora MV, Farias AQ, Cunha-Silva M, Franca Jl, et al. Epidemiology of HCC in Brazil: incidence and risk factors in a ten-year cohort. Annals of hepatology. 2014;13(4):386-93. 
12. Bruix J, Sherman M, Diseases AAftSoL. Management of hepatocellular carcinoma: an update. 2011. p. 1020-2.

13. Purysko AS, Remer EM, Coppa CP, Leao Filho HM, Thupili CR, Veniero JC. LI-RADS: a case-based review of the new categorization of liver findings in patients with end-stage liver disease. Radiographics : a review publication of the Radiological Society of North America, Inc. 2012;32(7):1977-95.

14. Kuo YH, Lu SN, Chen CL, Cheng YF, Lin CY, Hung $\mathrm{CH}$, et al. Hepatocellular carcinoma surveillance and appropriate treatment options improve survival for patients with liver cirrhosis. European journal of cancer (Oxford, England : 1990). 2010;46(4):744-51.

15. Zhang BH, Yang BH, Tang ZY. Randomized controlled trial of screening for hepatocellular carcinoma. Journal of cancer research and clinical oncology. 2004;130(7):417-22.

16. Bruix J, Gores GJ, Mazzaferro V. Hepatocellular carcinoma: clinical frontiers and perspectives. Gut. 2014;63(5):844-55.

17. Faria SC, Szklaruk J, Kaseb AO, Hassabo HM, Elsayes KM. TNM/Okuda/Barcelona/UNOS/CLIP International Multidisciplinary Classification of Hepatocellular Carcinoma: concepts, perspectives, and radiologic implications. Abdominal imaging. 2014;39(5):1070-87.

18. Llovet JM, Bru C, Bruix J. Prognosis of hepatocellular carcinoma: the BCLC staging classification. Semin Liver Dis. 1999;19(3):329-38.

19. Jianyong $L$, Lunan $\mathrm{Y}$, Wentao $\mathrm{W}$, Yong $Z$, Bo $L$, Tianfu $W$, et al. Barcelona clinic liver cancer stage $B$ hepatocellular carcinoma: transarterial chemoembolization or hepatic resection? Medicine. 2014;93(26):e180.

20. Hashimoto M, Watanabe G. Hepatic parenchymal cell volume and the indocyanine green tolerance test. The Journal of surgical research. 2000;92(2):222-7.

21. Makuuchi M, Kokudo N. Clinical practice guidelines for hepatocellular carcinoma: the first evidence based guidelines from Japan. World journal of gastroenterology : WJG. 2006;12(5):828-9.

22. Hanje AJ, Patel T. Preoperative evaluation of patients with liver disease. Nature clinical practice Gastroenterology \& hepatology. 2007;4(5):266-76. 
23. Ishizawa T, Hasegawa K, Aoki T, Takahashi M, Inoue Y, Sano K, et al. Neither multiple tumors nor portal hypertension are surgical contraindications for hepatocellular carcinoma. Gastroenterology. 2008;134(7):1908-16.

24. Cescon M, Cucchetti A, Grazi GL, Ferrero A, Vigano L, Ercolani G, et al. Indication of the extent of hepatectomy for hepatocellular carcinoma on cirrhosis by a simple algorithm based on preoperative variables. Archives of surgery (Chicago, III : 1960). 2009;144(1):57-63; discussion

25. Vauthey JN, Dixon E, Abdalla EK, Helton WS, Pawlik TM, Taouli B, et al. Pretreatment assessment of hepatocellular carcinoma: expert consensus statement. HPB : the official journal of the International Hepato Pancreato Biliary Association. 2010;12(5):289-99.

26. Pugh RN, Murray-Lyon IM, Dawson JL, Pietroni MC, Williams R. Transection of the oesophagus for bleeding oesophageal varices. The British journal of surgery. 1973;60(8):646-9.

27. Malinchoc M, Kamath PS, Gordon FD, Peine CJ, Rank J, ter Borg PC. A model to predict poor survival in patients undergoing transjugular intrahepatic portosystemic shunts. Hepatology. 2000;31(4):864-71.

28. Vorobioff JD. Hepatic venous pressure in practice: how, when, and why. Journal of clinical gastroenterology. 2007;41 Suppl 3:S336-43.

29. Bureau C, Metivier S, Peron JM, Selves J, Robic MA, Gourraud PA, et al. Transient elastography accurately predicts presence of significant portal hypertension in patients with chronic liver disease. Alimentary pharmacology \& therapeutics. 2008;27(12):1261-8.

30. Katyal S, Oliver JH, 3rd, Peterson MS, Ferris JV, Carr BS, Baron RL. Extrahepatic metastases of hepatocellular carcinoma. Radiology. 2000;216(3):698-703.

31. Fong $Y$, Sun RL, Jarnagin W, Blumgart LH. An analysis of 412 cases of hepatocellular carcinoma at a Western center. Ann Surg. 1999;229(6):790-9; discussion 9-800.

32. Poon RT, Ng IO, Fan ST, Lai EC, Lo CM, Liu CL, et al. Clinicopathologic features of long-term survivors and disease-free survivors after resection of hepatocellular carcinoma: a study of a prospective cohort. Journal of clinical 
oncology : official journal of the American Society of Clinical Oncology. 2001;19(12):3037-44.

33. Fan ST. Hepatocellular carcinoma-resection or transplant? Nature Reviews Gastroenterology \&amp; Hepatology. 2012;9(12):732-7.

34. Lopez PM, Villanueva A, Llovet JM. Systematic review: evidence-based management of hepatocellular carcinoma--an updated analysis of randomized controlled trials. Alimentary pharmacology \& therapeutics. 2006;23(11):1535-47. 35. Yao FY, Bass NM, Nikolai B, Davern TJ, Kerlan R, Wu V, et al. Liver transplantation for hepatocellular carcinoma: analysis of survival according to the intention-to-treat principle and dropout from the waiting list. Liver transplantation : official publication of the American Association for the Study of Liver Diseases and the International Liver Transplantation Society. 2002;8(10):873-83.

36. Bruix J, Boix L, Sala M, Llovet JM. Focus on hepatocellular carcinoma. CANCER CELL : MARCH 2004. 2004:1-5.

37. Silva MF, Sapisochin G, Strasser SI, Hewa-Geeganage S, Chen J, Wigg AJ, et al. Liver resection and transplantation offer similar 5-year survival for Child-Pugh-Turcotte A HCC-patients with a single nodule up to $5 \mathrm{~cm}$ : a multicenter, exploratory analysis. Eur J Surg Oncol. 2013;39(4):386-95.

38. Koniaris LG, Levi DM, Pedroso FE, Franceschi D, Tzakis AG, Santamaria-Barria JA, et al. Is surgical resection superior to transplantation in the treatment of hepatocellular carcinoma? Annals of Surgery. 2011;254(3):52737- discussion 37-8.

39. Llovet JM, Ricci S, Mazzaferro V, Hilgard P, Gane E, Blanc JF, et al. Sorafenib in advanced hepatocellular carcinoma. N Engl J Med. 2008;359(4):378-90.

40. Chirica M, Tranchart H, Tan V, Faron M, Balladur P, Paye F. Infection with Hepatitis $C$ Virus is an Adverse Prognostic Factor after Liver Resection for Early-stage Hepatocellular Carcinoma. Annals of Surgical Oncology. 2013:1-8.

41. Zhou Y, Si X, Wu L, Su X, Li B, Zhang Z. Influence of viral hepatitis status on prognosis in patients undergoing hepatic resection for hepatocellular carcinoma: a meta-analysis of observational studies. World Journal of Surgical Oncology. 2011;9(1):108. 
42. Kondo K, Chijiiwa K, Funagayama M, Kai M, Otani K, Ohuchida J. Differences in long-term outcome and prognostic factors according to viral status in patients with hepatocellular carcinoma treated by surgery. Journal of Gastrointestinal Surgery. 2008;12(3):468-76.

43. Miao RY, Zhao HT, Yang HY, Mao YL, Lu X, Zhao Y, et al. Postoperative adjuvant antiviral therapy for hepatitis B/C virus-related hepatocellular carcinoma: a meta-analysis. World journal of gastroenterology : WJG. 2010;16(23):2931-42.

44. Fitz-Henry J. The ASA classification and peri-operative risk. Ann R Coll Surg Engl. 2011;93(3):185-7.

45. Dindo DD, Demartines NN, Clavien P-AP. Classification of surgical complications: a new proposal with evaluation in a cohort of 6336 patients and results of a survey. Annals of Surgery. 2004;240(2):205-13.

46. Collett, D. Modelling Survival Data in Medical Research, 2ed. London: Chapman \& Hall/CRC, 2003, 391p

47. Bussab, WO.;Morettin, P.A. Estatística Básica. 5ed. São Paulo: Saraiva, 2006,526p.

48. R Core Team(2014). R: A Language and environment for statistical computing. R Foundation for Statistical Computing, Vienna, Austria. URL http://www.R-project.org/.

49. Stuart KE, Anand AJ, Jenkins RL. Hepatocellular carcinoma in the United States. Prognostic features, treatment outcome, and survival. Cancer. 1996;77(11):2217-22. 


\section{Apêndice}

Tabela A - Medidas-resumo do tempo de sobrevida global (em meses) dos pacientes submetidos à ressecção de $\mathrm{CHC}$

\begin{tabular}{ccccccc}
\hline \hline & $\mathrm{n}$ & média & mediana & mínimo & máximo & desvio-padrão \\
\hline Óbito & 44 & 24,6 & 16,9 & 1,0 & 100,0 & 23,8 \\
vivo & 51 & 51,9 & 50,4 & 7,4 & 132,9 & 30,5 \\
Total & 95 & 39,3 & 32,9 & 1,0 & 132,9 & 30,7 \\
\hline \hline
\end{tabular}

Tabela B - Medidas-resumo do intervalo livre de doença (em meses) dos pacientes submetidos à ressecção de $\mathrm{CHC}$

\begin{tabular}{ccccccc}
\hline \hline & $\mathrm{n}$ & média & mediana & mínimo & máximo & desvio-padrão \\
\hline com recidiva & 46 & 17,2 & 15,2 & 1,1 & 60,6 & 13,2 \\
sem recidiva & 49 & 37,9 & 32,9 & 1,0 & 125,9 & 30,4 \\
Total & 95 & 27,9 & 20,4 & 1,0 & 125,9 & 25,8 \\
\hline \hline
\end{tabular}

Tabela C - Medidas-resumo do tempo de sobrevida global (em meses) dos pacientes submetidos à ressecção de $\mathrm{CHC}$, segundo a presença de cirrose

\begin{tabular}{cccccccc}
\hline & & $\mathrm{n}$ & média & mediana & mínimo & máximo & desvio-padrão \\
\hline óbito & com cirrose & 34 & 24,0 & 16,9 & 1,0 & 86,9 & 22,0 \\
& sem cirrose & 10 & 26,8 & 17,8 & 1,8 & 100,0 & 30,3 \\
& Total & 44 & 24,6 & 16,9 & 1,0 & 100,0 & 23,8 \\
\hline \multirow{2}{*}{ vivo } & com cirrose & 37 & 46,7 & 49,6 & 7,4 & 132,9 & 28,1 \\
& sem cirrose & 14 & 65,5 & 56,0 & 25,8 & 125,9 & 33,5 \\
& Total & 51 & 51,9 & 50,4 & 7,4 & 132,9 & 30,5 \\
\hline \hline
\end{tabular}

Tabela D - Medidas-resumo do tempo livre de doença (em meses) dos pacientes submetidos à ressecção de $\mathrm{CHC}$, segundo a presença de cirrose

\begin{tabular}{lccccccc}
\hline \hline \multirow{2}{*}{ com recidiva } & & $\mathrm{n}$ & média & mediana & mínimo & máximo & desvio-padrão \\
& com cirrose & 34 & 16,5 & 14,0 & 1,1 & 49,5 & 12,4 \\
& sem cirrose & 12 & 19,0 & 19,2 & 1,5 & 60,6 & 15,6 \\
& Total & 46 & 17,2 & 15,2 & 1,1 & 60,6 & 13,2 \\
\hline \multirow{3}{*}{ sem recidiva } & com cirrose & 37 & 33,8 & 28,3 & 1,0 & 110,8 & 26,5 \\
& sem cirrose & 12 & 50,5 & 42,6 & 1,8 & 125,9 & 38,7 \\
& Total & 49 & 37,9 & 32,9 & 1,0 & 125,9 & 30,4 \\
\hline \hline
\end{tabular}


Tabela E - Medidas-resumo do tempo de sobrevida global (em meses) dos pacientes submetidos à ressecção de $\mathrm{CHC}$, segundo a etiologia da hepatopatia

\begin{tabular}{cccccccc}
\hline \hline & etiologia & $\mathrm{n}$ & média & mediana & mínimo & máximo & desvio-padrão \\
\hline óbito & VHB & 3 & 21,3 & 28,7 & 3,5 & 31,7 & 15,5 \\
& VHC & 15 & 17,4 & 13,4 & 1,1 & 57,2 & 16,1 \\
& OH & 4 & 40,6 & 36,9 & 1,9 & 86,9 & 35,2 \\
& NASH & 4 & 5,6 & 3,4 & 1,0 & 14,8 & 6,4 \\
& outras & 10 & 29,2 & 25,0 & 1,8 & 100,0 & 29,3 \\
& mista & 8 & 35,1 & 33,9 & 4,6 & 80,6 & 24,5 \\
& Total & 44 & 24,6 & 16,9 & 1,0 & 100,0 & 23,8 \\
\hline \multirow{6}{*}{ vivo } & VHB & 7 & 58,3 & 51,1 & 8,8 & 132,9 & 37,1 \\
& VHC & 15 & 41,9 & 42,0 & 11,0 & 92,6 & 25,0 \\
& OH & 9 & 42,2 & 38,4 & 7,4 & 110,8 & 31,8 \\
& NASH & 4 & 50,6 & 58,7 & 18,4 & 66,5 & 22,3 \\
& outras & 11 & 67,8 & 54,4 & 25,8 & 125,9 & 37,6 \\
& mista & 5 & 56,6 & 55,1 & 48,7 & 66,0 & 7,5 \\
& Total & 51 & 51,9 & 50,4 & 7,4 & 132,9 & 30,5 \\
\hline \hline
\end{tabular}

Tabela F - Medidas-resumo do tempo livre de doença (em meses) dos pacientes submetidos à ressecção de $\mathrm{CHC}$, segundo a etiologia da hepatopatia

\begin{tabular}{cccccccc}
\hline & etiologia & $\mathrm{n}$ & média & mediana & mínimo & máximo & desvio-padrão \\
\hline com recidiva & VHB & 7 & 17,0 & 16,0 & 2,0 & 48,2 & 15,7 \\
& VHC & 15 & 14,8 & 11,0 & 1,1 & 49,5 & 13,0 \\
& OH & 3 & 16,5 & 18,6 & 7,6 & 23,3 & 8,1 \\
& NASH & 2 & 17,5 & 17,5 & 11,9 & 23,0 & 7,8 \\
& outras & 11 & 18,3 & 18,8 & 1,5 & 60,6 & 16,6 \\
& mista & 8 & 20,5 & 22,2 & 2,3 & 34,9 & 11,2 \\
& Total & 46 & 17,2 & 15,2 & 1,1 & 60,6 & 13,2 \\
\hline \multirow{5}{*}{ sem recidiva } & VHB & 3 & 38,7 & 49,6 & 8,8 & 57,6 & 26,2 \\
& VHC & 15 & 28,8 & 21,0 & 1,1 & 84,0 & 23,0 \\
& OH & 10 & 38,5 & 32,4 & 1,9 & 110,8 & 32,6 \\
& NASH & 6 & 23,9 & 11,8 & 1,0 & 64,4 & 27,9 \\
& outras & 10 & 54,4 & 42,6 & 1,8 & 125,9 & 39,8 \\
& mista & 5 & 47,9 & 55,1 & 6,9 & 66,0 & 23,9 \\
& Total & 49 & 37,9 & 32,9 & 1,0 & 125,9 & 30,4 \\
\hline \hline
\end{tabular}

Tabela G - Medidas-resumo do tempo de sobrevida global (em meses) dos pacientes submetidos à ressecção de $\mathrm{CHC}$, segundo a etiologia (viral/não viral) da hepatopatia

\begin{tabular}{cccccccc}
\hline \hline & etiologia & $\mathrm{n}$ & média & mediana & mínimo & máximo & desvio-padrão \\
\hline \multirow{2}{*}{ óbito } & viral & 26 & 23,3 & 16,9 & 1,1 & 80,6 & 20,0 \\
& não viral & 18 & 26,5 & 18,1 & 1,0 & 100,0 & 28,9 \\
& Total & 44 & 24,6 & 16,9 & 1,0 & 100,0 & 23,8 \\
\hline \multirow{2}{*}{ vivo } & viral & 27 & 48,9 & 49,6 & 8,8 & 132,9 & 27,0 \\
& não viral & 24 & 55,3 & 52,9 & 7,4 & 125,9 & 34,3 \\
& Total & 51 & 51,9 & 50,4 & 7,4 & 132,9 & 30,5 \\
\hline \hline
\end{tabular}


Tabela H - Medidas-resumo do tempo livre de doença (em meses) dos pacientes submetidos à ressecção de $\mathrm{CHC}$, segundo a etiologia (viral/não viral) da hepatopatia

\begin{tabular}{cccccccc}
\hline \hline & etiologia & $\mathrm{n}$ & média & mediana & mínimo & máximo & desvio-padrão \\
\hline com recidiva & viral & 30 & 16,8 & 14,0 & 1,1 & 49,5 & 13,0 \\
& não viral & 16 & 17,8 & 18,7 & 1,5 & 60,6 & 14,0 \\
& Total & 46 & 17,2 & 15,2 & 1,1 & 60,6 & 13,2 \\
\hline \multirow{2}{*}{ sem recidiva } & viral & 23 & 34,2 & 30,5 & 1,1 & 84,0 & 23,8 \\
& não viral & 26 & 41,2 & 38,2 & 1,0 & 125,9 & 35,4 \\
& Total & 49 & 37,9 & 32,9 & 1,0 & 125,9 & 30,4 \\
\hline \hline
\end{tabular}

